\title{
Predicting the Lifespan of Vacuum Insulation Panels in Buildings using Hygrothermal Simulation
}

\author{
By \\ Tyler Kenneth Ulmer \\ B.Eng., Carleton University 2017
}

A thesis submitted to the Faculty of Graduate and Postdoctoral Affairs in partial fulfillment of the requirements for the degree of

Master of Applied Science

in

Sustainable Energy Engineering and Policy

Carleton University

Ottawa, Ontario

(C) 2019, Tyler Ulmer 


\section{Abstract}

Policymakers and building owners are increasingly demanding for Canadas building stock to have increased energy efficiency and lower energy consumption. An approach to meeting these demands is increasing the insulation level of building envelopes, either through increasing the thickness of building walls or through using better performing materials. Vacuum insulation panels (VIPs) have showed potential for use as building insulation as they provide significant insulation levels in thin profiles. VIPs consist of an evacuated open cell core material encased in a barrier film. There are many variables regarding VIPs that must be investigated to determine the suitability, both thermally and economically. One of the key areas of question regarding VIPs is their useful lifespan in buildings. VIPs experience reductions in thermal performance over time as moisture and air permeate through the barrier film and into the panel. Recent research has attempted to take measurements of moisture transfer rate of panel foils and predict the lifespan of the VIP. However, a shortcoming of current research is the consideration of weather effects on the conditions that a VIP is subjected to in a wall, and how that affects the lifespan. This thesis will focus on the use of weather data to model the conditions that a VIP is subjected to in a wall, and the calculation of its lifespan based on these conditions. This includes the construction of equipment to measure aging factors of VIPs, specifically the water-vapour transmission rates of foils, as well as the construction of a hygrothermal model to simulate the temperature and relative humidity throughout a wall over a 25 -year period. Two city climates were considered in the model, Ottawa and Niagara, and two building constructions were considered i.e., a new construction and a retrofit construction case. For the Ottawa climate, the predicted VIP lifespans were 22.6 and 23.6 years for the retrofit and new constructions, respectively. For the Niagara climate, the predicted VIP lifespans were 19.0 and 19.6 years for the retrofit and new constructions, respectively. The 
lifespan prediction model described provides an outline for using weather data to predict VIP lifespan, as well as discussion on the suitability of the finding and how to increase VIP life. 


\section{Acknowledgements}

I would like to thank my father, Mike Ulmer for giving me the discipline, confidence, and reason to complete this work. I would also like to thank my mother, Shelley for helping me through this time. As well thank as my sisters, Constable Jessica Ulmer and Kaitlyn Ulmer.

I would also like to thank Alec McNabb for his constant friendship, support, and interest in my work and our future.

I would like to thank my supervisor, Dr. Cynthia Cruickshank for giving me the opportunity to complete this work. As well as all the members of our research group, Chris, Brock, Jordan, Chris and Calene.

I would like to thank Zach Ulmer for always being there for me throughout this project, helping me find my passion, and having my back.

I would also like to thank Dr. Reinhold Schuster, Travis Moore, and Colin Wiebe for teaching me so much, building confidence, and helping me complete this work.

I would like to acknowledge Terry, Tasso, Kevin and the rest of the Hometown Crew without whom I would not have completed this work.

I would also like to acknowledge Norm Macdonald for keeping me sane throughout the writing process. 
Contents

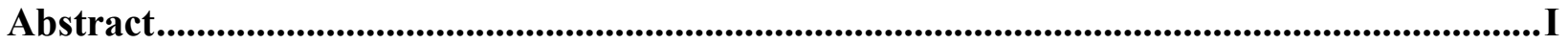

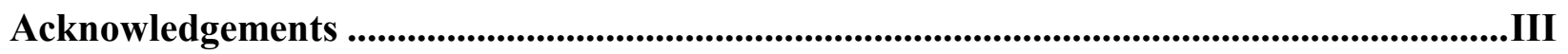

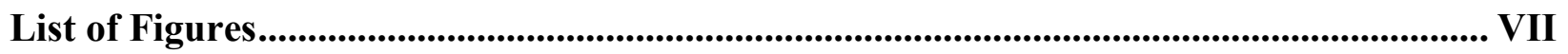

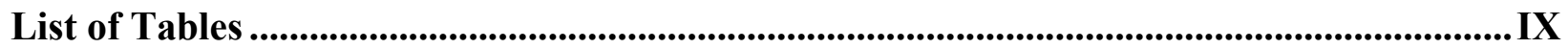

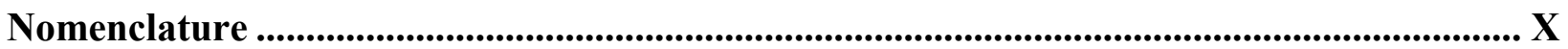

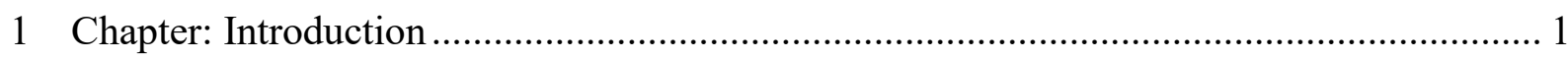

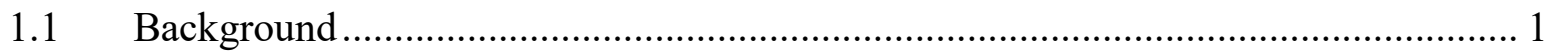

1.2 Building Envelopes and Resiliency .......................................................... 2

1.3 Standard Insulation Materials ...................................................................... 5

1.4 Vacuum Insulation Panels.......................................................................... 6

1.5 Life Cycle Cost Analysis ........................................................................ 9

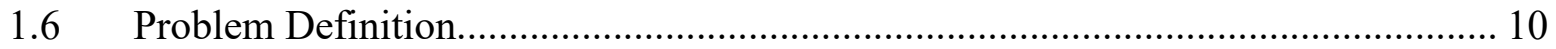

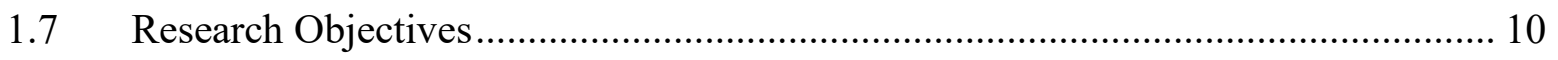

1.8 Organization of Research........................................................................... 11

2 Chapter: Literature Review ........................................................................... 12

2.1 Vacuum Insulation Panel Service Life ...................................................... 12

2.2 Laboratory Aging and Lifespan Assessment ................................................ 18

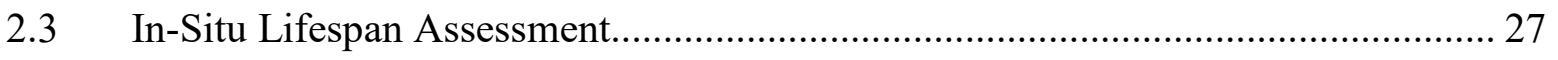

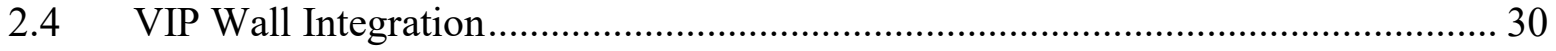

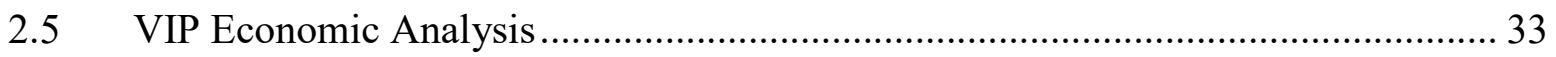

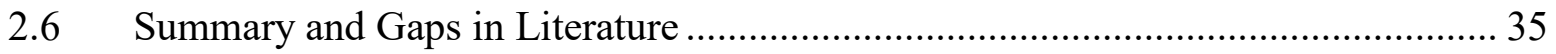

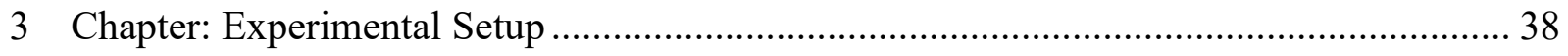




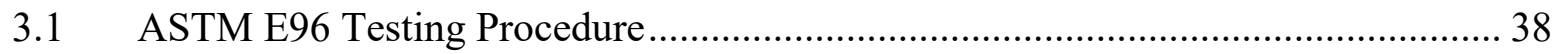

3.2 Climate Chamber Construction and Testing...................................................... 40

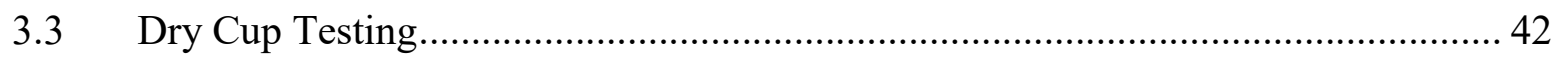

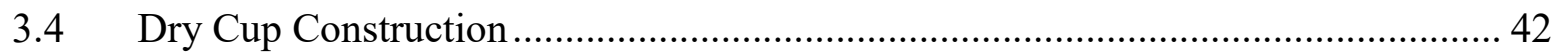

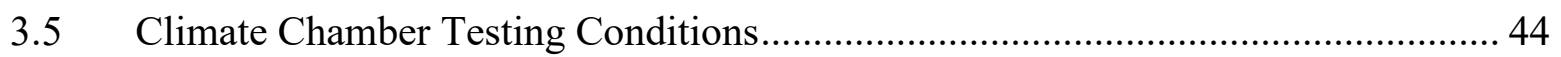

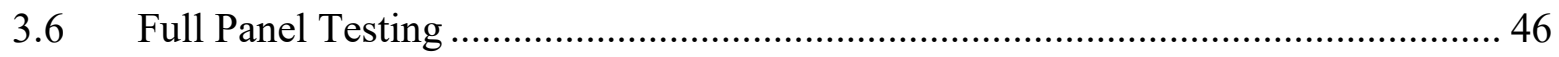

3.6.1 Guarded Hot Plate Apparatus ......................................................................... 47

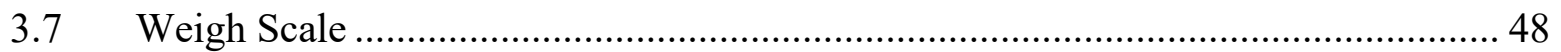

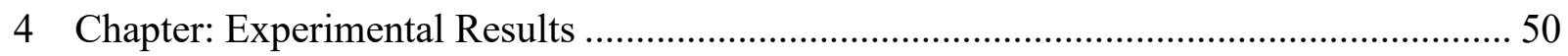

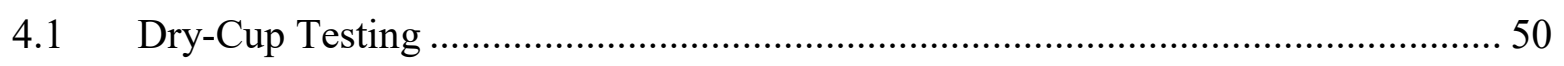

4.2 Full Panel Aging and Thermal Conductivity Testing …………............................. 54

4.3 Conclusions and Comparison to Measured Values ................................................... 57

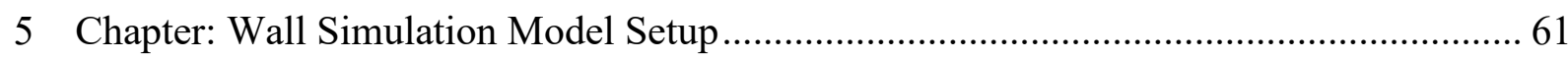

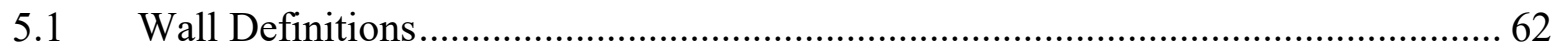

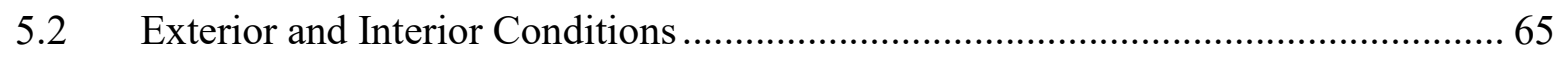

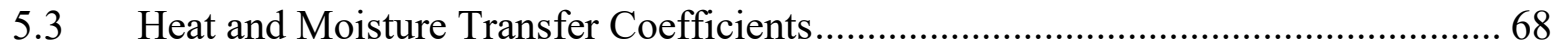

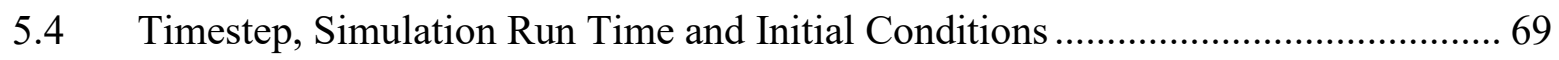

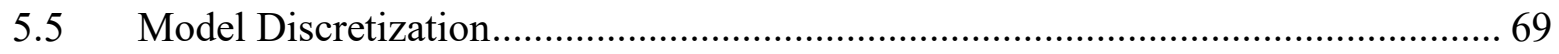

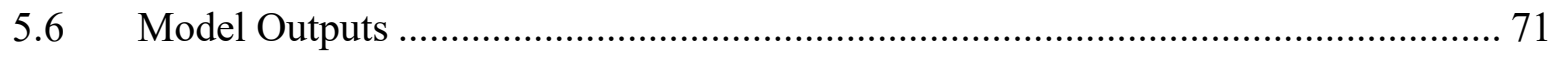

6 Chapter: Modelling Results and Lifespan Assessment..................................................... 72

6.1 Hygrothermal Simulation Results...................................................................... 72

6.2 Lifespan Model Development and Theory ………………………........................ 73

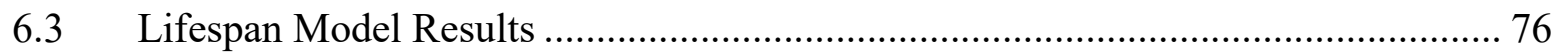




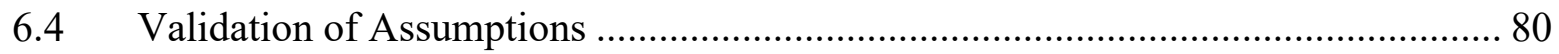

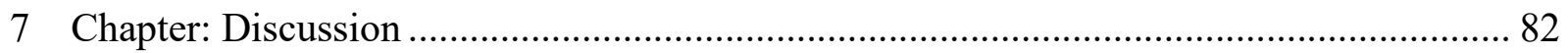

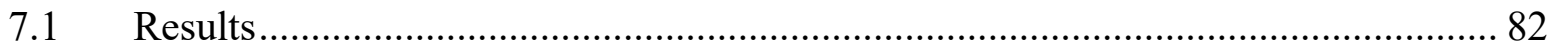

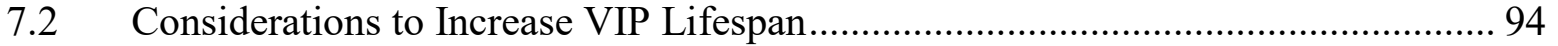

8 Chapter: Conclusions and Future Work.............................................................. 100

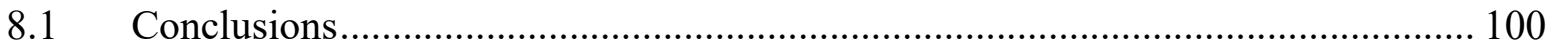

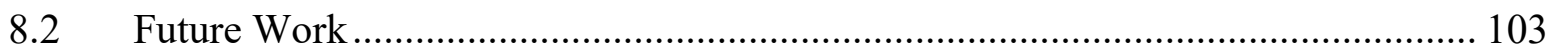

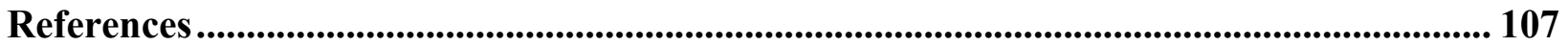




\section{List of Figures}

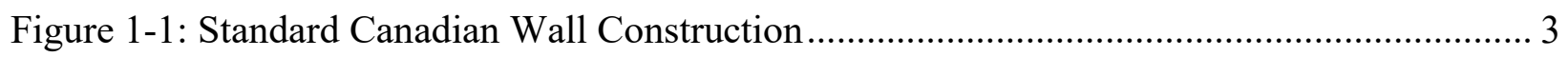

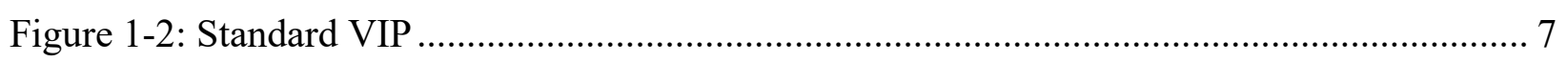

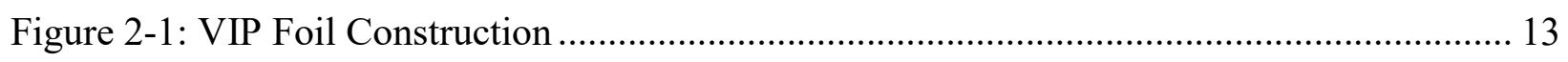

Figure 2-2: Moisture Sorption-Diffusion Model for VIPs........................................................ 15

Figure 3-1: Climate Chamber Component Diagram............................................................... 41

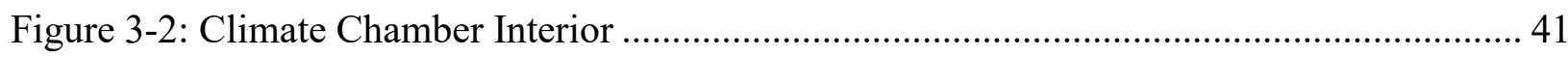

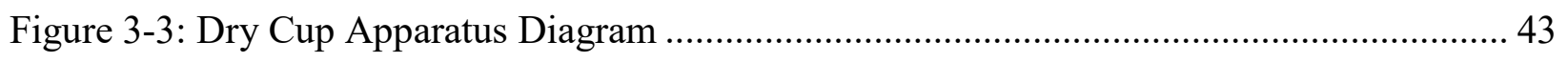

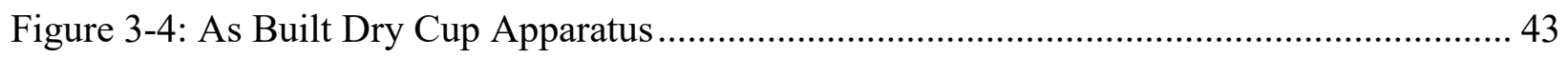

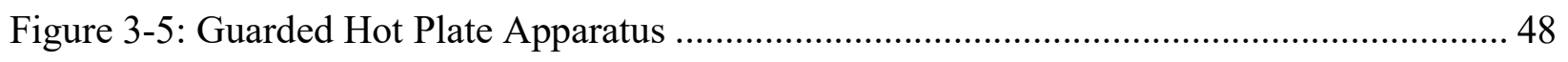

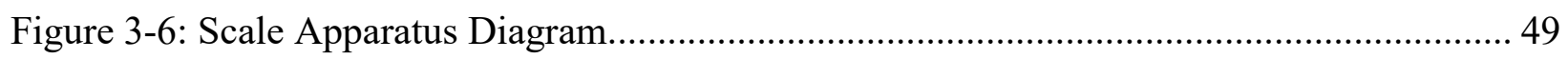

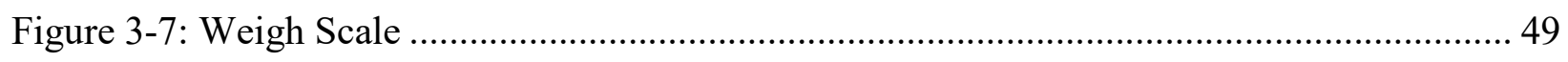

Figure 4-1: Manufacturer A Panel Mass Increase ……………............................................... 55

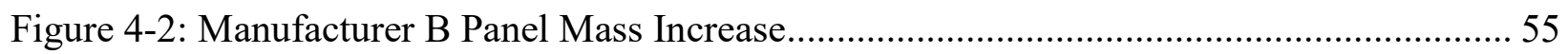

Figure 4-3: Measured and Published WVTR Trend ……………………………....................... 59

Figure 4-4: Thermal Conductivity and Water Content Relationships ......................................... 60

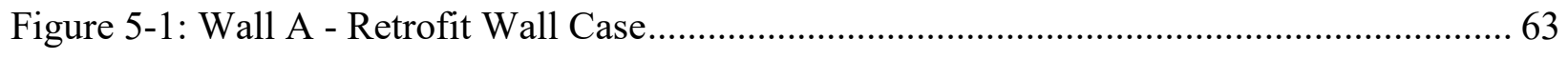

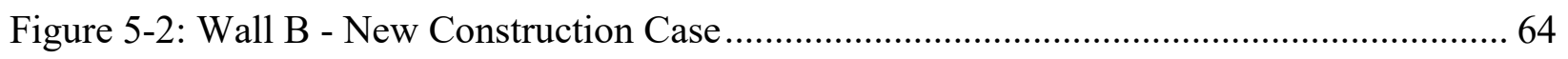

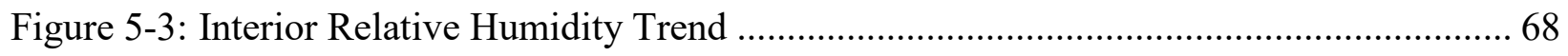

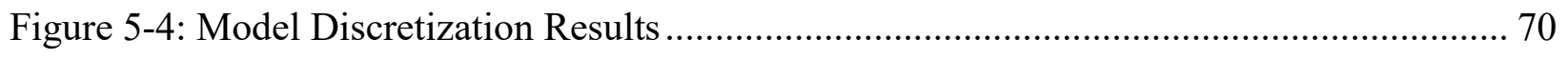

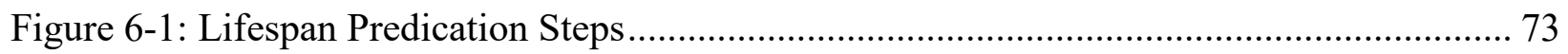

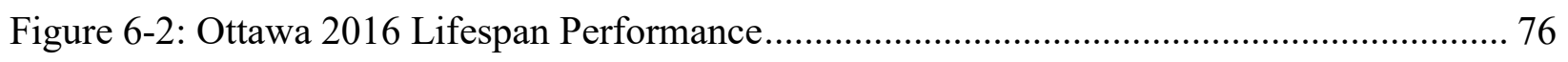

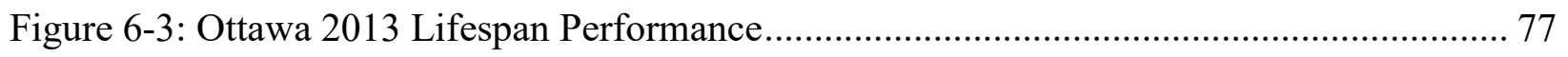


Figure 6-4: Niagara 2016 Lifespan Performance.

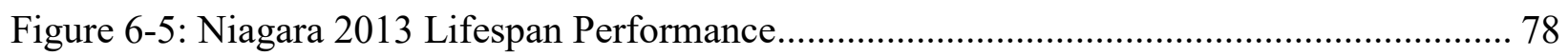

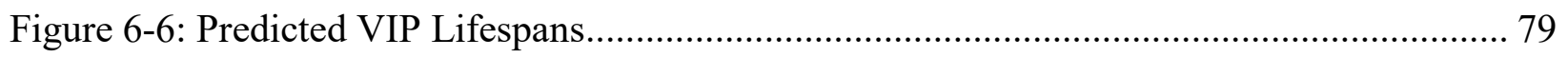

Figure 7-1: Ottawa Wet Year (2013) Panel Face Moisture Ingress Amounts .............................. 85

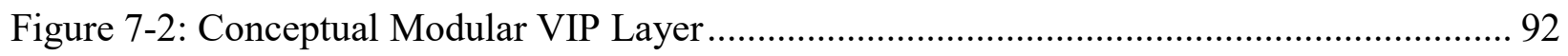

Figure 7-3: Yearly Average Vapour Pressure for Canadian Cities ............................................... 97

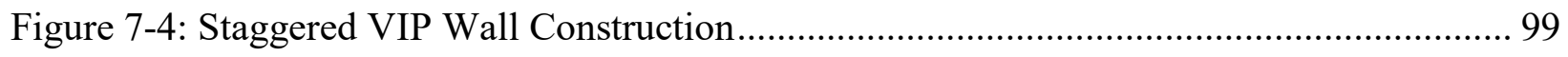

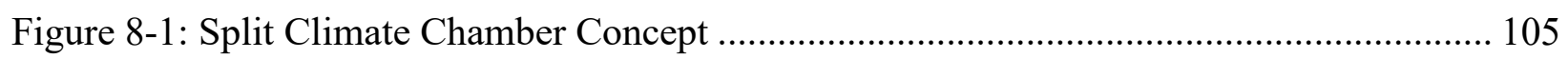




\section{List of Tables}

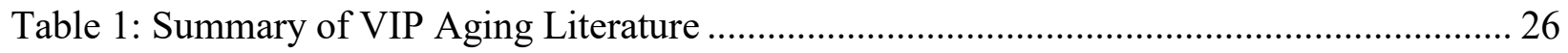

Table 2: Summary of In-Situ Lifespan Experiments ................................................................ 30

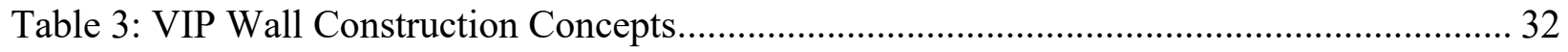

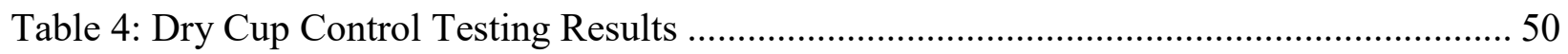

Table 5: Control Test Calculated WVTR and Permeance ........................................................ 51

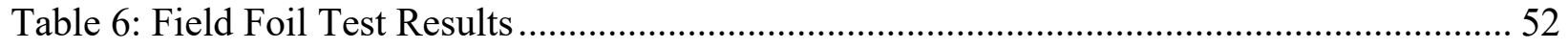

Table 7: Field Foil Experimental WVTR and Permeance ...................................................... 52

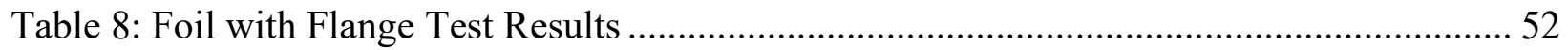

Table 9: Foil Flange Experimental WVTR and Permeance ……………….............................. 52

Table 10: Full Panel Experimental WVTR and Permeability ....................................................... 56

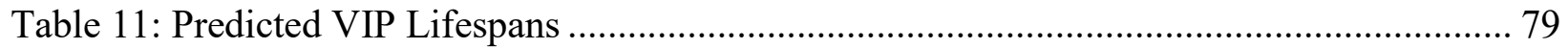

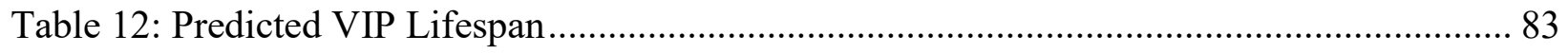

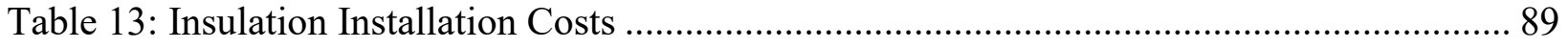

Table 14: Comparison of VIP Effect on Wall Thermal Conductivity .......................................... 93 
Nomenclature

\begin{tabular}{|c|c|c|}
\hline Symbol & Description & Units \\
\hline VIP & Vacuum Insulation Panel & - \\
\hline$k, \lambda$ & Thermal Conductivity & $\mathrm{W} / \mathrm{m} \cdot \mathrm{K}$ \\
\hline R-Value & - & $\mathrm{m}^{2} \mathrm{~K} / \mathrm{W}$ \\
\hline XPS & Extruded Polystyrene & - \\
\hline EPS & Expanded Polystyrene & - \\
\hline PE & Polyethylene & - \\
\hline PET & Polyethylene Terephthalate & - \\
\hline MF & Metallized Foil & - \\
\hline LCCA & Life Cycle Cost Analysis & - \\
\hline GTR & Gas Transmission Rate & $\mathrm{m}^{3} / \mathrm{m}^{2}$ day \\
\hline WVTR & $\begin{array}{c}\text { Water Vapour Transmission } \\
\text { Rate }\end{array}$ & $\mathrm{g} / \mathrm{m}^{2}$ day \\
\hline$c_{\mathrm{i}}$ & Concentration of molecules & Mole \\
\hline$S_{\mathrm{i}}$ & Solubility Coefficient & Mole/ATM \\
\hline$p_{\mathrm{i}}$ & Partial Pressure of Gas & ATM \\
\hline$g_{\mathrm{i}}$ & Ficks Law Mass Flow Rate & $\mathrm{Mol} / \mathrm{m}^{2} \mathrm{~s}$ \\
\hline$D_{\mathrm{i}}$ & $\begin{array}{c}\text { Diffusion Coefficient of } \\
\text { Material }\end{array}$ & $\mathrm{m}^{2} / \mathrm{s}$ \\
\hline$c_{\mathrm{i}}$ & $\begin{array}{c}\text { Concentration gradient of } \\
\text { permeant }\end{array}$ & $\mathrm{Mol} / \mathrm{m}^{3}$ \\
\hline$l$ & Thickness of VIP & $\mathrm{m}$ \\
\hline$V_{\text {eff }}$ & Effective Pore Volume & $\mathrm{m}^{3}$ \\
\hline$Q_{\mathrm{wv}, \text { total }}$ & Permeance & Perms \\
\hline$\Delta p_{\mathrm{wv}}$ & Pressure Difference & $\mathrm{Pa}$ \\
\hline OSB & Oriented Strand Board & - \\
\hline $\mathrm{OC}$ & On-Center & - \\
\hline$P_{\mathrm{F}}$ & Present Cost & $\$$ \\
\hline$F$ & Future Cost & $\$$ \\
\hline$i$ & Discount Rate & $\%$ \\
\hline $\mathrm{n}$ & Time Period & - \\
\hline G & Weight & $\mathrm{g}$ \\
\hline$t$ & Time & Hours \\
\hline$A$ & Area & $\mathrm{m}^{2}$ \\
\hline$S$ & Saturation Vapour Pressure & $\mathrm{Pa}$ \\
\hline$R$ & Relative Humidity & $\%$ \\
\hline$h_{\mathrm{c}}$ & Heat transfer coefficient & $\mathrm{W} / \mathrm{m}^{2} \mathrm{~K}$ \\
\hline$\beta$ & Moisture Transfer Coefficient & $\mathrm{s} / \mathrm{m}$ \\
\hline$X_{\mathrm{W}}$ & Moisture Content & $\mathrm{g}$ \\
\hline WDR & Wind-Driven Rain & $\mathrm{L} / \mathrm{m}^{2} \mathrm{~s}$ \\
\hline
\end{tabular}




\section{Chapter: Introduction}

\subsection{Background}

In order to mitigate the effects of climate change, the Canadian government has committed to significant reductions in greenhouse gas (GHG) emissions, specifically reducing GHG emissions to $40 \%$ of 2005 levels by 2030 (Ferland, 2017). The Canadian building sector is responsible for $12 \%$ of total GHG emissions (Canadian Wood Council, 2017); evolving standards for new and existing buildings will be a major focus for Canada to reach its emission targets goal. For the residential sector, $60 \%$ of buildings energy consumption is used for space heating (Bradford West Gwillimbury Building Division, 2012). One of the most popular approaches to reduce building energy consumption is to lower the heating and cooling loads of the building.

In addition to mitigating the effects of climate change by reducing GHG emissions, it is also necessary to adapt to new weather conditions brought about by climate change (Bristow \& Bristow, 2017). Climate change is predicted to have notable impacts on the weather conditions across the world. In Canada, climate change is expected to raise the average temperature experienced across a year by up to $2^{\circ} \mathrm{C}$. In addition to the temperature rise, climate change is predicted to increase the frequency of extreme weather events (Government of Canada, 2017). This means that Canada's existing and future building stock will be subject to more extreme climate loads, including rain, temperature, and humidity, than the past. These increasingly intense weather conditions mean that buildings must be built to a greater standard, including better materials, better building practices, and more intelligent understanding of building resiliency.

There are many approaches to reduce the energy demand of a building. These include high efficiency equipment, energy recovery, on-site storage, and even integrated renewable energy sources. The most passive and effective method of reducing energy consumption is enhancing the 
thermal performance of building envelopes and reducing the heat flow through the envelope. This can be done by increasing the physical quantity (thickness and amount) of conventional insulation materials in the walls or by incorporating new insulation materials with more attractive thermal properties. Increasing the amount of physical insulation in walls is challenging, as it requires thicker building walls. Thicker building walls lead to many construction and design challenges as well as the larger footprint of the wall consuming valuable property space or useful indoor floorspace. This has encouraged the research of new thinner materials with better insulating properties to increase the thermal performance of a building without the challenge of increasing wall footprint.

\subsection{Building Envelopes and Resiliency}

The building envelope is defined as the outside facing structure of the building, including walls, windows, and doors (Jelley, 2017). The fundamental purpose of a building envelope is to isolate the building interior and occupants from the exterior weather conditions, including rain, wind, and high/low temperatures. A building envelope fulfills this purpose by incorporating multiple layers of insulation, protection, and vapour and air barriers into its structure. A standard building envelope of a residential building in Canada consists of the following layers: An exterior exposed cladding (such as siding or brick), an air gap, an air barrier, rigid exterior insulation, batt

insulation in the wall cavity, a polyethylene moisture barrier, and an interior exposed gypsum sheet 
(Canada Mortgage and Housing Corporation , 2013). This typical construction is shown in Figure 1-1.

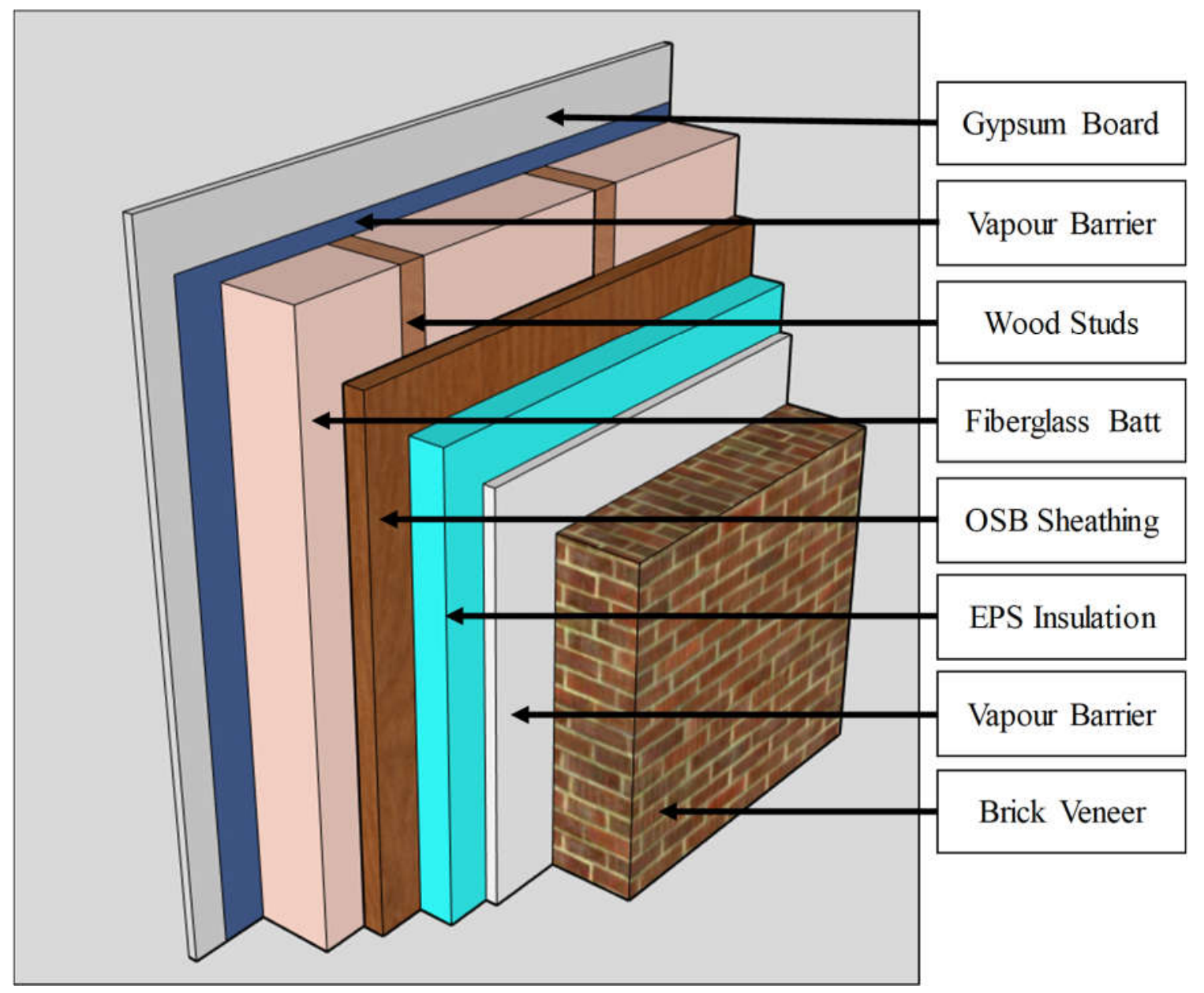

Figure 1-1: Standard Canadian Wall Construction (Canada Mortgage and Housing Corporation, 2013)

The thermal performance of a building envelope is a measure of the total thermal conductivity of the envelope materials. Thermal conductivity is a material property describing the rate at which heat passes through a material, measured in Watts per meter-Kelvin $(\mathrm{W} /(\mathrm{m} \cdot \mathrm{K}))$. Another measure of insulating property more commonly used in the building sector is R-value, which is a total measure of how well a given geometry of a material or series of materials resists heat flow, incorporating the thickness of the material. R-value is measured as $\left(\left(\mathrm{m}^{2} \mathrm{~K}\right) / \mathrm{W}\right)$. There 
are two practical approaches to increasing the thermal resistance of a building wall. The first approach involves increasing the thickness of either the cavity insulation layer or exterior insulation layer, or similarly, by installing additional layers of insulation. The total thermal performance of a wall is dependent on thickness, so increasing the thickness of the insulation increases thermal resistance provided by the insulation. Another method to increase the thermal performance of a building envelope is to use materials with better thermal properties, i.e., a lower thermal conductivity than conventional building insulation materials. These materials have a greater R-value per unit thickness, increasing the total R-value of the wall without effecting the thickness of the wall.

In addition to mitigating heat transfer between building interior and exteriors, the building envelope must also be able to mitigate bulk water and moisture transfer between the interior and exterior environments. The building envelope construction must also be resilient against the accumulation of moisture. Moisture enters the building envelope through four mechanisms i.e., bulk water movement, capillary action, air transported moisture, and vapour diffusion (U.S. Department of Energy, 2014). Bulk water movement is the most significant moisture source in building envelopes. This stems from weather events, such as wind-driven rain, and snow/ice melting events. Wind-driven rain is rainfall that is given horizontal velocity due to wind and is the greatest source of moisture in building envelopes (Blocken \& Carmeliet, 2004). Water movement due to capillary action is another significant source of moisture accumulation and transport in building envelopes, however not as significant as bulk water movement. Nearly all construction materials are porous, with microscopic holes (pores) present throughout the material surface. The combination of surface tension with adhesive and cohesive forces pulls water through the small pores, causing the transfer of moisture through the material (Park \& Allaby, 2013). All materials, 
to greatly varying degrees, are permeable to water vapour. Vapour diffusion is capable of driving moisture through materials in building envelopes. A combination of temperature and pressure differentials across a material are the driving forces responsible for vapour diffusion. Moisture is also driven into building envelopes as it is transported by air. Air contains moisture, and as air enters and exits buildings, condensation can cause the accumulation of moisture on surfaces. An ideal building envelope must be resilient to each form of moisture transport. An envelope lacking in moisture resiliency will experience significant increases in the thermal conductivity as the moisture content of envelope materials increases (Koci, et al., 2016). Additionally, moisture accumulation inside walls increases the likelihood of mould growth and rot.

As regulations regarding the building constructions are encouraging lower heating loads and energy consumption, envelopes increasingly are required to have greater thermal performance and resiliency. Numerous new technologies have been emerging in order to efficiently increase the thermal performance of building envelopes.

\subsection{Standard Insulation Materials}

Insulating materials currently used in the building sector vary depending on application, budget, intended outcomes, climate, and regulations/code. This also includes incorporating the properties of various materials into the decision-making criteria, including moisture and air permeability and most importantly, thermal conductivity. In a standard wood framed building, there are two layers of insulating materials the exterior (rigid) insulate sheathing layer and the cavity insulation. The rigid insulation layer is mounted on the exterior of the structural frame of the building. Exterior rigid insulation is generally polystyrene, either extruded (XPS) or expanded (EPS). XPS is manufactured using extrusion, resulting in a closed cell board. EPS is manufactured through the expansion of beads within a mould, which results in small voids throughout the 
structure that allow moisture to pass through. The cavity insulation is inserted into the cavity between the building structural members, generally wood studs. In a conventional building assembly, the exterior rigid insulation makes up approximately $30 \%$ of the total wall insulating capacity while the cavity accounts for nearly $60 \%$ of the total insulating capacity of the wall (Canadian Wood Council, 2018). The cavity insulation varies between four main types: fiberglass, mineral wood, cellulose, and spray foam. It is important to note that the cavity portion of building insulation is much more susceptible to thermal bridging. Thermal bridging is a phenomenon where heat transfer concentrates through higher conductivity pathways reducing the overall wall R-value. These pathways occur in building envelopes due to fasteners, studs, and often exist as an inherent part of construction techniques (Jelley, 2017).

\subsection{Vacuum Insulation Panels}

Vacuum Insulation Panels (VIPs) are an existing technology breaking into the building sector. VIPs consist of an open cell solid material core. The solid core is sealed with an air-tight foil envelope in which the inner air is evacuated, creating a near vacuum within the foil. VIPs vary in core and foil materials, as well as in size and thickness. VIPs have three to six times better thermal performance than the same thickness of conventional insulation material (Baetens, et al., 2010). VIPs achieve high thermal performance by using the near vacuum inside the panel to virtually eliminate convective heat transfer - the main mode of heat transfer through insulating materials. A standard VIP is shown in Figure 1-2. 


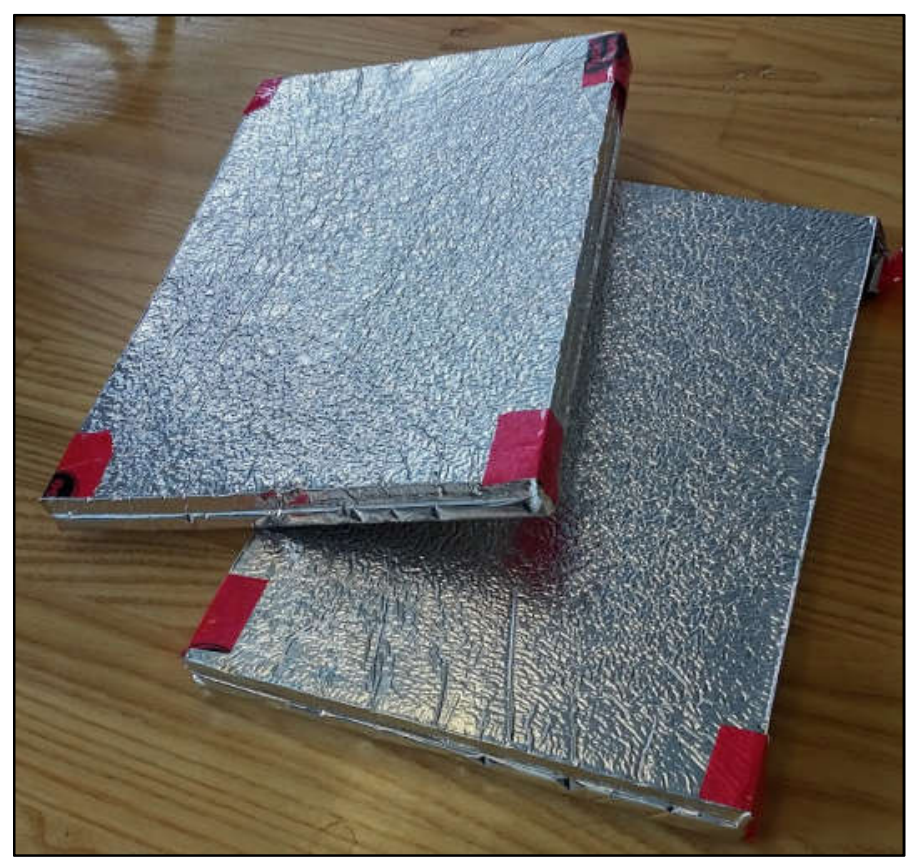

Figure 1-2: Standard VIP

VIPs have two main components: the core and the foil envelope. The most important property of the core material is that it be open-cell. This allows the gas from within the material to be evacuated for the creation of a vacuum within the panel. The core material must also be nanoporous, this greatly reduces the amount of vacuum required to eliminate gaseous conduction. When the average pore size is in the same magnitude as the mean free path length of the gas molecules, the remaining gas molecules interact only with the sides of the pores without transferring energy across the panel (Baetens, et al., 2010). A common core material is fumed silica, which is both open-cell and nano-porous. Additionally, fumed silica on its own has a thermal conductivity of $0.02 \mathrm{~W} /(\mathrm{m} \cdot \mathrm{K})$ comparable to EPS insulation. This is important as in the event of a VIP being punctured, the dry fumed silica would still provide levels of insulation comparable to conventional insulation materials. The primary purpose of the VIP foil is to maintain the vacuum, being virtually impermeable to gas permeation. The VIP foil must also minimize the thermal bridging effects 
present at the perimeter of the envelope, while remaining durable enough to withstand the installation process. Currently there are three main types of VIP foils: metal foils with interior polyethylene (PE) and exterior polyethylene terephthalate (PET) layers, metalized foils with interior PE and exterior PET layers, and polymer films. Metalized foils are the most common VIP foil type as they combine the low permeation rates of a metal foil while minimizing the high rates of conduction through the foil that occur with metal envelopes. Metal films are continuous metal foils where metalized foils are films made by applying droplets of liquid metal onto a surface. Metal foils have a much finer, more consistent surface than metalized foils.

Vacuum insulation panels have widely been implemented in the refrigeration and shipping industries, where it is highly economical to use the smallest amount of area possible for insulation. This is where VIPs thrive as they provide high amounts of insulation in thin wall sections. VIPs were first implemented as building insulation in 1999 (Song \& Mukhopadhyaya, 2016). The uses of VIPs in buildings have several potential benefits. Firstly, using VIPs as the primary insulation in walls allows the footprint of the wall to be significantly reduced. This allows high levels of insulation to be achieved without the usually associated thick building envelopes that highly insulated homes have. This is especially beneficial in areas where land is limited (physically or economically) as high levels of insulation can be achieved without encroaching on the usable floor space of the building. Another valuable use for VIPs is in energy retrofits. The thin profile of VIPs allows them to raise an existing buildings R-value without considerable loss of usable floor space or property area (Saber et al., 2015).

VIPs have many drawbacks. Foremost is the cost, they are currently considerably more costly than conventional insulation. They are also susceptible to puncture and damage, which eliminates the benefits of using vacuum insulation panels and makes the core material even more 
susceptible to moisture damage. One of the more unknown factors related to VIPs is their lifespan. The foil envelopes are not perfectly impermeable to gas and moisture transport. This means that over time, moisture and gas transfer into the VIP accumulate in the VIP, with moisture being the main contributor to declining performance. This permeation of moisture is directly connected the conditions seen at each face of the VIP over its life. These conditions are functions of the building construction that the VIP is integrated into as well as the climate that the building is located in. Therefore, it is advantageous to develop a prediction of VIP lifespan considering three main factors. The first factor is the rate at which moisture enters the panel. This depends on both the temperature and relative humidity that the VIP is subjected to. The second factor is the temperature and relative humidity at each face of the VIP installed in a wall. This is a function of weather and building construction. The last factor is the reduction in performance a VIP experiences as moisture accumulate within the panel. The development of knowledge surrounding these three unknowns and how they are interconnected will allow for the development of realistic lifespan predictions.

\subsection{Life Cycle Cost Analysis}

In order to properly understand the suitability of an emerging technology, the economics of that technology must be considered. For a finite life product, such as VIPs, the most encompassing economic analysis is a life cycle cost analysis (LCCA). LCCA incorporates all economics of a product. Life cycle costs for building envelope materials can be grouped into 3 categories: upfront costs, maintenance and replacement costs, miscellaneous, including taxes, rebates. One of the key concepts of an LCCA is incorporating the time value of money, as money loses value over time due to effects of missed interest and inflation. An LCCA accounts for this by amortization of all future costs and incomes into a single present value usable for comparison. 
A detailed life cycle cost analysis is important to determine the economic suitability of new products, such as VIPs. An LCCA would provide insight into if the economic benefit of VIPs outweighs the initial investment cost of VIPs.

\subsection{Problem Definition}

The problems that this research answers are as follows:

- Experimentally measure the rate of moisture accumulation and corresponding reduction in thermal performance of VIPs

- Simulate the temperature and relative humidity a VIP is subject to over a 25 -year period using detailed weather data from two different Canadian cities, including dry and wet representative years

- Predict the lifespan of the VIP dependent on the fulfillment of a thermal conductivity-based failure criteria

\subsection{Research Objectives}

The objectives of this study were to:

- Develop the required equipment and procedures to measure water-vapour transmission rates of VIP foils

- Measure the thermal conductivities of panels as water content increases

- Develop a method of 1-dimensional simulation of heat and moisture transport through building envelopes

- Predict the lifespan of VIPs installed in building envelopes in two difference Canadian cities 


\subsection{Organization of Research}

The information presented in this thesis is a summary of work conducted over two years and is presented in the following chapters.

Chapter 1 - Introduction: Introducing VIPs, their use in building and research motivation

Chapter 2 - Literature Review: A review of previous research surrounding the aging and lifespan of VIPs to determine approaches and shortcomings of previous work.

Chapter 3 - Experimental Setup: Detailed discussion into the procedure and approach for measuring water vapour permeability and thermal conductivity.

Chapter 4 - Experimental Results: Detailed investigation into the results obtained from experimental tests.

Chapter 5 - Wall Simulation Setup: Detailed discussion into the construction of a wall model.

Chapter 6 - Modelling Results and Lifespan Assessment: Overview of the results obtained from simulation and the development of lifespan predictions based on simulation results.

Chapter 7 - Discussion: A summary of lifespan prediction results and discussion into the meaning of these results.

Chapter 8 - Conclusions and Future Work: A summary of conclusions from this thesis and an outline of future work. 


\section{Chapter: Literature Review}

This chapter will discuss the current literature regarding VIP service life, including the definition of a failed VIP and the mechanisms and theory behind VIP aging. Aging experiments both in laboratory and in-situ will be discussed including each authors predictions of VIP lifespan (where available). A discussion on the economic feasibility of VIPs will follow. A concluding section of gaps and shortcomings in the current literature will provide insight into the contributions to literature being made by this thesis.

\subsection{Vacuum Insulation Panel Service Life}

Unlike conventional insulation materials, VIPs lose their thermal performance over time. As gas and moisture permeate into the panel, the internal pressure and thermal conductivity increases, reducing the thermal performance of the panel. This means that the significant thermal benefits VIPs provide at the beginning of their life slowly become less pronounced over time. Because of this, numerous studies have been done investigating the aging of VIPs, attempting to quantify the aging mechanisms and lifetime performance of vacuum insulation panels. Baetens et al. (2010) have thoroughly investigated the application of VIPs in building envelopes, including the development of a service life definition that is accepted amongst researchers. This research found two factors influencing the thermal performance of a VIP: internal gas pressure and internal moisture content. Baetens et al. found that there are two main definitions of a VIPs service life. The most common definition is that the panel is failed when the effective thermal conductivity of a panel doubles from its initial value. The second, less common definition, is that when the thermal conductivity, averaged over time, reaches a predetermined critical value, generally double the 
initial thermal conductivity. Similarly, Schwab et al. (2005) defined the lifetime of a VIP as the time it takes the thermal conductivity of a panel to increase by $50 \%$.

\subsubsection{Foil Barrier and Permeation Related Performance Declines}

In order to understand the aging of VIPs, the construction and permeability of the foil envelope must be investigated. Bourquerel et al. (2012), Schwab et al. (2005), and Yeo et al. (2014) have studied VIP foils and the permeation of moisture and various gases through various types of panels. Starting with the construction of the foils, Bouquerel et al. identified two types of VIP foils currently in use, Laminated Aluminum Foils (AF) and Multilayer Metalized Films (MF). These films are shown in Figure 2-1. AF foils consist of an outer cover layer of PET, a continuous layer of aluminum foil, and an inner weld layer of PE. Similarly, MF foils have the same inner and outer PE and PET layers. However, instead of a continuous aluminum layer, MF foils have a metalized layer, consisting of many alternating layers of PET and deposited aluminum.
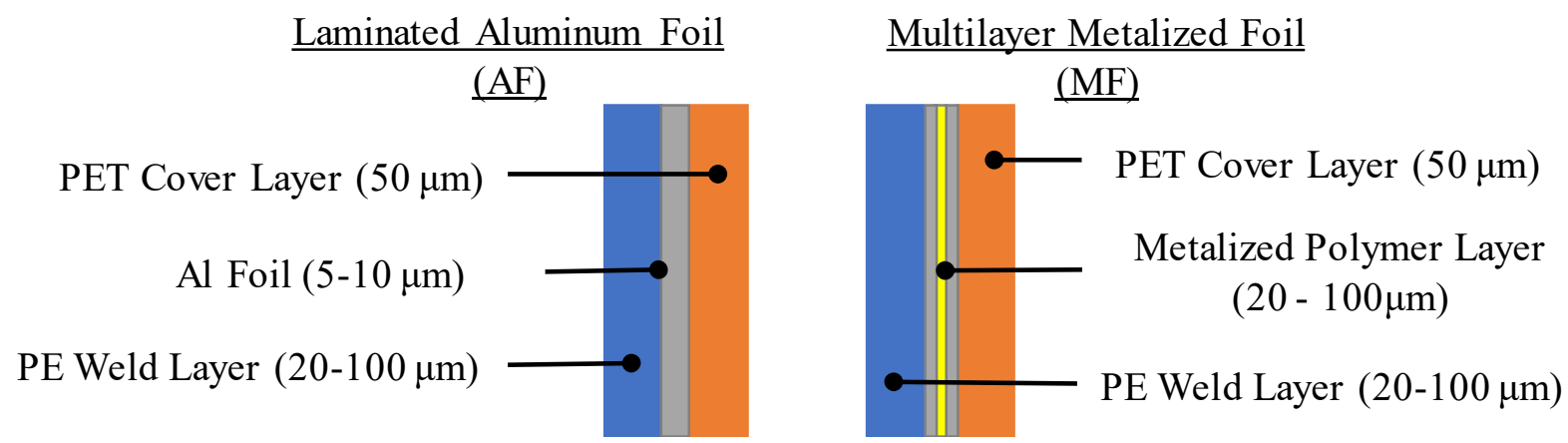

Figure 2-1: VIP Foil Construction (Adapted from (Baetens, et al., 2010))

Bouquerel found that $\mathrm{AF}$ barriers are superior in preventing the permeation of moisture and gases into the panel, however, the continuous foil surrounding the panel creates a considerable thermal bridge pathway. This reduces the effective thermal resistance of the panel by creating a low resistance pathway through the foil, around the panel. MF barriers reduce this thermal bridging effect by utilizing coated films with layers of PET, which greatly reduce thermal bridging effects 
around the panel. However, it was discovered that the application of metalized aluminum during the manufacturing phase results in numerous microscopic pinholes in the metalized aluminum layer. These pinholes were found to reduce the foils effectiveness at limiting gas and moisture permeation into the panels.

Two mechanisms of moisture and gas entry into panels were identified by Yeo et al. permeation through the foil field and permeation through the foils heat sealed flanges. Heat sealed flanges and pinhole defects in foil covers are perhaps the largest culprits of gas and moisture permeation into panels. However, few studies have investigated these sources alone as isolating a specific mode of entry is very challenging. Most researchers focus on overall permeation into the panel, considering flow through the foil, flanges, and pinholes all as one, rather than attempt to quantify a single mode (Kwon et al., 2010). According to Bouquerel et al., the best way to quantify the ability for a foil to withstand gas and moisture entry is to evaluate the permeability of the foil based on a linear sorption-diffusion model. This model assumes that the rate gas and moisture travels through the foil is a function of the solubility and diffusion coefficients of the foil (Meares, 1966). The transport of gas and moisture into the foil is divided into three different steps, according Bouquerel et al., condensation and sorption on the surface of the foil, diffusion driven by a concentration gradient, and the evaporation of the permeant at the other side of the foil and the absorption of the permeant by the core of the VIP. The sorption-diffusion model is shown in Figure 2-2. This overall process can be represented by the mass flow rate, often divided into the Gas- 
Transmission Rate (GTR) and the Water-Vapour Transmission Rate (WVTR). Corresponding units for GTR and WVTR are $\left[\mathrm{m}^{3} / \mathrm{m}^{2}\right.$ day $]$ and $\left[\mathrm{g} / \mathrm{m}^{2}\right.$ day $]$.

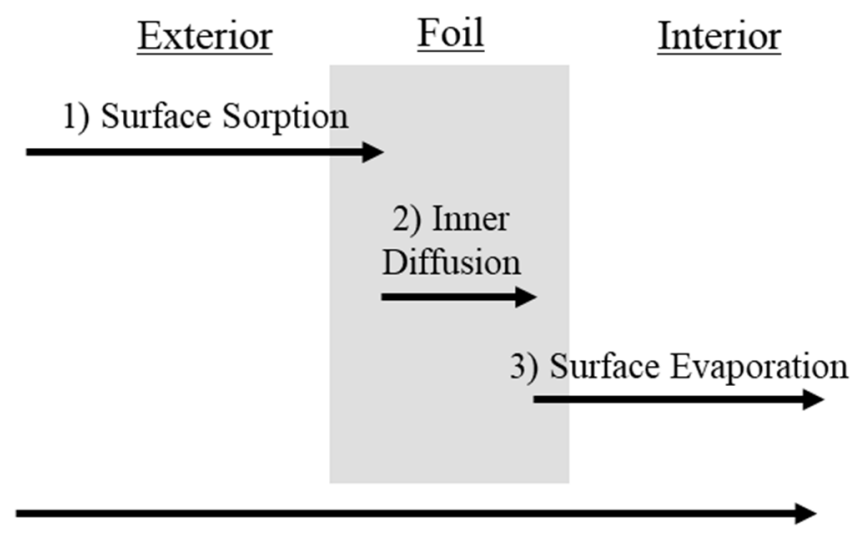

Overall Mass Transfer

Figure 2-2: Moisture Sorption-Diffusion Model for VIPs (Adapted from (Yeo, Jung, \& Song, 2014))

For the processes occurring at each boundary of the foil, surface sorption on the exterior and evaporation on the interior, Bouquerel et al. found that Henry's Law of Sorption best represents the mechanisms. Bouquerel et al. discusses that Henry's Law considers a linear relationship between the rate of molecule dissolution at the surface and the temperature of the process. Bouquerel et al. provided Henry's Law as:

$$
c_{\mathrm{i}}=S_{\mathrm{i}} p_{\mathrm{i}}
$$

where $c_{\mathrm{i}}$ is the concentration of dissolved molecules at the surface of the VIP foil. $S_{\mathrm{i}}$ is the solubility coefficient of the material, and $p_{\mathrm{i}}$ is the partial pressure of the gaseous molecule in atmospheres. For the diffusion through the membrane, Bouquerel et al. uses Fick's Law of Diffusion to characterize the movement. Fick's Law characterizes the flow rate of permeant across a known surface area of material per unit time. Fick's Law states that there is a linear relationship between the flow rate of a molecule through a permeant and the concentration gradient of the molecule in a material. Bouquerel et al. provided Fick's Law as: 


$$
g_{\mathrm{i}}=-D_{\mathrm{i}} \nabla c_{\mathrm{i}}
$$

where $g_{\mathrm{i}}$ is the mass flow rate of permeant, $D_{\mathrm{i}}$ is the diffusion coefficient of the material, and $c_{\mathrm{i}}$ is the concentration gradient of the permeant. Bouquerel et al. identified that diffusion in VIPs is unidirectional, since the dry low-pressure conditions of the VIP interior allow for the assumption that moisture only flows into the panel. In addition to this assumption, Bourequel et al. also identified that VIP foils can be assumed as homogenous and non-porous, allowing for the integration of Fick's Law across the entire thickness of the foil, this allows for the calculation of all three parts of permeance previously mentioned, resulting in a single GTR across the material.

$$
G T R=-D_{\mathrm{i}} \frac{c_{\mathrm{i}, 2}-c_{\mathrm{i}, 1}}{l}
$$

where $l$ is the thickness of the VIP foil. Schwab et al. (2005) also discussed the mechanisms of moisture and gas ingress into VIPs at great length. Schwab et al. states total transfer rates rather than investigating into the specific mechanisms responsible for permeation. Schwab et al. separate the ingress of air from the ingress of moisture. Similarly, to Bouqourel et al., Schwab et al. assume that diffusion forces are responsible for drawing air molecules through VIP foils through voids and pores in the foil. Schwab et al. first classifies the transmission of air into the panels as a function of standard temperature and pressure. The amount of air transferring into the panel is quantified by the increase in internal VIP pressure.

$$
\frac{d p}{d t_{\mathrm{air}}}=\frac{A T R_{\mathrm{total}}}{V_{\mathrm{eff}}} .
$$

where $A T R_{\text {total }}$ is the total air transmission rate across the entire panel, $V_{\text {eff }}$ is the effective pore volume of the foil. Schwab et al. argue that VIP foils are essentially impermeable to air but are permeable to the smaller molecules of water vapour (moisture). However, the exact mechanism of moisture transport into panels is not clear, but capillary transport through foil pores is a probable 
culprit. Schwab found that the permeance of moisture into VIP panels is several orders of magnitude higher than the permeance of oxygen or nitrogen. Schwab uses this to define moisture content increase in a VIP panel by the increase in panel weight over time:

$$
\frac{d m_{\mathrm{v}}}{d t}=Q_{\mathrm{wv}, \text { total }} \cdot \Delta p_{\mathrm{wv}}=W V T R_{\text {total }}
$$

where $Q_{w v, t o t a l}$ is the total foil permeance to water vapour, generally expressed in perms. $\Delta p_{\mathrm{wv}}$ is the pressure difference across the VIP foil in Pascals $(\mathrm{Pa})$, and $W V T R_{\text {total }}$ is the water-vapour transmission rate across the foil, expressed in $\left(\mathrm{g} / \mathrm{m}^{2}\right.$ day). Schwab also compared gas versus moisture permeation into VIPs and the corresponding effects on thermal conductivity from either source. Schwab found that moisture ingress into panels is not only greater in quantity, but also has a more significant effect on reducing the thermal resistivity of panels. Gas permeation into the panels only effects the internal pressure of the panel as it increases as more gas permeates through the foil. However, the relationship between internal pressure and thermal conductivity is not linear. There must be a substantial increase in internal pressure before the thermal conductivity is affected. Schwab found that for fumed silica cores the thermal conductivity is only affected once the internal pressure increases to over 20 mbar. For reference the initial internal pressure achieved during manufacturing of panels is between 0.001 and 1.5 mbar (Morgan Advanced Materials, 2017).

Moisture has been proven to be the primary source of increasing VIP thermal conductivity over time (Morlidge, 2014). Moisture content in VIPs increases the thermal conductivity through 3 mechanisms, two identified by Schwab et al., and a potential third mechanism discovered by Yrieix et al. (2014). Schwab identified the two traditionally accepted mechanisms for moisture related aging: increase in internal pressure of the panel (similar to gas permeant aging) and heat transfer through absorbed moisture. Absorbed moisture causes latent heat transfer when moisture 
on the warm side of the panel evaporates and travels to the cold side as well as heat conduction by liquid water absorbed in the panel. In addition to this, unlike increases internal gas pressure, the thermal conductivity of the panel immediately begins to increase with water content in a linear relationship. The third mechanism, identified by Yrieix et al. (2014), is a change in the microstructure of fumed silica after it comes into contact with moisture. Yrieix et al. aged VIPs in climate chamber conditions, held at a constant humidity of $80 \%$. Results showed a decrease in silica specific area and an increase in hydrophilic behavior. Yrieix et al. determined that this influences the moisture behavior within the VIP, adding to the conduction of heat.

The results of this research are that VIP foils are most susceptible to moisture permeation. The research has concluded that overall moisture transfer into a VIP is the main driving force behind VIP aging and the drop in thermal performance VIPs experience over time.

\subsection{Laboratory Aging and Lifespan Assessment}

Numerous studies have been done to attempt to quantify moisture and gas transmission into VIPs and the corresponding useful service life. Most studies are similar in general approach. They begin by baselining the VIP performance, then attempt to age the panel in laboratory settings, and a re-assessment of the VIP performance after aging. Within that, the studies can be split into two different categories: studies simply trying to obtain moisture permeation rates of panels and the corresponding effects on thermal performance and studies focused on accelerated aging and attempts to quantify a useable lifespan of VIPs.

One of the first experiments done to relate the quantity of moisture in a panel to its thermal conductivity was completed by Schwab et al. (2005). In this experiment, panel cores were dried in an oven at $150^{\circ} \mathrm{C}$ for $3 \mathrm{~h}$, before being weighed, evacuated and sealed in the foil envelope. Once this was complete, a baseline thermal conductivity was measured using a hot plate apparatus. Next, 
the foil was sprayed with a known amount of water and immediately froze. Once the panel was frozen the foil was re-evacuated and sealed and the thermal conductivity was taken again. This was repeated once more with the core being removed, dried, and retested. This allowed the thermal conductivity of a panel to be measured when an exact known amount of water is present in the panel. Experimental results showed that the thermal conductivity increased by $3.0 \cdot 10^{-3} \mathrm{~W} / \mathrm{m} \cdot \mathrm{K}$ when the water content was increased from $0 \%$ to $6 \%$ of VIP mass. Schaub found that the effects of water vapour on panel thermal conductivity were considerably higher than what was expected at the time. Schwab assumed that moisture ingress into VIPs would be between $0.02 \%$ and $3.8 \%$ per year, resulting in yearly increases of the panels thermal conductivity of $0.01 \cdot 10^{-3} \mathrm{~W} / \mathrm{m} \cdot \mathrm{K}$ to $1.90 \cdot 10^{-3} \mathrm{~W} / \mathrm{m} \cdot \mathrm{K}$. Schwab used these testing results to create a function to define the thermal conductivity of a panel dependent on the amount of water present in the panel, this is shown in Equation (6).

$$
\lambda\left(X_{\mathrm{w}}\right) \approx \lambda_{\mathrm{VIP}, \mathrm{dry}}+0.5 \times 10^{-3} \frac{\mathrm{W}}{\mathrm{mK}} \cdot \frac{X_{w}}{m} \%
$$

where $\lambda\left(X_{\mathrm{w}}\right)$ is the center of panel thermal conductivity at a known water content, $\lambda_{\mathrm{VIP}, \mathrm{dry}}$ is the dry center of panel thermal conductivity, and $\frac{X_{w}}{m} \%$ is the water content of the panel expressed as a percentage of total panel mass. These results were critical in demonstrating how moisture in VIPs is the main source of the degradation in performance they experience over time.

Schwab performed yet another study attempting to predict the lifetime of VIPs based on permeation rates and corresponding drops in thermal performance (2005). This research intended to determine rates of pressure and water content transmission into panels at differing temperatures and relative humidity. Once these rates are known, an estimation of thermal conductivity over time would be estimated. Schwab used two climate chambers set at constant climatic conditions to 
simulate the temperature and humidity levels the panels could see while implemented in buildings. The first chamber was set at a constant temperature of $23^{\circ} \mathrm{C}$ and $75 \%$ relative humidity while the second chamber was at $23^{\circ} \mathrm{C}$ and $15 \%$ relative humidity. Panels of varying sizes and foil types were placed in each chamber, every 2-4 weeks the panels were removed from the chamber and measured for moisture content and pressure increase. The water content increase was measured by weighing of the panel mass with a high precision scale. Pressure increase was measured using the foil-lift method. This method consists of placing a panel on a sealed gasket, and greatly reducing the air pressure on one side of the panel until the chamber pressure is lower than the internal pressure of the VIP. This results in the foil to lifting off the core material. The distance the foil lifts is measured with a laser which allows for the calculation of internal pressure. Schwab used this experimental data to determine the WVTR and ATR for each foil type tested AF, MF1, and MF2. This thesis will focus on MF2 foil types as they are currently the most common foil material for VIPs. For the prediction of lifetime, Schwab used rates measured in the climate chamber at $23^{\circ} \mathrm{C}$ and $75 \% \mathrm{RH}$, these rates are $0.0086 \mathrm{~g} / \mathrm{m}^{2} \mathrm{~d}$ and $0.0039 \mathrm{~cm} / \mathrm{m} \cdot \mathrm{d}$ for WVTR and ATR, respectively. The thermal conductivities were analytically estimated and a trend of thermal conductivity over time for each foil type was created. Schwab found that MF1 foils have between a 5- and 10-year service life, depending on the size of the panel. MF2 panels were found to have service lives between 16- and 38-years. This paper made great steps towards determining the lifespan of VIPs. However, there were two main shortcomings in the method. Firstly, climate data were taken as constant. The temperature and humidity were assumed to be the same throughout the panel life. This fails to account for temperature and relative humidity fluctuations due to weather, as well as moisture levels outside of the panel due to water entry in the building envelope. 
This study also used analytically calculated thermal conductivities, depending on the internal water content and internal pressure. It is unclear how accurate these analytical relationships were.

Wegger et al. (2010) covered various methods for aging VIPs. The first aging experiment consisted of temperature aging. This experiment used a modified version of the CUAP 23.02/30 recommended aging process. This consists of first baselining the panel at $23^{\circ} \mathrm{C}$ and $50 \% \mathrm{RH}$ for 72 hours, the thermal conductivity is then taken. Eight Cycles of the following procedure are completed: the panel is held at $80^{\circ} \mathrm{C}$ for $8 \mathrm{~h}$ and $-15^{\circ} \mathrm{C}$ for $16 \mathrm{~h}$ before the thermal conductivity is measured again. The panel is then aged for 90 days at $80^{\circ} \mathrm{C}$, the thermal conductivity is measured, and aged for another 90 days at $80^{\circ} \mathrm{C}$ before the final thermal conductivity is measured. Wegger found that no change in thermal conductivity was found after the freeze/thaw cycles. However, these panels had an outer fleece fire protection layer that became significantly deteriorated in the first month of the experiment but maintained condition from that point onwards. The thermal conductivity of the panel went unchanged over this experiment, other than a slight increase attributable to the increase in thickness due to the swelling of the fleece layer.

The next aging protocol Wegger used was based on the Nordtest method NT Build 495, developed to determine suitability of vertical building materials to extreme climate conditions. The purpose of this testing was to determine the sensitivity of VIPs to different climatic factors. The testing involves 1-hour cycles between the four following climate strains: 1) UV and IR radiation, 2) spraying with liquid water, 3) freezing at $-20^{\circ} \mathrm{C}$, and 4) thawing at room temperature. This cyclic testing was performed directly on VIPs as well as onto a wall section with installed VIPS. Results from this testing showed a slight increase in thermal conductivity, the panel directly exposed to 
the testing conditions increased in thermal conductivity from 4.3 to $4.5 \mathrm{~mW} / \mathrm{m} \cdot \mathrm{K}$, where the panel installed in a wall assembly increased from 4.3 to $4.4 \mathrm{~mW} / \mathrm{m} \cdot \mathrm{K}$.

The final test procedure done by Wegger consisted of a combination of moisture and temperature aging of VIPs. The purpose of this experiment was to expose a VIP to a high moisture pressure, which is achieved by creating a high temperature, high humidity environment. This testing consisted of placing the VIP in a sealed chamber held at $70^{\circ} \mathrm{C}$ with an open water container. The VIP thermal performance was measured after 30 days in the chamber, this was repeated three times. The thermal conductivity increased from 4.4 to $4.6 \mathrm{~mW} / \mathrm{m} \cdot \mathrm{K}$ after the first 30-day cycle, however, a catastrophic failure was experienced after this point and the test was discontinued. Wegger used the experimental results to attempt to quantify a total VIP lifespan, however it is not clear how the results were extrapolated along multiple years. Wegger predicted that, for each of the foils tested, the thermal conductivity would not reach a failure point (double its original value) within 50 years (Morlidge, 2014).

An analytical prediction of lifespan was completed by Thorsell (Thorsell, 2010). Thorsell estimated the size and frequencies of defects in a VIP foil and used a pressure difference-based model to predict the gas flux through the foil, water vapour transfer was not accounted for in this model. Thorsell attempted to identify the number of foil layers required to meet the lifetime requirements defined by an International Energy Agency (IEA) report, which stated that VIPs must last 30-50 years, similar to the useful life of building. Thorsell concluded that a two-layer foil, MF2, is more than sufficient at maintaining a VIP service life of 30-50 years.

One of the most referenced lifespans was completed by the Authors of Annex 39 (Subtask A) (Simmler H. , et al., 2005), where VIPs were the topic of discussion. The aim of this study was to quantify a service life based on both gas and water vapour permeation into the panel. ATR was 
measured by following the American Standard Test Method ASTM D1434 (ASTM International, 2015). This involves the creation of a pressure differential across a material, causing the transport of molecules from the high-pressure side to the low-pressure side. The pressure or concentration of molecules is measured using mass spectrometry or precise pressure measurements. Measurements taken for the ATR found it to be under $1 \mathrm{mbar} / \mathrm{year}$, resulting in an insignificant effect on panel thermal conductivity. The WVTR were measured in accordance to ASTM E96 (ASTM International, 2013), which provides guidelines for completing the dry-cup test for determining the WVTR of material specimens. This involved using a material specimen to cover the top of a cup filled with a desiccant. The desiccant within the cup causes the humidity of the cup interior to be $0 \%$. The entire sample is then placed in chamber at $23^{\circ} \mathrm{C}$ and $75 \% \mathrm{RH}$, creating a significant pressure gradient across the sample. The entire cup and sample system were weighed before and after being placed in a high humidity environment. The mass increase of the system is representative of the amount of water vapour that passed through the specimen. At these conditions, the WVTR of MF2 foils was measured to be $0.0086 \mathrm{~g} / \mathrm{m}^{2}$ day. The authors defined the failure of the panel to be when the thermal conductivity doubled from its original value. The authors calculated a lifespan of panels based on constant climatic conditions of $23^{\circ} \mathrm{C}$ and $75 \%$. Lifespans for MF2 foils were found to be 16 years for panels sized $50 \mathrm{~cm} \times 50 \mathrm{~cm} \times 1 \mathrm{~cm}$, and 38 years for panels sized $100 \mathrm{~cm} \times 100 \mathrm{~cm} \times 2 \mathrm{~cm}$. The reason for the significant difference between the two panel sizes is attributed to the reduction in internal pressure increases seen by the exponentially larger volume that the bigger panel has. The authors note that generally, larger panels 
are desirable in building applications due to the reduced thermal bridging effect that occur due to gaps between panels.

The final study into VIP lifespan discussed here was completed by Simmler et al. (2005) To characterize the aging of VIP panels, Simmler focused on the two generally accepted aging mechanisms: internal pressure increases and moisture accumulation in the panel. Simmler attempted accelerated aging of VIPs through exposure to elevated temperature and humidity conditions. Simmler performed aging tests to panels under four different conditions: 1) $80^{\circ} \mathrm{C}$ dry, this is based on the VIP manufactures stated maximum operating temperature of $\left.80^{\circ} \mathrm{C}, 2\right) 80^{\circ} \mathrm{C}$ and $80 \% \mathrm{RH}, 3) 30^{\circ} \mathrm{C}$ and $90 \% \mathrm{RH}$, based on the authors judgment for the maximum conditions seen in a wall, and 4) 4 hour cycling of conditions between $80^{\circ} \mathrm{C} / 90 \% \mathrm{RH}$ and $25^{\circ} \mathrm{C} / 50 \% \mathrm{RH}$ for comparing cyclic aging to static aging. The internal pressure of the panel was monitored throughout the test using the previously discussed depressurization method, while the panel moisture content was measured by periodically weighing the panels. Tests 2 and 3 were run for approximately 50 days and showed significant increases in internal pressure and moisture content. Test 2 showed panel water content of nearly $3 \%$ by mass, where Test 3 showed over $5 \%$. Simmler attributes these significant increases to shear between foil layers due to the temperature being equal to the max rated temperature, and in the case of the cyclic test, shearing between the polymer and aluminum layers in the foil due to a mismatch of thermal expansion properties. Tests 1 and 4 were ran approximately 150 days and showed very slight increases in water content and internal pressure. Simmler found that these results demonstrate VIPs high sensitivity to moisture. Additionally, Simmler noted that the internal pressure increases were almost directly correlated to increases in moisture content, indicating that moisture content is the main source of internal pressure increases. Simmler went on to perform two more tests, this time focusing on comparing 
different types of VIP foils, AF, MF1 and MF2. Two climate conditions were tested for 103 days each, the first at $65^{\circ} \mathrm{C} / 75 \%$ relative humidity and another at $23^{\circ} \mathrm{C} / 50 \%$ relative humidity. Results for a $50 \mathrm{~cm} \times 50 \mathrm{~cm} \mathrm{MF} 2$ panel show a $4.0 \%$ mass increase and $0.12 \%$ mass increase for $65^{\circ} \mathrm{C} / 75 \%$ relative humidity and the $23^{\circ} \mathrm{C} / 50 \%$ relative humidity test, respectively. Instead of directly measuring the thermal properties, as most other research has done, Simmler combined the test results with core material properties. The core material properties were gathered from previous research and provide trends of thermal conductivity versus water content for compacted fumed silica cores. Simmler used these values to begin developing a service life estimate for VIPs. Across the VIP life, the surrounding relative humidity is assumed to be constant at $80 \%$. Simmler addresses that, in a real scenario, this would change with weather but took it as a conservative value that should account for water penetration in the wall, which is not directly accounted for in the estimation. The temperature seen by either side of the VIP was calculated based on a constant interior building temperature of $22^{\circ} \mathrm{C}$ and varying exterior temperatures calculated from temperature, wind, and radiation data taken from weather recordings for Zurich, Switzerland. Simmler calculated a yearly water accumulated of $0.18 \%$ mass and a corresponding internal pressure increase of 2.1 mbar. Considering a doubling of original thermal conductivity as a failure criterion, the panels have a lifespan of 31.6 years, according to Simmler.

A summary of current literature on VIP aging and lifespan is provided in Table 1. The current literature has successfully identified mechanisms of aging for VIPs, however, there has not been a proper link made between laboratory measurements of aging mechanisms and the weather conditions a VIP is subjected to. 
Table 1: Summary of VIP Aging Literature

\begin{tabular}{|c|c|c|c|}
\hline Author & Aging Method/Approach & $\begin{array}{l}\text { Estimated } \\
\text { Service Life }\end{array}$ & $\begin{array}{l}\text { Key Takeaways (if } \\
\text { Applicable) }\end{array}$ \\
\hline $\begin{array}{l}\text { Simmler et al. } \\
(2005)\end{array}$ & $\begin{array}{l}\text { - Monitoring water content and } \\
\text { internal pressure at }\left(65^{\circ} \mathrm{C} / 75 \% \mathrm{RH}\right. \\
\left.\text { and } 23^{\circ} \mathrm{C} / 50 \% \mathrm{RH}\right) \\
\text { - Relate to thermal conductivity based } \\
\text { on core material properties } \\
\text { - Extrapolated across life at constant } \\
\text { RH of } 80 \% \text { and weather dependent } \\
\text { temperature }\end{array}$ & - $\quad 31.6$ Years & $\begin{array}{ll}\text { - } & \text { VIPs are } \\
\text { humidity } \\
\text { sensitive } \\
\text { - } \\
\text { Internal pressure } \\
\text { increases are } \\
\text { likely due to } \\
\text { moisture } \\
\text { accumulation } \\
\end{array}$ \\
\hline $\begin{array}{l}\text { Annex } 39 \\
(2005)\end{array}$ & $\begin{array}{l}\text { Test various VIP foils to determine } \\
\text { average WVTR and ATR } \\
\text { Create a lifespan based on foil } \\
\text { properties at constant climate } \\
\text { conditions }\end{array}$ & - 38 years & $\begin{array}{l}\text { Transmission } \\
\text { properties of } \\
\text { various VIP foil } \\
\text { types }\end{array}$ \\
\hline $\begin{array}{l}\text { Thorsell et al. } \\
(2010)\end{array}$ & $\begin{array}{l}\text { - Analytical analysis of defects in VIP } \\
\text { foils and rates of permeation through } \\
\text { the defects }\end{array}$ & $\begin{array}{l}\text { - } 30-50 \\
\text { Years }\end{array}$ & $\begin{array}{l}\text { Two layer foils } \\
\text { (MF2) are the } \\
\text { most appropriate } \\
\text { for VIPs }\end{array}$ \\
\hline $\begin{array}{l}\text { Wegger et al. } \\
(2010)\end{array}$ & $\begin{array}{l}\text { Performed various standard building } \\
\text { material test procedures including } \\
\text { freeze/thaw testing and high } \\
\text { temperature/ humidity }\end{array}$ & - $\quad>50$ years & $\begin{array}{l}\text { - Panels much } \\
\text { more sensitive to } \\
\text { humidity than } \\
\text { temperature }\end{array}$ \\
\hline $\begin{array}{l}\text { Schwab et al } \\
\text { (1) } \\
(2005)\end{array}$ & $\begin{array}{l}\text { Investigated how moisture content } \\
\text { influences thermal conductivity } \\
\text { Placed a known amount of water in } \\
\text { panels and measured thermal } \\
\text { conductivity before/after }\end{array}$ & - $\quad \mathrm{N} / \mathrm{A}$ & $\begin{array}{l}\lambda\left(X_{\mathrm{w}}\right) \\
\approx \lambda_{\mathrm{VIP}, \mathrm{dry}} \\
+0.5 \times 10^{-3} \frac{\mathrm{W}}{\mathrm{mK}} \\
\cdot \frac{X_{w}}{m} \% \\
\text { - } \quad \text { Trend between } \\
\quad \text { water content and } \\
\text { thermal } \\
\text { conductivity }\end{array}$ \\
\hline $\begin{array}{l}\text { Schwab et al. } \\
(2) \\
(2005)\end{array}$ & $\begin{array}{l}\text { - Placed panels in high humidity and } \\
\text { temperature chambers to monitor the } \\
\text { increase in moisture content by } \\
\text { weighing the panels periodically }\end{array}$ & $\begin{array}{l}16-38 \\
\text { Years }\end{array}$ & - $\quad \mathrm{N} / \mathrm{A}$ \\
\hline
\end{tabular}




\subsection{In-Situ Lifespan Assessment}

There is a lack of existing research on measuring the service life of VIPs when subjected to actual weather conditions in an in-situ experiment. Two studies have been done where VIPs were installed into flat roofs. These studies involve periodically measuring VIP performance over the course of long, multi-year experiments. Another study involved installing the VIPs in a building façade, although this study was not intending the monitor service life but rather installed thermal performance, aging was only a takeaway from the research.

Brunner and Simmler (2008) conducted an in-situ experiment of VIPs installed in a flat roof construction near Zurich, Switzerland. This study consisted of installing VIP panels in an existing roof structure, the construction of the roof is as follows, from interior to exterior: concrete roof structure, vapour barrier, protective layer, VIP, protective layer, tar water barrier, and a layer of crushed gravel. VIPs were instrumented with exterior and interior facing temperature and humidity sensors. Panels from one portion of the wall were periodically removed for performance monitoring. The panel performance was monitored through measuring the internal pressure using the lift-off method and by monitoring moisture content through precise weighing. The test was run continuously from 2004 to 2007 . Temperature sensors showed that the exterior VIP face was subject to a temperature range of $-10^{\circ} \mathrm{C}$ to $+60^{\circ} \mathrm{C}$, humidity in the exterior ranged from $45 \%$ to $90 \%$ relative humidity, Brunner and Simmler attributes this high humidity to rain loads on the roof causing water penetration into the envelope. Brunner and Simmler found that the internal pressure of the VIP rose approximately $2.1 \mathrm{mbar} /$ year while the moisture increased the total VIP weight by $0.1 \% /$ year. To attempt to predict a service life, Simmler linearly increased the measured values to be suitable for a panel sized $100 \mathrm{~cm} \times 60 \mathrm{~cm} \times 2 \mathrm{~cm}$, the values were increased to $1.5 \mathrm{mbar}$ and $0.17 \%$ mass increase per year. Simmler extrapolated performance over a 25 -year period, stated as 
the standard period for the specification of long-term insulation products. The results showed that the theoretical performance after this period would be $7.4 \times 10^{-3} \mathrm{~W} / \mathrm{m} \cdot \mathrm{K}$ based on an initial value of $4.5 \times 10^{-3} \mathrm{~W} / \mathrm{m} \cdot \mathrm{K}$. Based on the standard failure criteria, a service life beyond 25 years could be expected.

Another in-situ study on VIPs was conducted by Molleti et al. (2018). Similarly, this had VIPs installed into the flat roof system of an NRC building in Ottawa. This roof system was constructed with VIPs sandwiched between polyiso insulation to form a composite panel. This panel was installed in the roof with a concrete deck, vapour barrier, and topped with an asphalt core board and bituminous cap sheet. On each side of the composite, thermocouples and heat flux sensors were installed. In order to compare the thermal performance of the VIP composite, an adjacent part of the roof was also instrumented, but instead of the polyiso-VIP composite, an equal thickness of polyiso was installed instead. This allowed the researchers to compare the thermal performance of the section with VIPs installed versus the sectional with traditional insulation. The thermal data gathered allowed for the monitoring of VIP thermal performance over the life of the experiment. The average daily R-value for a typical winter week for each year was calculated, this was then used to calculate a performance ratio. The performance ratio was defined as the ratio of thermal resistance of the VIP assembly to the thermal resistance of the conventional Polyiso insulation. The maximum performance ratio seen was 3.3 , while the minimum was 1.5 . The thermal performance decrease as the panels age was also observed. Over the four-year test, the authors found that the thermal performance of the assembly was within $10 \%$ of the initial 
performance. The authors concluded that VIPs can maintain high thermal performance characteristics on a long-term basis.

Brunner et al. (2012) investigated an energy retrofit of 1954 building located in central Europe. VIPs encased in EPS were installed on the exterior face of a multi-unit housing building. The VIPs were left installed for approximately one year before being investigated. Out of a total of 88 VIPs installed in the building, 17 were found to be extremely deteriorated. The panels appeared to be blistered and "blown up", indicating a significant rise of internal pressure. Some panels were brought back to a lab for testing, where the internal water content was found to minimal; however, it was measured after conditioning the panel for 17 days at $50^{\circ} \mathrm{C}$. As well, the VIP foils were closely examined with a magnifying glass and ultraviolet light, the purpose of this was to determine if the deterioration had been caused by physical damage to the VIP, such as wear or puncture of the foil. No physical damage was found. However, a method for finding micro defects using transmitted light was used. This method consisted of illuminating the interior of the VIP and using a camera to capture the amount of light passing through the foil in a dark room. This imaging showed that a considerable number of microdefects were present in the foil. By measuring the VIP internal pressure using the foil-lift method, the thermal conductivity was estimated to be $0.010 \mathrm{~W} / \mathrm{m} \cdot \mathrm{K}$, which the author states are much higher than the expected thermal conductivity of $0.008 \mathrm{~W} / \mathrm{m} \cdot \mathrm{K}$ after 25 years of use. Brunner's main takeaway from this research was that the foil did not meet manufacturer specifications, and that the high number of defects in the foil is responsible for the deterioration seen in the panels after one year of use. 
A summary of in-situ experiment results is provided in Table 2. In-situ testing has shown the sensitivity of VIPs to premature failure seemingly due to non-aging related mechanisms. The small sample size of these tests has limited the ability to draw conclusions on VIP lifespan.

Table 2: Summary of In-Situ Lifespan Experiments

\begin{tabular}{|c|c|c|c|}
\hline Author & Testing Method & $\begin{array}{l}\text { Predicted } \\
\text { Service Life }\end{array}$ & $\begin{array}{l}\text { Key Takeaways (If } \\
\text { Applicable) }\end{array}$ \\
\hline $\begin{array}{l}\text { Brunner \& } \\
\text { Simmler } \\
(2008)\end{array}$ & $\begin{array}{l}\text { - VIPs installed in a flat roof } \\
\text { construction for three years } \\
\text { - Inner pressure and moisture } \\
\text { content measured } \\
\text { - Thermal conductivity }\end{array}$ & - $>25$ Years & $\begin{array}{l}\text { Temperatures and } \\
\text { relative humidity } \\
\text { can reach up to } \\
60^{\circ} \mathrm{C} \text { and } 90 \% \mathrm{RH}\end{array}$ \\
\hline $\begin{array}{l}\text { Molleti et } \\
\text { al. } \\
(2018)\end{array}$ & $\begin{array}{l}\text { VIP composite panels installed in } \\
\text { a flat roof, compared next to } \\
\text { standard insulation } \\
\text { - Thermal performance measured } \\
\text { in-situ with heat flux meters }\end{array}$ & - N/A & $\begin{array}{l}\text { VIPs maintain } \\
\text { performance long } \\
\text { term }\end{array}$ \\
\hline $\begin{array}{l}\text { Brunner et } \\
\text { al. } \\
(2012)\end{array}$ & $\begin{array}{l}\text { - Installed composite VIP panels in } \\
\text { a building façade } \\
\text { - Analyzed panels after one year of } \\
\text { use showed large increases in } \\
\text { internal pressure }\end{array}$ & - $\mathrm{N} / \mathrm{A}$ & $\begin{array}{l}\text { Very high level of } \\
\text { microdefects in } \\
\text { VIP foil causes } \\
\text { extreme } \\
\text { degradation in } \\
\text { short amounts of } \\
\text { time }\end{array}$ \\
\hline
\end{tabular}

\subsection{VIP Wall Integration}

Currently, there are two main scenarios which involve the use of VIPs in building envelopes: 1) energy retrofits and 2) new high-performance constructions. Baetens et al. (2010) discussed these two scenarios, the main benefit in using VIPs in both these scenarios is the possibility to reduce wall thickness while maintaining high levels of thermal insulation. Baetens stated that the size of building insulation has the potential to be reduced in thickness by 5 to 10 times with the use of VIPs. Using VIPs in energy retrofits allows constructors to improve thermal performance of a wall without the restrictions of conventional insulation and wall cavities. Energy 
retrofits to the building envelope involve the installation of additional insulation to either the exterior or interior of existing building walls. When using conventional insulation, this results in a loss of floor space on the exterior, or a much larger building footprint when installed from the exterior. VIPs provide a solution to this as they allow the building envelope to be thermally enhanced without a significant loss of floor space. VIPs also allow buildings in high density urban environments to have exterior insulation added with less a risk of encroaching on property lines or other obstacles.

The other scenario for the use of VIPs in buildings discussed by Baetens involves the use of VIPs in new building construction, aiming to achieve high levels of thermal insulation. Baetens suggests that VIPs can provide an installed, total wall, thermal conductivity of $0.1 \mathrm{~W} / \mathrm{m} \cdot \mathrm{K}$ without the complications of thick building envelopes generally plague walls with high levels of thermal insulation.

There is no exact consensus on how to install VIPs in an envelope, although most applications show that a prefabricated foam-VIP composite may be the best for ease of insulation and manufacturing. A National Research Council (NRC) of Canada report outlined 4 potential concepts for VIP walls in Canada. The four wall concepts are described in Table 3. 
Table 3: VIP Wall Construction Concepts

\begin{tabular}{|c|c|}
\hline Concept Name & Construction Layers (Exterior to Interior) \\
\hline 1 - Final Improvement & $\begin{array}{l}\text { - } \quad \text { Tyvek Air Barrier } \\
\text { - } 7 / 16 " \text { OSB } \\
\text { - } 2 \times 4 \text { Framing with } 24 \text { "OC with fiberglass batt } \\
\text { - } 1 / 2 \text { "XPS } \\
\text { - Neoprene sheeting } \\
\text { - VIP } \\
\text { - Neoprene sheeting } \\
\text { - VIP } \\
\text { - Neoprene sheeting } \\
\text { - } 1 / 2 " X P S \\
\text { - } 2 \times 3 \text { framing, } 24 " \text { OC with fiberglass batt } \\
\text { - } 1 / 2 " \text { Gypsum Board }\end{array}$ \\
\hline $\begin{array}{l}2-\text { Exterior Retrofit } \\
\text { (VIP nailed in place } \\
\text { with XPS blocks) }\end{array}$ & $\begin{array}{l}\text { - } \text { Structural panel siding } \\
\text { - } 1 / 2 " \text { XPS } \\
\text { - } \quad \text { VIP } \\
\text { - } 7 / 16 " \text { OSB } \\
\text { - } 2 \times 4 \text { framing, } 24 " \text { OC with fiberglass batt } \\
\text { - } \quad \text { Polyethylene vapour barrier } \\
\text { - } 1 / 2 " \text { Gypsum board }\end{array}$ \\
\hline $\begin{array}{l}3-\text { Exterior Retrofit } \\
\text { (VIPs helped in place } \\
\text { with plastic clipped) }\end{array}$ & $\begin{array}{l}\text { - } \quad \text { Structural Panel Siding } \\
\text { - Fiberglass batt held with clips } \\
\text { - } \quad \text { VIP held with clips } \\
\text { - } \quad \text { Tyvek air barrier } \\
\text { - } 7 / 16 " \text { OSB } \\
\text { - } 2 \times 4 \text { framing with spray foam cavity } \\
\text { - Polyethylene vapour barrier } \\
\text { - } 1 / 2 " \text { Gypsum board }\end{array}$ \\
\hline $\begin{array}{l}4-\text { Pre-Fabricated } \\
\text { Composite VIP Panels }\end{array}$ & $\begin{array}{l}\text { - Pre-Fabricated VIP Composite } \\
0 \quad 1 / 2 " \text { XPS } \\
0 \quad \text { VIP } \\
0 \quad 1 / 2 " \text { XPS } \\
07 / 16 " \text { OSB } \\
\text { - } 2 \times 4 \text { cavity with fiberglass batt } \\
\text { - Polyethylene Vapour barrier } \\
\text { - 1/2" gypsum. }\end{array}$ \\
\hline
\end{tabular}


Concept 1 was made to represent a highly insulated new construction wall or a very extensive retrofit. Concepts 1 and 2 represent more conventional walls with VIPS used to increase the exterior insulation level, with Concept 2 representing a nailed foam mounting system. Concept 3 involves the use of plastic clips to hold materials. Concept 4 represents a wall that utilizes prefab VIP composite panels; these vary in exact construction amongst manufacturers but generally consist of VIPs suspended in rigid foam sheeting.

\subsection{VIP Economic Analysis}

To classify the suitability of an insulation material, the economic feasibility of the material must be investigated; most current research is limited to thermal performance and service life of VIPs and has ignored economic feasibility. Cho et al. (2014) addressed this by performing a lifecycle cost analysis (LCCA) on VIPs installed in a typical Korean home. An LCCA is an encompassing economic analysis that accounts for costs and benefits through the life of a product, including purchase and installation costs, operating costs, financing costs, salvage value after service life, and taxes and other costs. An LCCA allows for different products, with varying costs, to be directly compared. Cho et al. performed a LCCA on a theoretical $1 \mathrm{~m}^{2}$ wall section from a typical Korean hose. Two analyses were performed, one with a wall containing VIPs and the second on a wall of equivalent size with a standard Styrofoam insulation panel (SIP) in place of 
the VIP. In order to account for the time value of money, Cho used the present worth method to equate the costs, shown in Equation (7).

$$
P_{\mathrm{F}}=F \frac{1}{(1+i)^{\mathrm{n}}}
$$

where $P_{\mathrm{F}}$ represents the cost in present dollars of future amounts, $F$ represents the anticipated future dollar amount, $i$ is the discount rate applied to the cost, and $\mathrm{n}$ is the time period that the costs are adjusted across. To gather cost data for VIPs, Cho et al. gathered VIP costs from 5 different panel manufactures. The installation costs were based solely on the material costs of VIPs and conventional insulation, labour and other installation costs were assumed to be equal amongst each type of insulation. The installation costs were taken as (in USD) $\$ 8 / \mathrm{m}^{2}, \$ 56 / \mathrm{m}^{2}$, and $\$ 84.5 / \mathrm{m}^{2}$ for SIP, 20mm VIP, and 30mm VIP respectively. To estimate heating costs, the heating loads on the building were estimated using a building energy simulation program, $\mathrm{CE} 3^{\mathrm{TM}}$, this allowed monthly energy consumptions for a single test year to be calculated. Cho et al. stated the annual energy consumption as $143.10 \mathrm{kWh} / \mathrm{m}^{2}, 76.00 \mathrm{kWh} / \mathrm{m}^{2}$, and $60.40 \mathrm{kWh} / \mathrm{m}^{2}$ for the conventional SIP insulation, 20mm VIP, and 30mm VIP, respectively. Cho et al. chose the life of the analysis to be 40 years, the approximate useful life of buildings in Korea, across these 40 years, the energy consumption and costs remain constant. The total costs for a typical Korean house, at $\$ 0.69 / \mathrm{kWh}$, in present dollars over the assumed 40-year life of insulation are as follows: \$200 598.58 for the SIP insulation, \$106 537.33 for the 20mm VIP, and \$84 669.14 for the 30mm VIP. Cho et al. expressed this in percentages to show the economic advantage that the VIP systems have over the 
SIP systems. Cho stated that the $20 \mathrm{~mm}$ VIP are $88.28 \%$ more economic advantage than the SIP insulation, and the 30mm VIP had $136.92 \%$ more economic advantage.

This economic analysis misses one of the most important factors when considering VIP performance over time, which is the reduction in thermal performance the VIPs will experience. In order to properly calculate the heating loads, the reduction in performance must be considered. This likely is responsible for the overestimation of VIP economic feasibility. Additionally, the assumption of constant energy costs likely causes significant uncertainty and energy prices fluctuate and rise overtime. Furthermore, it is likely that in most climates there are diminishing returns to be made from increasing the R-value beyond a certain point. Investigating the point of diminishing returns is required to fully understand the economic viability of VIPs. This is related to the HVAC system installed in buildings. Buildings that are considered for VIP installations likely have very efficient HVAC systems installed. This reduces the benefits from additional Rvalue in the wall as the heating system is so efficient that small changes in the envelope conductivity don't have large impacts.

\subsection{Summary and Gaps in Literature}

This section will provide a summary of the current literature regarding VIP aging and how it can be linked together, as well as shortcomings of the current literature. Research has accepted that VIPs experience performance declines over time as gas and moisture permeate into the panel. Current research agrees that moisture is the main culprit in decreasing the thermal performance of VIPs. Theory on moisture transport through foils shows that water molecules have a greater ability to pass through than air molecules due to their smaller molecule size. The theory also proves that moisture increases the thermal conductivity more than gas on a per unit bases. Moisture molecules have an ability to conduct heat through the panel, air molecules on the other hand just increase the 
internal pressure of the panel. Increasing the internal pressure has a very delayed response on the thermal conductivity where the pressure needs to rise exponentially to have any effect on the panels thermal performance. This theory has been reinforced by experimental work that focused on the individual effects on moisture and gas presence in VIPs.

Researchers have used a variety of approached to age VIPs. Most researchers attempt to quantify the moisture transfer into panels, either by conditioning or by using laboratory techniques to measure the permeability of a small sample of foil. These measurements provide researchers with the knowledge of the amount of moisture that enters the panels over a certain amount of time at a known vapour pressure. In order to relate this to the thermal performance of VIPs, VIP performance is measured at increasing water contents. This provides researches with the rate that moisture enters the panel, and how moisture accumulation affects the thermal conductivity of the panels. Knowing these two variables has allowed researchers to make lifespan predictions for VIPs. This leads to the largest and most fundamental gap in the current literature, which is correlating laboratory aging results to actual geographical climate conditions, specifically the temperature and moisture that the panel would be exposed to while installed in a building envelope. The current lifespan estimates are unclear as to how laboratory results are extrapolated to predict lifespans. It appears that most of the researchers simply take a measured WVTR, measured at a specific relative humidity and temperature, and maintain that value across an entire year. This fails to consider how the conditions at the panel are affected by weather. Simmler et al. considered changing temperatures throughout the year, however a constant relative humidity of $80 \%$ was used, this did not consider how rain or wall construction would affect conditions. Since the vapour pressure, a combination of temperature and humidity, is the driving force behind moisture permeation, not considering the changing climate conditions and accumulation of moisture in the 
all likely causes significant overestimations of VIP service life. This prediction is reinforced by experiments done on panels in-situ, where significant deterioration is seen after only a few years of service. A more accurate service life prediction would include the effects of the entire wall assembly, interior climate, and exterior weather including wind driven rain to calculate the instantaneous moisture transfer rate into the panels. This is something that has not been done by current researchers, leading to the overestimation of panel life.

In addition to the need for proper service life predictions, there is also a need to see how this impacts the economic feasibility of VIPs. The only current economic analysis of VIPs does not consider the declining performance of VIPs over the length of their service, rather the study assumed that the initial thermal conductivity of a VIP lasted for a full 40-year life. All available research has proven that VIP performance does decline over time, albeit at differing rates. This again causes a significant over estimation of the economic benefits of VIPs. To properly assess the economic viability of VIPs, the declining thermal properties and limited lifespan must be considered. 


\section{Chapter: Experimental Setup}

This section will discuss the construction of testing equipment and the methods and procedures used to obtain experimental data. The purpose of the experimental work was to accelerate the aging of VIPs in a laboratory setting while measuring the two key factors defining VIP aging: 1) water vapour transmission rates and 2) the dependence thermal properties have on panel water content.

\subsection{ASTM E96 Testing Procedure}

ASTM E96 provides a standardized test procedure for measuring the WVTR of materials. This was used as the fundamental doctrine for attempting to determine the WVTR of VIP foils. The standard focuses on two methods: 1) The desiccant method and 2) the water method. Both methods use the same general approach, isolate a sample of material and induce high humidity conditions on one side of the sample and low humidity on the opposite side. This creates a high vapour pressure differential, increasing the driving force behind water vapour transmission. This research focuses on the desiccant testing method. This method consists of using an open-faced container or dish constructed of an impermeable material. The test specimen is sealed onto the open face of the container. A desiccant is placed inside the container to force a dry, $0 \%$ relative humidity environment. The entire testing dish is then placed in a chamber of known high humidity and temperature. The weight of the testing dish is measured before and after being placed in the chamber, the additional of weight to the dish is considered the moisture accumulation from transfer through the testing material. 
The WVTR and permeance are both calculated from the change in mass of the entire dish assembly using Equation (8).

$$
W V T R=\left(\frac{G}{t \cdot A}\right)
$$

where $W V T R$ is the water vapour transmission rate measured in $\mathrm{g} / \mathrm{h} \cdot \mathrm{m}^{2}, G$ is the change in weight between the start and end of the test measured in grams, $t$ is the test time in hours, and $A$ is the mouth area of the testing dish, measured in $\mathrm{m}^{2}$. Next, the permeance can be calculated using Equation (9). This is important to consider the effects of vapour pressure in the system.

$$
\text { Permeance }=\frac{W V T}{S\left(R_{1}-R_{2}\right)}
$$

where Permeance is measured in metric Perms $\left(\mathrm{g} / \mathrm{h} \cdot \mathrm{m}^{2} \cdot \mathrm{Pa}\right), S\left(R_{1}-R_{2}\right)$ calculates the vapour pressure gradient across the sample. $\mathrm{S}$ is the saturation vapour pressure at the test temperature in $\mathrm{Pa}, R_{1}$ and $R_{2}$ are the relative humidity's in the test chamber and inside the desiccant dish, respectively. It is important to note that the standard states that due to the presence of the desiccant in the cup, $R_{2}$ is assumed to be $0 \%$ as long as the total weight gain remains under $10 \%$. When weight gain reaches $10 \%$, the test is considered failed and new desiccant is required.

The experimental equipment and testing procedures were constructed based on procedures outlines in ASTM E96. The following sections will cover the construction of equipment for watervapour transmission testing, including the construction of climate chambers and two different approaches to desiccant testing. The first approach discussed attempted to use the standard desiccant method presented in ASTM E96, involving a cup with a desiccant and samples of VIP foils, both with and without heat sealed flanges. The second testing method was based of ASTM 
E96 but instead of isolating a small sample of foil on a dish the entire VIP was used, with the core material acting as a desiccant.

\subsection{Climate Chamber Construction and Testing}

To perform testing at high temperatures and relative humidifies, it was necessary to construct climate chambers. A general list of design specifications was created, based off testing conditions recommended in ASTM E96, VIP size constraints, and budgetary constraints. The most important requirement for the climate chambers was to reliably be able to meet and hold, for extended periods of time, the temperature and relative humidity values specified by ASTM E96. The standard specifies that for desiccant testing, the climate should be at $38 \pm 1{ }^{\circ} \mathrm{C}$ and $90 \pm 2 \%$ relative humidity. The working interior dimensions of the chambers are $7.6 \mathrm{~cm} \times 7.6 \mathrm{~cm} \times 7.6 \mathrm{~cm}$ to accommodate multiples of the largest panels available to the Solar Energy Systems Lab at Carleton University, where the chambers are to be located. Additionally, the air heating and humidity system requires enough ventilation to ensure uniform conditions around the chamber. Figure 3-1 shows the ventilation model of the chambers, while Figure 3-2 shows the completed construction. 


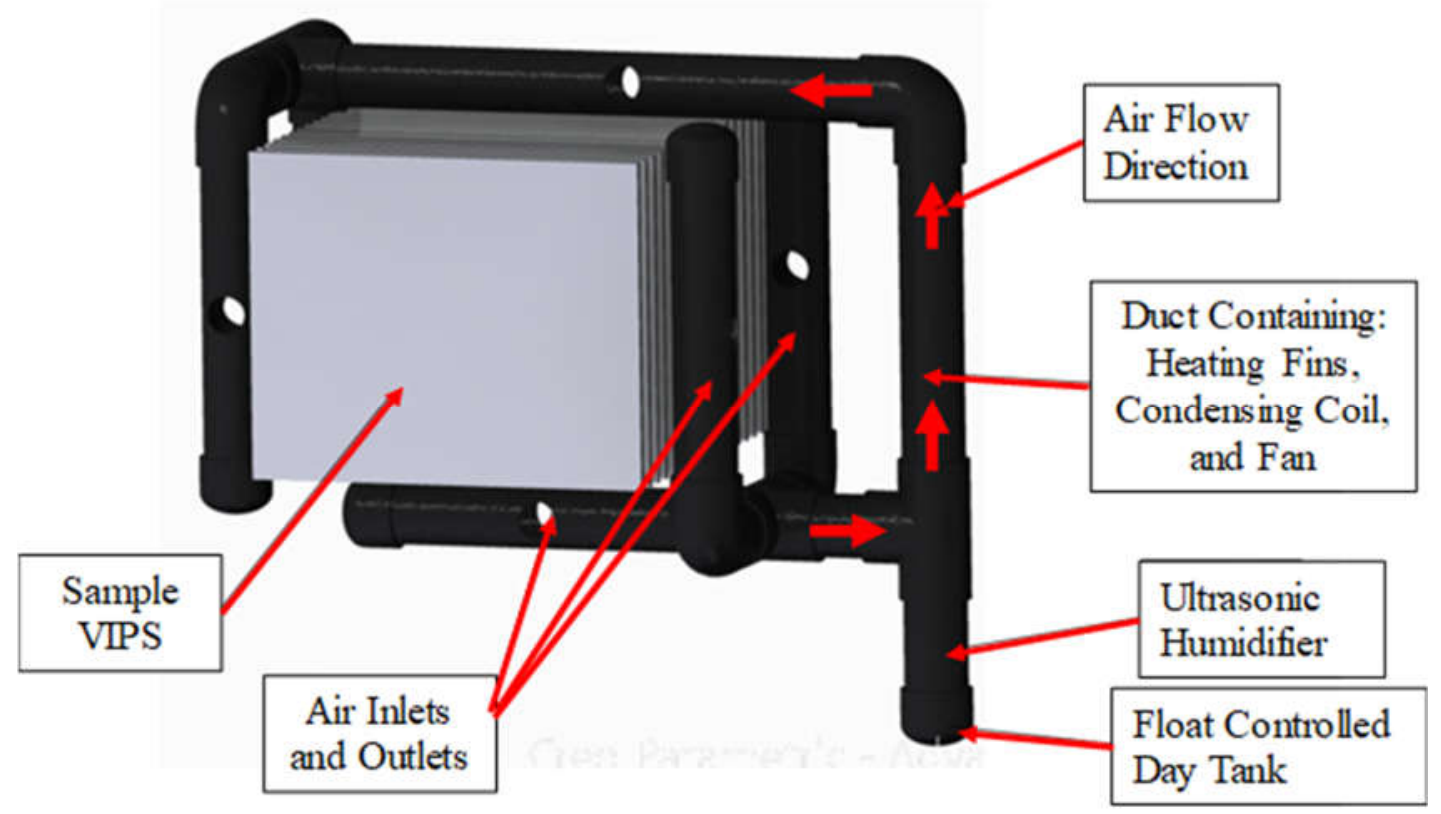

Figure 3-1: Climate Chamber Component Diagram

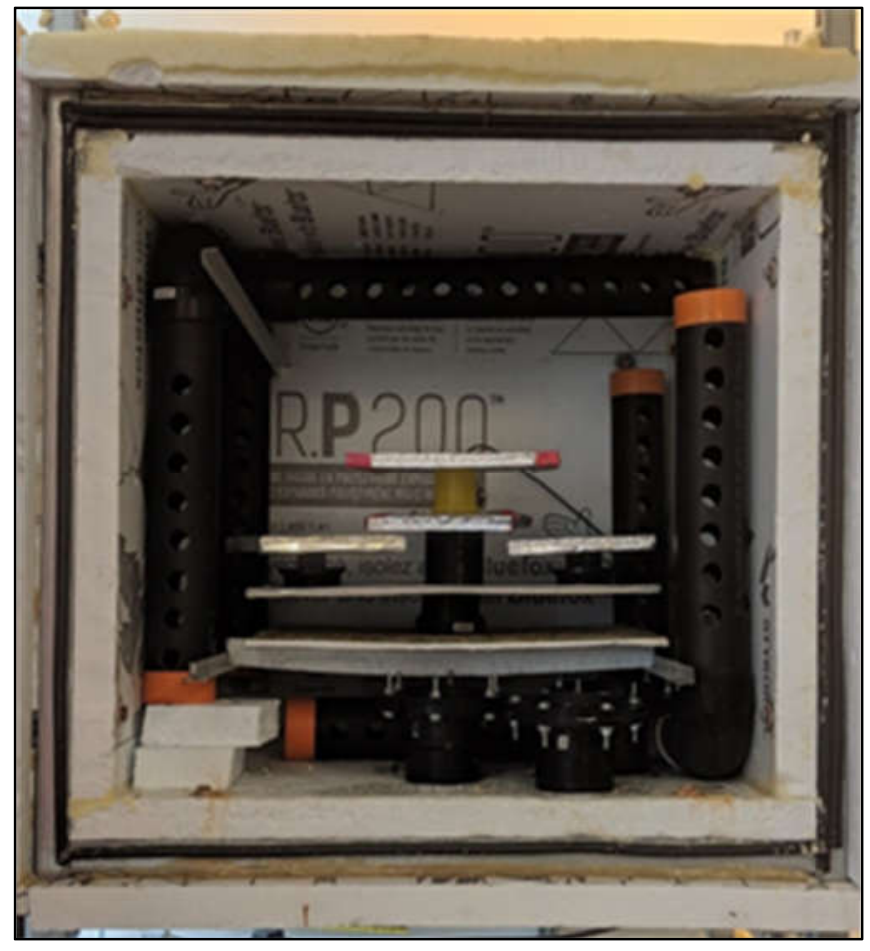

Figure 3-2: Climate Chamber Interior 
A single temperature and relative humidity sensor were placed within the chamber, another temperature sensor was placed in the heating fins to prevent overheating. As chamber conditions were intended to last for long periods of time, on the scale of months and years, the operation of the chambers was made to be as automated as possible. This includes automating the program controlling equipment as well as a float-fill system to continuously provide the humidifier with a supply of water. The chambers were controlled using a DELTA Building Automation system. The automation system used user-programmable setpoints for temperature, relative humidity, and a deadband for each of the chambers. The program monitored the temperature and relative humidity, and when either dropped below the deadband-adjusted setpoint, the program would trigger either the heater or humidifier, accordingly. Once the chambers were operating reliably, the temperature and relative humidity was gently increased to determine if the required conditions by ASTM E96 could be met. The chambers were able to maintain over $40^{\circ} \mathrm{C}$ and $95 \% \mathrm{RH}$, beyond the requirements for moisture permeability testing provided by ASTM E96.

\subsection{Dry Cup Testing}

Dry-cup testing was performed, based on ASTM E96. The purpose of this testing was to determine the water-vapour permeability of VIP foils depending on the surrounding vapour pressure. This would provide the necessary measurements to calculate the amount of moisture passing through the foil at any relative humidity and temperature condition. The following sections will cover the construction of the cup and the testing procedure.

\subsection{Dry Cup Construction}

The construction of the cup was designed based on specifications on material, dimensions, and fastening from ASTM E96. In order to minimize costs, ABS flanges for home plumbing were 
used. To eliminate the need to use adhesives, rubber gaskets connected to a flange were used, where the sample material is pressed between two flanged surfaces and held with bolts. The desiccant used was anhydrous calcium-chloride, as specified by ASTM E96. The cup was filled to ensure that the desiccant reached within $1 / 4$ " of the sample surface. A drawing of the apparatus as well as a photograph of the as-built apparatus are provided in Figure 3-3 and Figure 3-4.

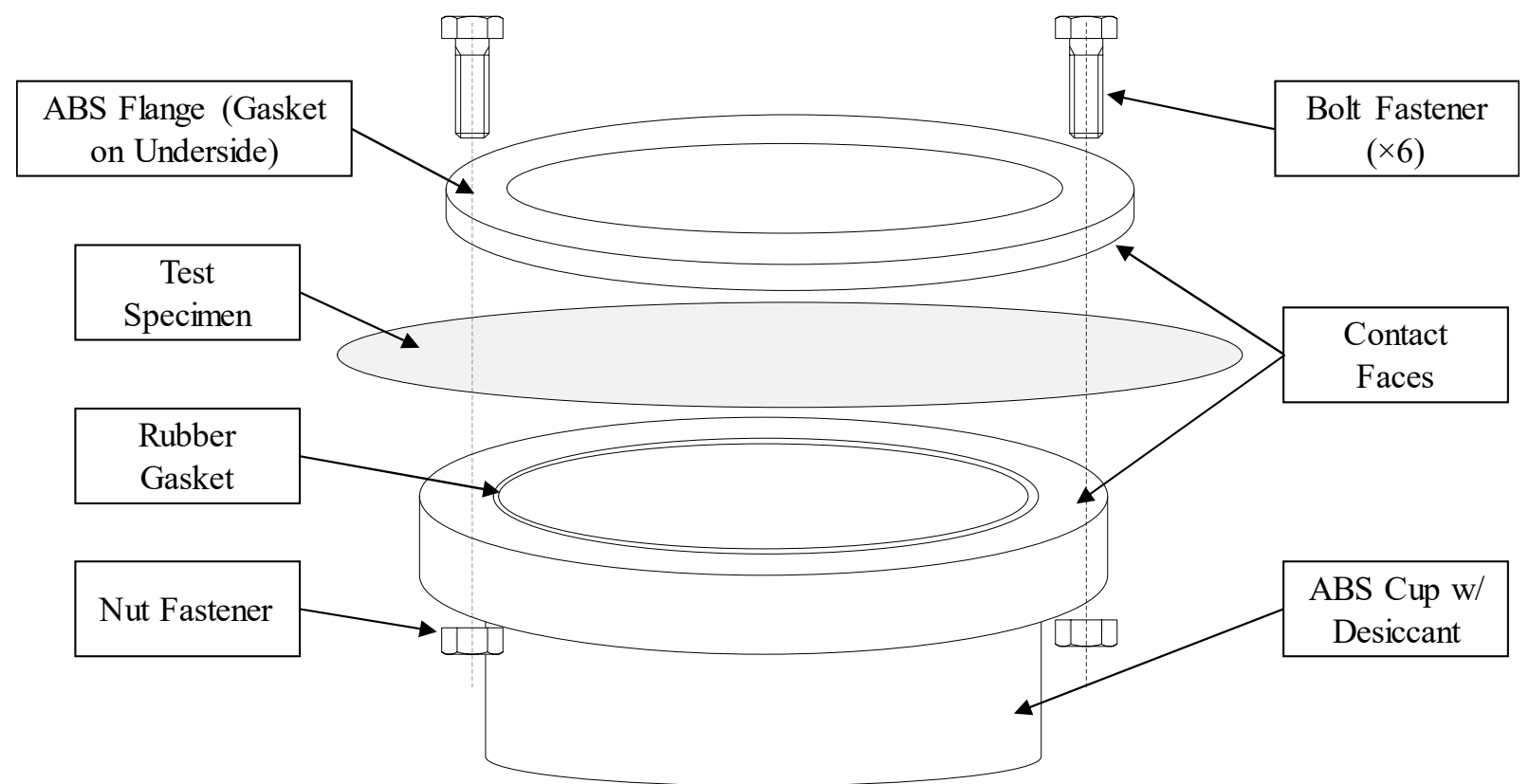

Figure 3-3: Dry Cup Apparatus Diagram

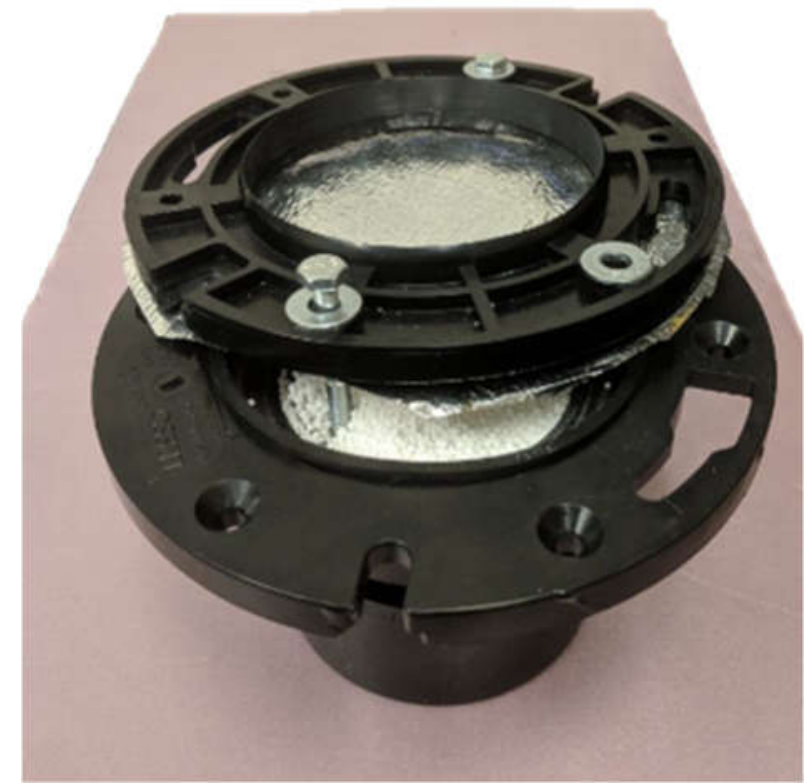

Figure 3-4: As Built Dry Cup Apparatus 
In order to ensure an airtight seal, the ABS flanges were placed on a lathe and turned down to ensure proper gasket relief, and a consistent surface area to clamp the specimen against.

\subsection{Climate Chamber Testing Conditions}

Both approaches to measuring the permeability of VIP foils used the same climate chamber condition set points. ASTM E96 recommends a set point of $38^{\circ} \mathrm{C}$ and $90 \% \mathrm{RH}$ for high humidity condition setpoints. These recommended setpoints were slightly modified to better suit VIP testing. Many researchers have attempted to accelerate aging by aging VIPs at high temperatures and relative humidity. However, research (Yrieix, Morel, \& Pons, 2014) has shown that testing at temperatures close to the gas transition temperature of the PET and PE layers of the film, around $70^{\circ} \mathrm{C}$, may cause damage to the foils and an overprediction of aging rate. Similarly, Conley et al. determined that testing at conditions above $90 \% \mathrm{RH}$ can lead to corrosion of the aluminum layers, however $90 \% \mathrm{RH}$ is a realistic condition seen in application by VIPs (2018). The chamber climate conditions were based on measurements taken from an in-situ instrumented wall in Ottawa, Ontario. The highest maintained conditions maintained were $33^{\circ} \mathrm{C}$ and $90 \% \mathrm{RH}$. These conditions are within maximum tests limits found by other researchers, while still subjecting the panels to realistic conditions.

\subsubsection{Dry Cup Testing Procedure}

Dry cup testing was completed on four different test specimens. Two control tests and two VIP foil tests were completed. The VIP foil tests were done using the "field" of the foil, this is uniform oil from the center of the panel. The second foil sample was from the edge of a VIP, where the heat-sealed flange is located. This was done to determine the effects of the flange on the overall 
panel permeability. The testing procedure followed the guidelines outlined by ASTM E96. The procedure for testing was as follows:

1. Desiccant drying for 60 minutes in a $300^{\circ} \mathrm{F}$ convection oven

2. Fill cup with desiccant

3. Place foil sample on cup, tighten flange against gasket ensuring tight, square, fit along gasket

4. Using a calibrated scale, weigh the entire apparatus 10 times

5. Place apparatus in climate chamber set at desired conditions

6. Leave in climate chambers for 14 days

7. Repeat steps $4-6$ as required or until apparatus weight reaches $10 \%$ of original weight

The biggest separation from the ASTM E96 procedure was in the duration of testing periods. ASTM E96 recommends measuring the weight in 0.5-hour to 1-hour intervals. This was extended to 14-day periods due to the low permeability of the materials being tested. A two-week testing period was required to achieve enough water vapour transmission into the cup to have a noticeable change in weight of the apparatus.

The use of this dry cup method has a level of uncertainty due to corrosion of the cup material, moisture transport through the gasket and cup material, as well as moisture accumulation on the surface of the apparatus. This issue isn't addressed in detail in the ASTM standard, due to the standard being designed for materials that have much greater permeation rates than VIP foils. This uncertainty was attempted to be quantified by the use of two different control experiments: 1) dry cup testing with Tyvek ${ }^{\circledR}$ building air barrier sheeting and 2) dry cup testing with aluminum plate. Tyvek ${ }^{\circledR}$ air barrier was chosen as it is a non-vapour tight material with a known range of moisture permeability. Aluminum plate was chosen as it has a moisture permeability of virtually 
zero, this means that in an idealized case, the dry-cup would not change in mass over the course of the experiment. The aluminum plate test provides the ability to quantify mass gain due to error in the apparatus. The purpose being that whatever weight the aluminum apparatus gains can be assumed to have entered the system through imperfections in the cup design. Using this correction factor on the Tyvek ${ }^{\circledR}$ would prove the accuracy of the system, as the permeability of the Tyvek ${ }^{\circledR}$ is known.

\subsection{Full Panel Testing}

The dry cup testing method fails to account for two key factors related to the permeance and aging of VIPs. Firstly, dry cup testing does not account for edge effects or transfer through the flange. Testing full panels accounts for the entire foil assembly, including the edges and heatsealed flanges. This should provide a more accurate to real-life value of permeability than simply using the dry-cup testing method. The second factor for performing full panel tests is to measure the trend between thermal performance of panels and the moisture content of the panels, in order to calculate VIP aging as a dependent on the transport of moisture into the panel. The testing procedure mimicked the procedure followed for the dry cup tests. The chambers were at the same conditions as the dry cup tests, $33^{\circ} \mathrm{C}$ and $90 \% \mathrm{RH}$ for a high the high humidity point and $60 \% \mathrm{RH}$ for the low humidity point. Before aging the panels, the thermal conductivity of the sampled VIPs was measured. This was also done periodically throughout the experiment, on approximately 8week intervals. The procedure followed for this testing is as follows:

1. Measure thermal conductivity of panel

2. Using a calibrated scale, weigh the VIP 10 times

3. Place VIP in climate chamber

4. After 3-4 weeks, record the time in the chamber and weigh the VIP 
5. Every 2-3 weigh periods, place VIPs in guarded hot plate to measure thermal conductivity

6. Return VIP to chamber and repeat steps 3-6 for as long as desired

\subsubsection{Guarded Hot Plate Apparatus}

A Guarded Hot Plate (GHP) apparatus was used to measure the thermal conductivity of the VIPs. The GHP apparatus was custom-built for the Solar Energy Systems Laboratory at Carleton University, detailed description of the design, construction, and operation behind this apparatus is provided by Hayes (2018). The apparatus measures the average thermal conductivity between two test specimens. On the outer face of each specimen are cold plates, chilled with a glycol solution, separating the specimens is a single heating plate, heated with electrical resistive heaters. On each specimen face, there is a network of thermocouple monitoring the temperature. The temperature of each plate is held constant. Once the entire system is maintained at steady-state conditions the total energy consumption of the apparatus is recorded. The energy required to maintain the system at steady state is a function of the thermal conductivity of the test specimens, thus monitoring the energy required and system temperatures allows the thermal conductivity of the samples to be determined. The apparatus is shown in Figure 3-5. 


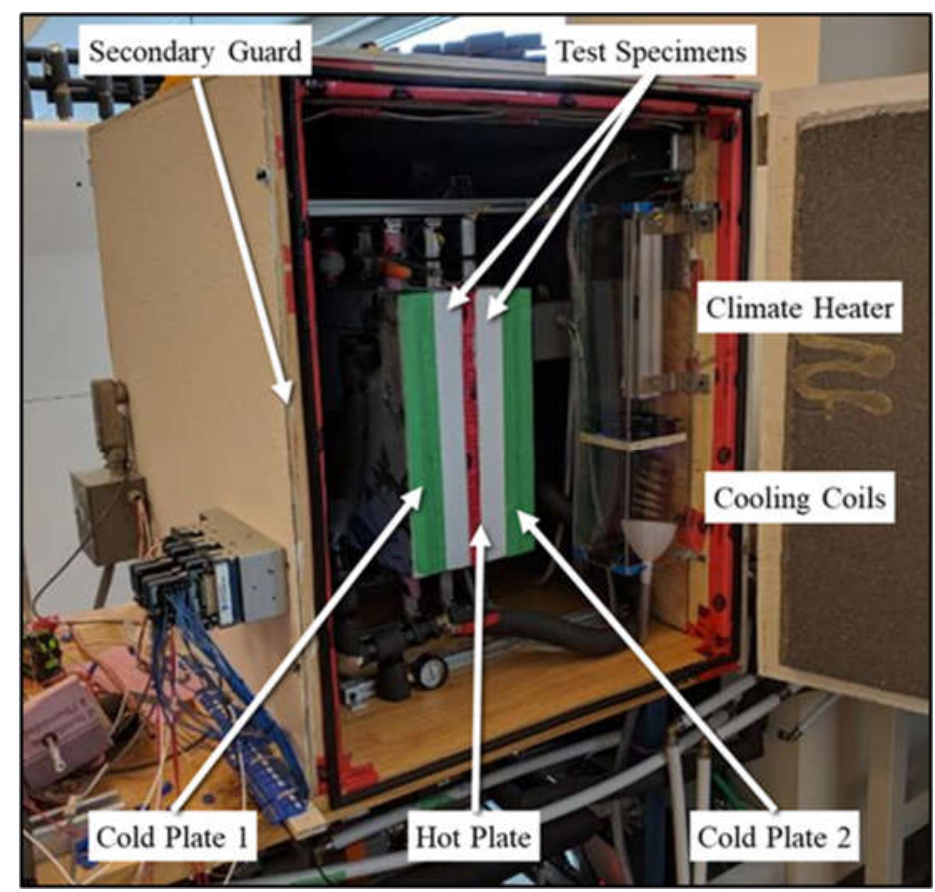

Figure 3-5: Guarded Hot Plate Apparatus

\subsection{Weigh Scale}

One of the most important pieces of equipment in this testing is the weigh scale. The scale is required to measure both the mass of the panels and the mass of the desiccant cups. The scale must measure to a precision appropriate for observing the minor gains in mass due to the transport of moisture through the VIP foils. The scale used was an Intell-Lab PBX-3200, this scale provides a readability of $0.01 \mathrm{~g}$, accuracy of $\pm 0.01 \mathrm{~g}$, and a weight limit of $3200 \mathrm{~g}$ (Intelligent Weighing Technology, 2015). The smallest panels present to the SESL lab weigh above 500g, meaning this scale can detect weight changes of $0.002 \%$, suitable for detecting moisture presence. Literature on the uncertainty of this model scale is limited. The total error on measurements was calculated based on random and systematic error, with a $90 \%$ confidence interval. In order to reduce impacts on the scale from the surroundings, two measures were taken. First, the scale was placed on a large, 3" shop-grade granite block, which itself sat on a thin rubber mat. This was done to ensure the scale 
sits level and is isolated from ground vibrations. The second measure was to isolate the air around the scale, a scale of this sensitivity will be severely affected by passing air currents. This was done by placing the entire scale in a clear casing to ensure the scale can be read while no air flow is affecting the readings. The scale set-up is shown in Figure 3-6 and Figure 3-7.
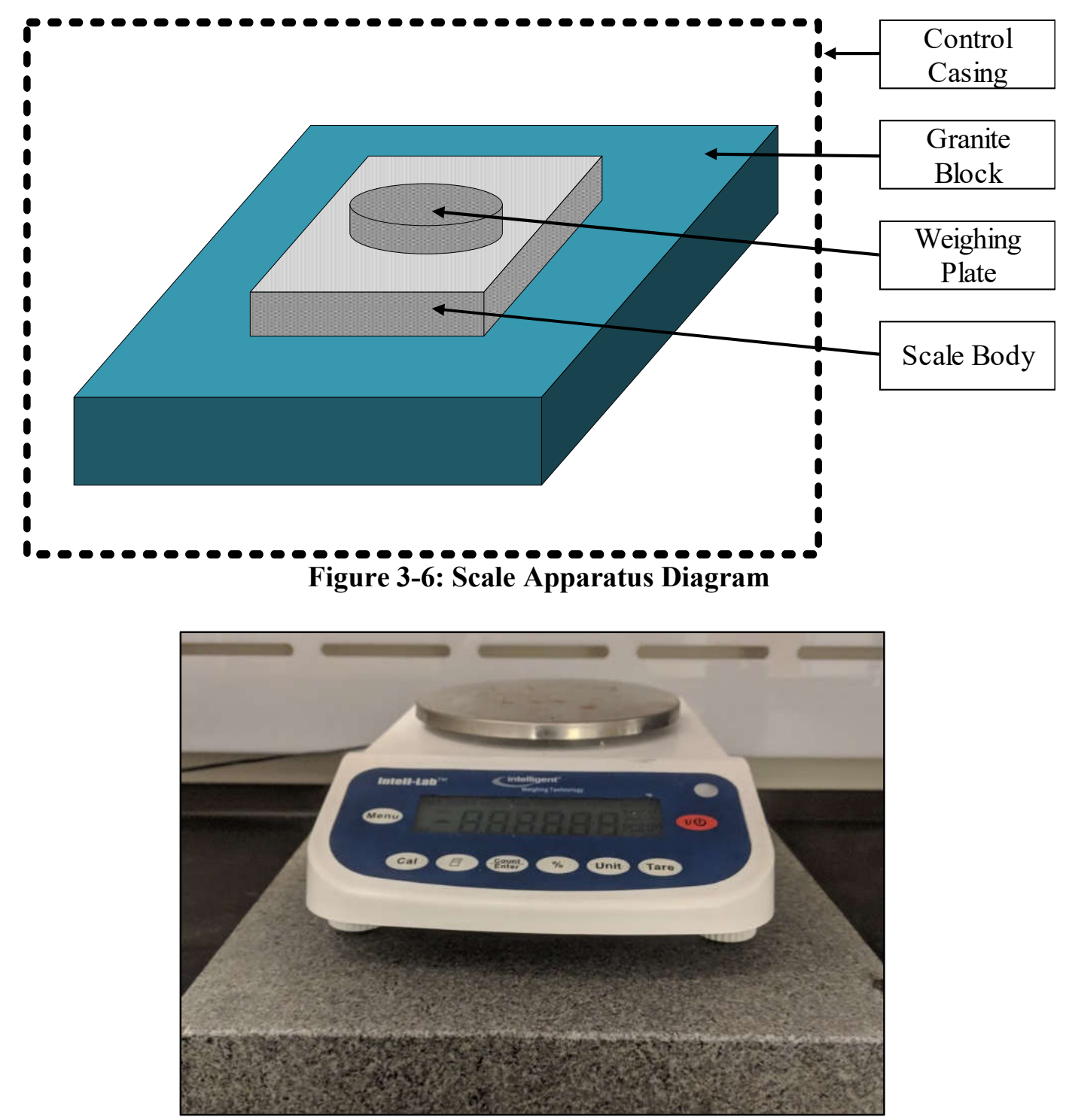

Figure 3-7: Scale 


\section{Chapter: Experimental Results}

This section covers the results obtained from the experiments and procedures outlined in Chapter 3. This includes the results from the dry-cup testing, full panel testing, and thermal conductive tests. This section will cover the measurements taken as well as error and analysis performed on the results

\subsection{Dry-Cup Testing}

The dry-cup testing consisted of measuring the water vapour transmission rates of VIP foils by following ASTM E96, the detailed procedure is outlined in Chapter 3. Six unique tests were conducted. Two of these tests were calibration tests using aluminum plate and a Tyvek air barrier as the samples. Four tests were of VIP foils, two field foils and two sections of foil containing the heat-sealed flange. One field and one flanged sample were put into a chamber at $90 \% \mathrm{RH}$ and $33^{\circ} \mathrm{C}$ while the remaining two were subject to conditions of $60 \% \mathrm{RH}$ and $33^{\circ} \mathrm{C}$.

The calibration tests were each run for 56 consecutive days. However, ASTM E96 states that when the mass of the sample has increased beyond $10 \%$ of its original weight, for the Tyvek test the specimen weight was increased by $17 \%$ at the time of the final weighing on Day 56 , so only the value at Day 31 was used for the Tyvek test. Table 4 below shows the weight increase experienced by each of the specimens.

Table 4: Dry Cup Control Testing Results

\begin{tabular}{|l|l|l|l|l|}
\hline Specimen & Day 0 Mass $(\mathrm{g})$ & Day 31 Mass (g) & Day 56 Mass (g) & \% Increase \\
\hline Tyvek Air Barrier & $995.2 \pm 0.03$ & $1090.2 \pm 0.03$ & Failed & $9.5 \%$ \\
\hline $\begin{array}{l}\text { 1/8” Aluminum } \\
\text { Plate }\end{array}$ & $883.5 \pm 0.05$ & $885.8 \pm 0.05$ & $886.4 \pm 0.02$ & $0.32 \%$ \\
\hline
\end{tabular}


Table 4 shows that the aluminum plate specimen increased in mass by $0.32 \%$. This is assumed to be the error of the specimen and is to be used as a correction factor for the testing of actual VIP specimens. The Tyvek air barrier was used to ensure that the apparatus can accurately predict the water transfer rates of materials. The Water-Vapour Transmission Rate was calculated using Equation (8) and the Permeance using Equation (9) and are provided in Table 5

Table 5: Control Test Calculated WVTR and Permeance

\begin{tabular}{|l|l|l|}
\hline & WVTR $\left(\mathrm{g} / \mathrm{h} \cdot \mathrm{m}^{2}\right)$ & Permeance \\
\hline Tyvek Air Barrier & 13.4 & $0.399 \mathrm{~g} / \mathrm{m}^{2} \cdot \mathrm{s} \cdot \mathrm{Pa}(45.6$ Perms $)$ \\
\hline $1 / 8 ”$ Aluminum Plate & 0.23 & $0.007 \mathrm{~g} / \mathrm{m}^{2} \cdot \mathrm{s} \cdot \mathrm{Pa}(0.78$ Perms $)$ \\
\hline
\end{tabular}

These measurements were compared to published data on the moisture transport performance of Tyvek. These values are generally provided in units of Imperial Perms, the measured value of which is 45.6 Perms. Tyvek Air Barrier has a rated permeability of between 40 to 60 Perms (DuPont, 2007), this shows that the experimental procedure is able to produce results for a permeable material within the expected range of values.

The field foil tests specimens represent the foil of the panel, not considering seams or edges. The high condition $\left(33^{\circ} \mathrm{C} / 90 \% \mathrm{RH}\right)$ test and the low condition $\left(33^{\circ} \mathrm{C} / 60 \% \mathrm{RH}\right)$ were run for 56 consecutive days. Measurements for the high condition tests were taken prior to testing, at the halfway point, and after the tests were completed. The low test, to provide more time for moisture to transport into the specimen, were only measured at the start and end of the testing period. The results from this testing are shown in Table 6, with the calculated WVTR and Permeability provided in Table 7 . 
Table 6: Field Foil Test Results

\begin{tabular}{|l|c|c|c|c|}
\hline $\begin{array}{l}\text { Field Foil } \\
\text { Condition }\end{array}$ & Day 0 Mass (g) & Day 31 Mass (g) & Day 56 Mass (g) & \% Increase \\
\hline $90 \% \mathrm{RH}-33^{\circ} \mathrm{C}$ & $980.04 \pm 0.03$ & $985.46 \pm 0.05$ & $988.86 \pm 0.02$ & $0.9 \%$ \\
\hline $60 \% \mathrm{RH}-33^{\circ} \mathrm{C}$ & $965.26 \pm 0.05$ & N/A & $967.85 \pm 0.04$ & $0.27 \%$ \\
\hline
\end{tabular}

Table 7: Field Foil Experimental WVTR and Permeance

\begin{tabular}{|l|c|c|}
\hline Field Foil Condition & WVTR $\left(\mathrm{g} / \mathrm{h} \cdot \mathrm{m}^{2}\right)$ & Permeance $\left(\mathrm{g} / \mathrm{m}^{2} \cdot \mathrm{s} \cdot \mathrm{Pa}\right)$ \\
\hline $90 \% \mathrm{RH}-33^{\circ} \mathrm{C}$ & 0.71 & 0.021 \\
\hline $60 \% \mathrm{RH}-33^{\circ} \mathrm{C}$ & 0.21 & 0.006 \\
\hline
\end{tabular}

These same tests were also performed for VIP foil samples containing the heat-sealed flange.

These results are shown in Table 8 and Table 9.

Table 8: Foil with Flange Test Results

\begin{tabular}{|l|c|c|c|c|}
\hline $\begin{array}{l}\text { Foil with Flange } \\
\text { Condition }\end{array}$ & Day 0 Mass (g) & Day 31 Mass (g) & Day 56 Mass (g) & \% Increase \\
\hline $90 \% \mathrm{RH}-33^{\circ} \mathrm{C}$ & $953.93 \pm 0.08$ & $957.39 \pm 0.12$ & $959.29 \pm 0.12$ & $0.56 \%$ \\
\hline $60 \% \mathrm{RH}-33^{\circ} \mathrm{C}$ & $973.20 \pm 0.07$ & N/A & $975.34 \pm 0.02$ & $0.22 \%$ \\
\hline
\end{tabular}

Table 9: Foil Flange Experimental WVTR and Permeance

\begin{tabular}{|l|c|c|}
\hline & WVTR $\left(\mathrm{g} / \mathrm{h} \cdot \mathrm{m}^{2}\right)$ & Permeance $\left(\mathrm{g} / \mathrm{m}^{2} \cdot \mathrm{s} \cdot \mathrm{Pa}\right)$ \\
\hline $90 \% \mathrm{RH}-33^{\circ} \mathrm{C}$ & 0.44 & 0.013 \\
\hline $60 \% \mathrm{RH}-33^{\circ} \mathrm{C}$ & 0.17 & 0.005 \\
\hline
\end{tabular}

These results were not in agreement with what researchers expected. The tests were considered failed and results were not used. It was expected that the VIP sample containing the heat-sealed flange would have a higher WVTR than the field only containing foil. The results show that this was not observed in testing as the high humidity condition WVTR was $0.44 \mathrm{~g} / \mathrm{h} \cdot \mathrm{m}^{2}$ with the flange and $0.71 \mathrm{~g} / \mathrm{h} \cdot \mathrm{m}^{2}$ with just the foil. Although research shows that moisture transports through both the field and seam of a panel, considering the seam still provides a greater rate of transfer than just the foil (Baetens, et al., 2010). The most troubling result of this testing was the comparison of results between the VIP foils and the aluminum plate control test. If the dry-cup 
apparatus worked perfectly, the calculated permeability of aluminum should be below 0.1 Perms, as it is defined as vapour impermeable (Barrett, 2016), but the measured permeability was 0.78 Perms. The correction factor provided by the aluminum is very large compared to the mass increase seen by the actual VIP foil samples. This leads the determinization that while the general procedure developed may be suitable for determining VIP permeability, there are two main shortcomings of the dry cup method. The length of the test, a longer test would eliminate uncertainty created from an initial spike in weight that may be created by moisture getting caught on the external surface of the apparatus. Additionally, a longer test would allow more data to be collected and the rate of moisture transport to be better represented. The other shortcoming of this testing is the design of the dry-cup apparatus. The aluminum experienced much greater moisture accumulation than expected, this is likely due to a failure in the design of the dry-cup apparatus. The integration of the rubber gaskets into the cup may not have provided enough pressure or contact surface to withstand moisture penetration.

The material and intricacies of the cup may have allowed an amount of moisture to accumulates on the surface of the apparatus. The last design shortcoming was the use of steel bolt, nuts, and washers to secure the top plate onto the cup. It is likely that these components corroded during testing as visible corrosion was observed on the washers which would increase the mass of the system. In addition to this, corrosion was abundant inside the chamber, likely encouraged my minerals in the tap water used by the system. The issues observed with this testing can be mitigated through the use of better designed dry cup apparatuses. Simplifying the design and using an adhesive to attach the sample rather than gaskets and bolts may reduce the uncertainty on the test.

A different approach may also provide better results, such as basing the procedure on ASTM F1249-13 (ASTM International, 2013) which designed specifically for low transmittance 
materials. This procedure involves using an infrared sensor to monitor the transfer of molecules across high barrier flexible foils when a large vapour pressure is induced across the sample. This is discussed further in Chapter 8 .

\subsection{Full Panel Aging and Thermal Conductivity Testing}

This testing consisted of monitoring the moisture accumulation of panels to determine the WVTR of the panel foil material as well as measuring the thermal conductivity as the panel moisture content increased in attempt to determine an aging rate of the panels. The procedure for this testing is discussed in Chapter 3.

Panels manufactured by two different brands were tested, both manufacturers used an MF2 type foil. For each manufacturer, labelled as Manufacturer A and B, two panels were placed in the chamber at $90 \% \mathrm{RH} / 33^{\circ} \mathrm{C}$ and two were placed in the chamber at $60 \% \mathrm{RH} / 33^{\circ} \mathrm{C}$. Figure $4-1$ and Figure 4-2 show the high humidity aging results for manufacturer A and B, respectively. The test was run for 295 days for manufacturer A and 211 days for manufacturer B. 


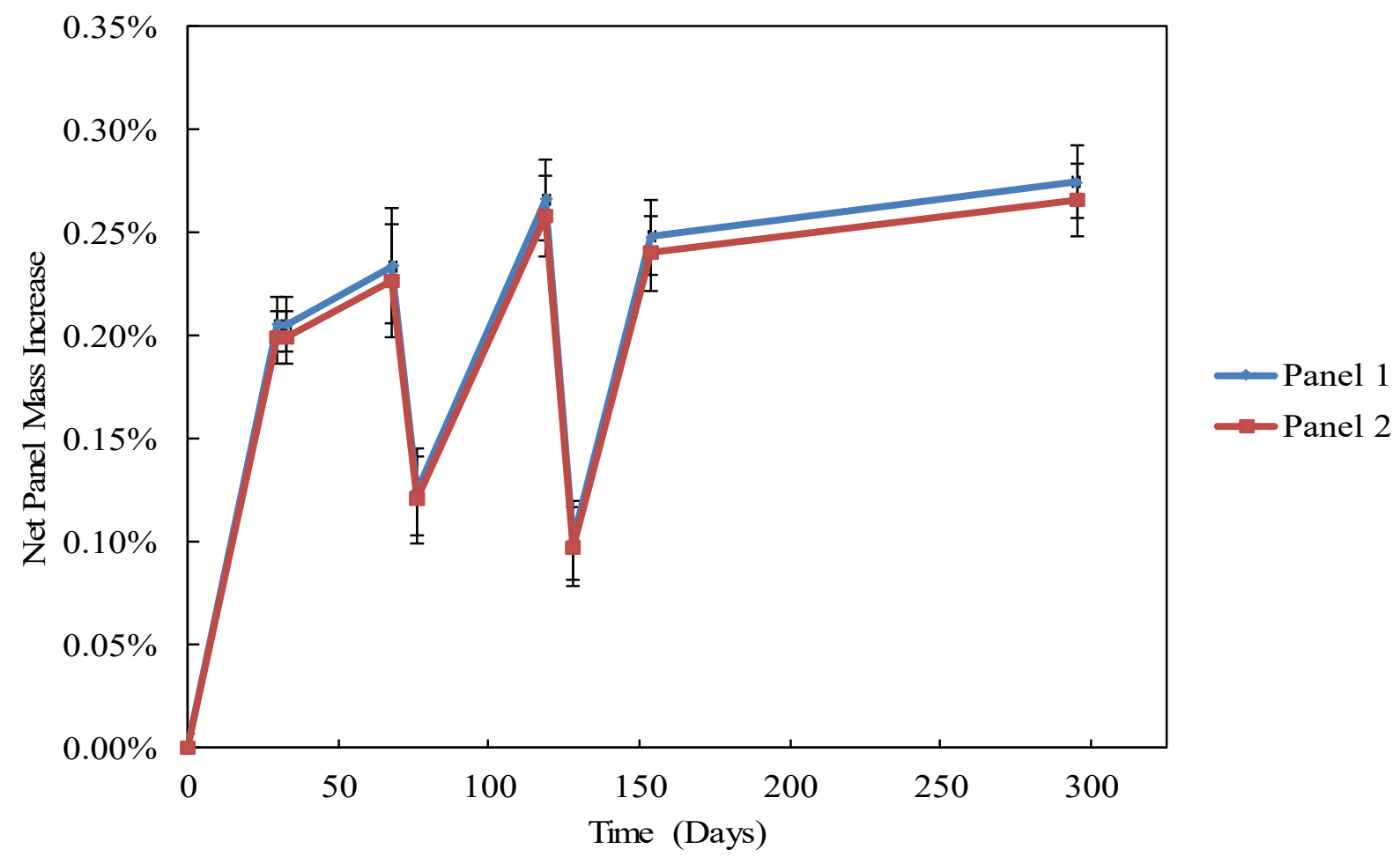

Figure 4-1: Manufacturer A Panel Mass Increase

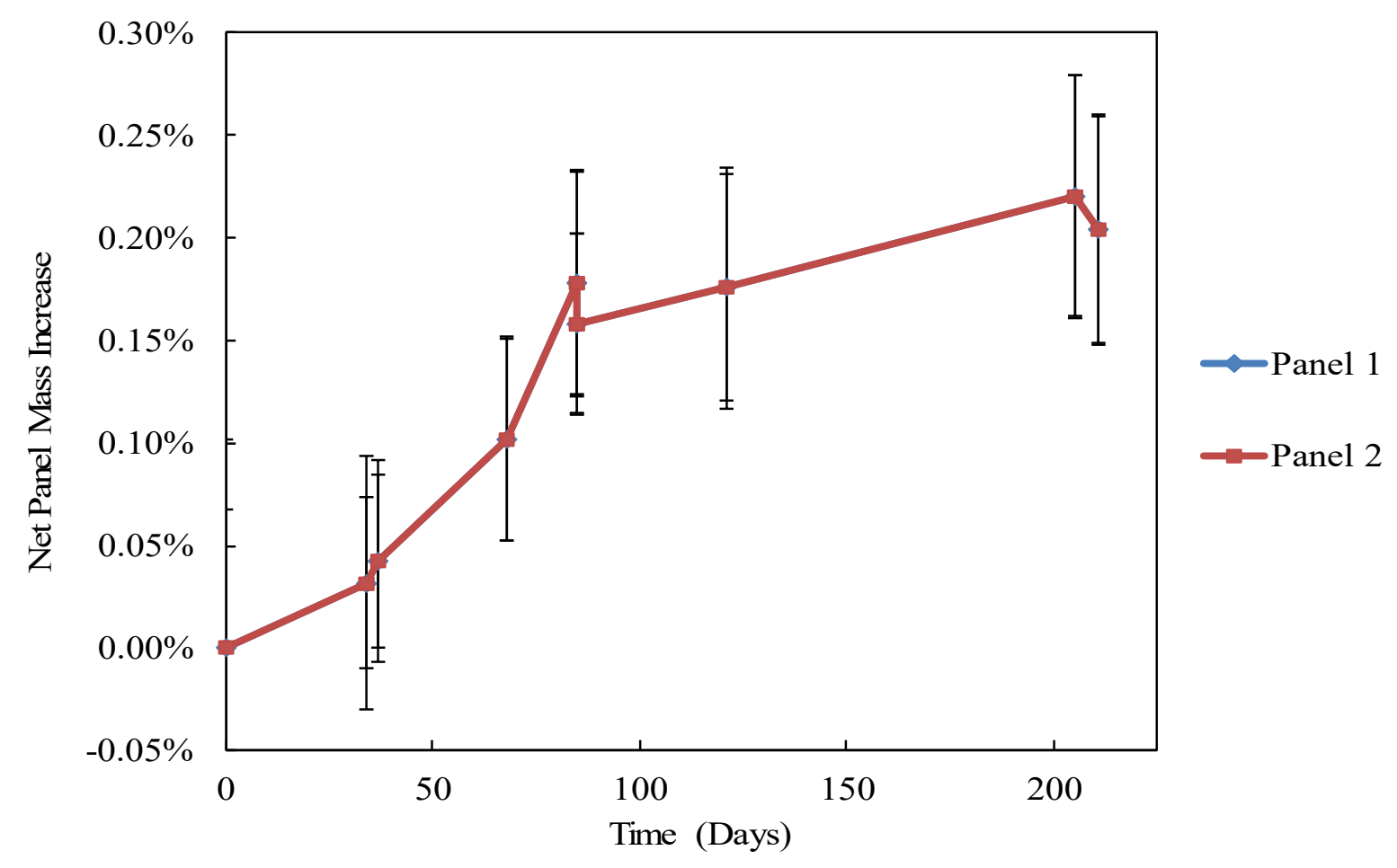

Figure 4-2: Manufacturer B Panel Mass Increase 
The panel from manufacturer A showed extreme increases and decreases in the mass of the panel. This is caused by an adhesive coating on one face of the A panels, intended to be used for mounting the panels to a building wall. This adhesive was gaining moisture and drying out rapidly when the panels were undergoing thermal conductivity testing in the GHP apparatus. Manufacturer $\mathrm{B}$ also showed decreases in moisture content that are not repeating nor predictable. This is attributed to uncertainty in the entire system as well as moisture accumulation on the exterior of the panel. As shown in Figure 4-2, there is a significant amount of uncertainty in the system, specifically the weighing of the samples. The flange of the foil may allow for the containment of small amounts of moisture. These small amounts may affect the weighing of the panels after removal from the chamber but evaporate during GHP testing. This could cause the increase and decrease seen in the panel weight. These results are further analyzed in Section 4.3.

Equations (8) and (9) allow for the calculation of WVTR and permeability for each of the panels aged in the high humidity chamber. These values are provided in Table 10, further discussion on these values is provided in Section 4.3

Table 10: Full Panel Experimental WVTR and Permeability

\begin{tabular}{|l|l|l|}
\hline & $90 \% \mathrm{RH} / 33^{\circ} \mathrm{C}$ \\
\cline { 2 - 3 } & $\begin{array}{l}\text { WVTR } \\
\left(\mathrm{g} / \mathrm{h} \cdot \mathrm{m}^{2}\right)\end{array}$ & $\begin{array}{l}\text { Permeability } \\
\left(\mathrm{g} / \mathrm{m}^{2} \cdot \mathrm{s} \cdot \mathrm{Pa}\right)\end{array}$ \\
\hline Manufacturer A & $0.0005 \pm 0.001$ & $0.00001 \pm 0.00001$ \\
\hline Manufacturer B & $0.0007 \pm 0.0001$ & $0.00002 \pm 0.00001$ \\
\hline
\end{tabular}

Each of the panels was placed in the GHP prior to aging tests in order to establish a baseline thermal conductivity value. The thermal conductivity was also measured at the end of test, and in certain instances, midway through the aging test. GHP testing was limited due to the length of time 
a test requires and operation difficulties with the apparatus (such as power loss and difficulties reaching steady-state).

\subsection{Conclusions and Comparison to Measured Values}

One of main goals of the testing was to develop a suitable procedure and testing method for measuring the moisture ingress into VIPs and the associated drop in performance. In order to determine the suitability of measured data, it was compared to published data. Annex 39 provided values for the WVTR of MF2 foil VIPS, measured using a procedure similar to the procedure outlined in ASTM E96.

A difficulty in comparing various values for the WVTR of materials is the conditions (temperature and relative humidity) at which the rate was measured. In order to interpolate between measured WVTR points, the temperature and relative humidity each point was measured at was converted to vapour pressure. This is possible because vapour pressure is a function of both temperature and relative humidity. Equation (10) (Hens, 2012) was used to convert each measured point from temperature and relative humidity to vapour pressure.

$$
\begin{gathered}
\text { For: }-30 \leq T \leq 0^{\circ} \mathrm{C} ; \\
P_{\mathrm{vap}}=\varphi_{\mathrm{RH}} \cdot P_{\text {sat }} \\
=\varphi_{\mathrm{RH}} \cdot\left[611 \cdot \exp \left(82.9 \cdot 10^{-3} T-288.1 \cdot 10^{-6} T^{2}+4.403 \cdot 10^{-6} T^{3}\right]\right. \\
\text { For: } 0 \leq T \leq 40^{\circ} \mathrm{C} ; \\
P_{\mathrm{vap}}=v \cdot P_{\mathrm{sat}} \\
=\varphi_{\mathrm{RH}} \cdot\left[611 \cdot \exp \left(72.5 \cdot 10^{-3} T-288.1 \cdot 10^{-6} T^{2}+0.79 \cdot 10^{-6} T^{3}\right]\right.
\end{gathered}
$$


where $P_{\text {vap }}$ represents the vapour pressure of the system, in $\mathrm{Pa}, \varphi_{\mathrm{RH}}$ represents the relative humidity as a decimal, $P_{\text {sat }}$ represents the saturated vapour pressure, and finally $T$ represents the temperature of the system in degrees Celsius.

Figure 4-3 shows that the measured WVTR for Manufacturer B are nearly perfectly in line with the published values from Annex 39. It is important to note that the water vapour transmission rate as a property, is driven by the differential vapour pressure across the material. The WVTR of a material increases linearly with the vapour pressure differential (ASTM International, 2013). This is shown as the measured and published WVTR values fall in linear agreement, demonstrated by the linear dotted trendline. The measured value for manufacturer A falls outside of this trend, but this is attributed to the adhesive glue on the exterior of the panel causing error in the result. This data shows that the procedure followed for measuring the WVTR of panels using full panel testing can produce results that are in line with published values for panel foils. This will allow the testing procedure to be used to reliably measure the WVTR of various panels and panel materials in the future to develop values for various panels, brands, coatings, and more. 


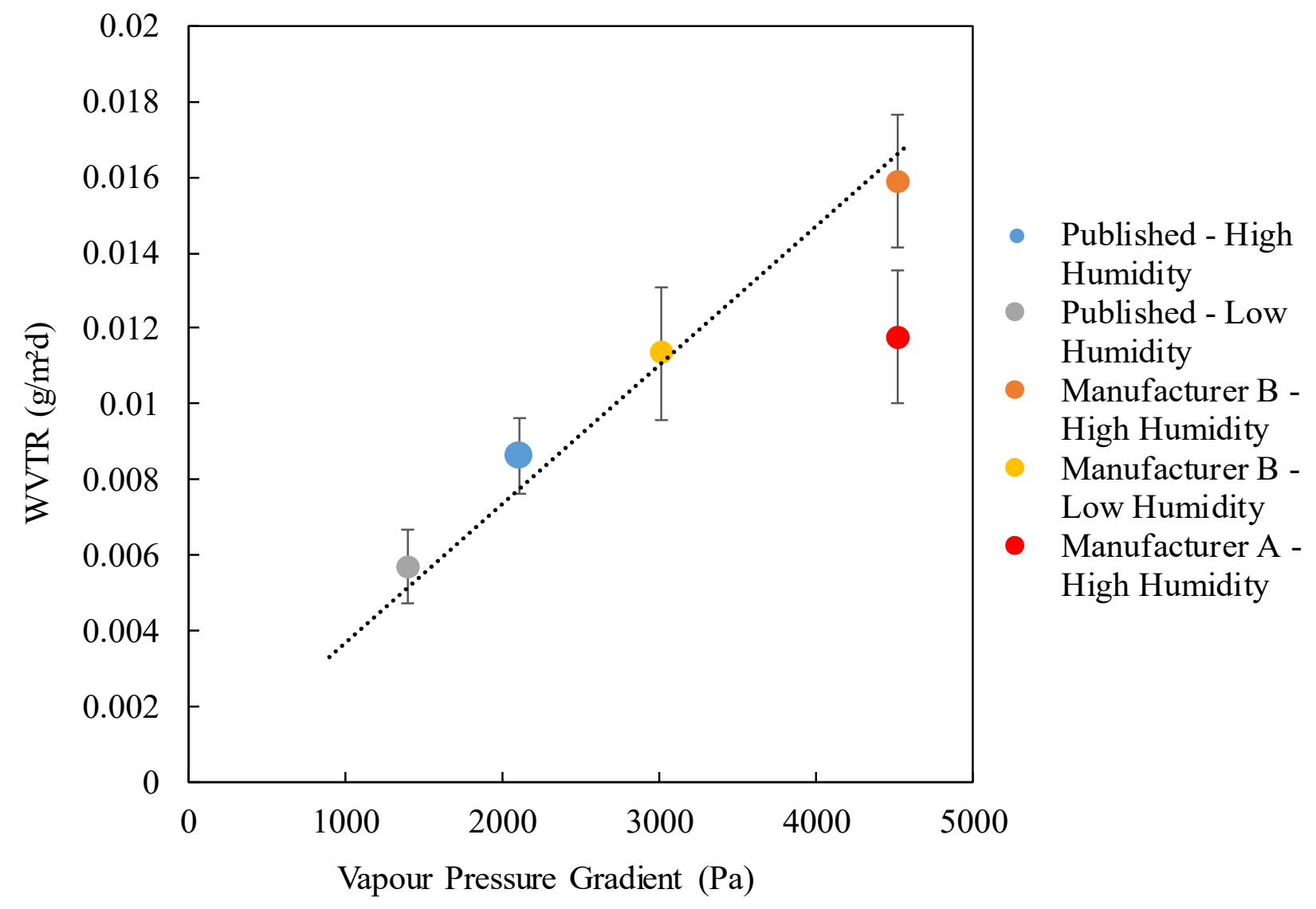

Figure 4-3: Measured and Published WVTR Points and Linear Trend Between Points

The experimental work also provided a measured relationship for thermal conductivity at increasing panel water contents, this functions as an aging factor, as aging is caused by water accumulation in the panels and quantified by the reduction in thermal conductivity. Equation (6) provides a relationship for thermal conductivity as a function of water content percentage for VIPs. This is shown in Figure 4-4. The starting point of each relationship is when the panels are dry (no water content). To simplify the comparison, each panel was assumed to have a dry thermal conductivity of $0.0038 \mathrm{~W} / \mathrm{m} \cdot \mathrm{K}$ (Kevothermal, 2010). 


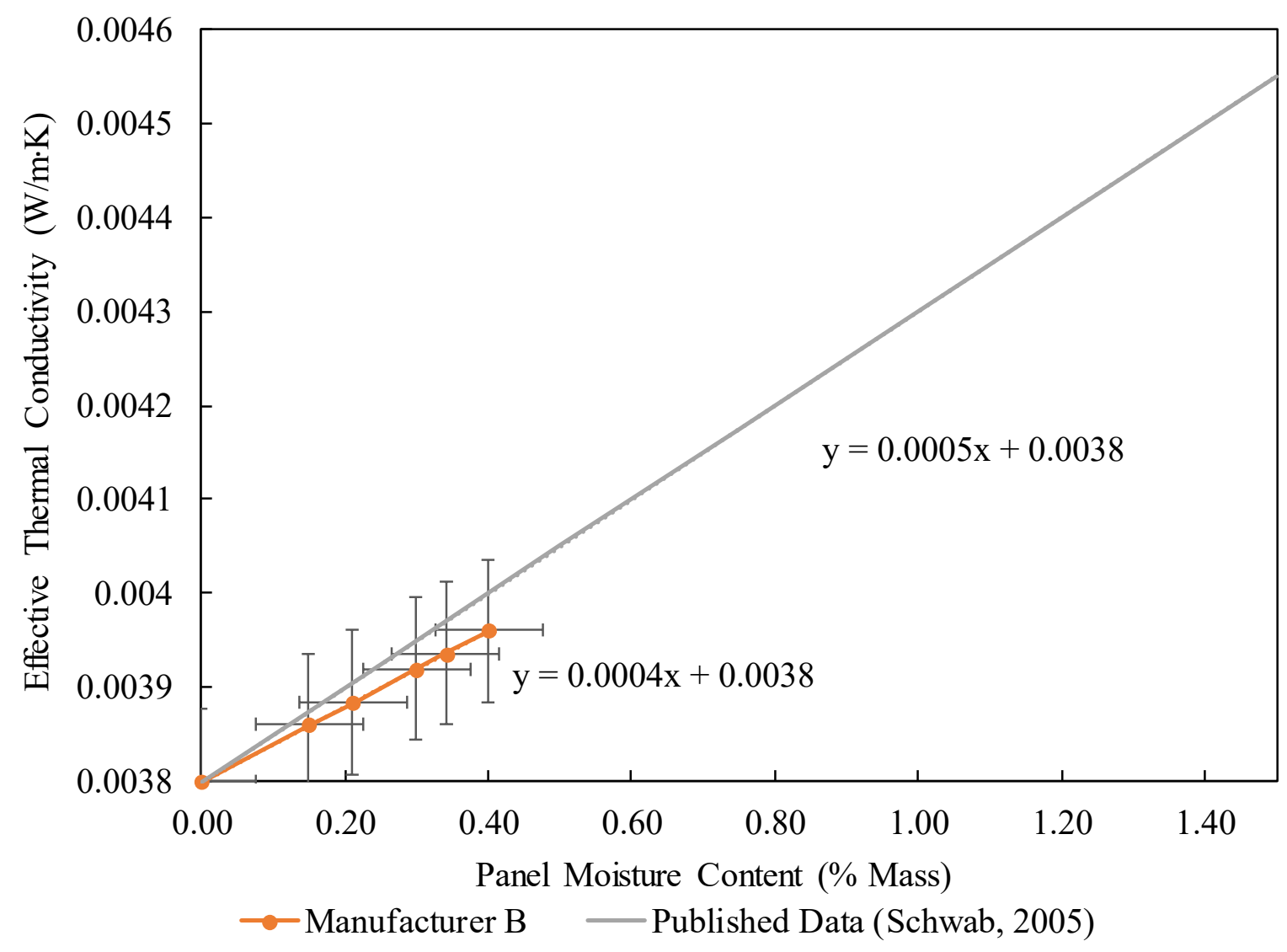

Figure 4-4: Thermal Conductivity and Water Content Relationships

Figure 4-4 shows that the measured properties of the panels built by Manufacturer B are similar to the published values. The published results show a $20 \%$ greater rate of aging than the measured results for Manufacturer B. However, due to constraints in experimental testing timelines, the moisture accumulation in the panels was limited to below $0.5 \%$ of mass. Results for A were inconclusive due to the adhesive causing significant variation in results.

These results show the potential for the experimental procedure to be used to quantify the aging rate of VIPs and building materials using relatively simple procedures and cost-effective equipment. These values are required for use in the modelling of moisture transport into panels. 


\section{Chapter: Wall Simulation Model Setup}

The main purpose of this research is to develop a lifetime estimation for VIPs in building applications. To do this, the conditions the VIP is subjected to throughout its life must be known. This is challenging, as the VIP is sheltered within a building envelope. The conditions at the VIP depend on the exterior weather, the interior building conditions, and wall construction. To determine the conditions the VIP is subject to across a year, Delphin Hygrothermal software (Delphin, 2019) was used to simulate the conditions that a VIP in a wall would be subjected to. Hygrothermal modelling consists of simulating the heat and moisture transfer across a wall. Constructing a hygrothermal model includes defining the wall construction (materials and dimensions), interior building conditions (temperature and relative humidity), and exterior weather conditions (temperature, relative humidity, radiation, and wind). Simulating a given weather year will provide an output of the temperature and relative humidity profiles through the wall, specifically at the interior and exterior face of a VIP foil. Knowing the relative humidity and temperature at the boundary of the VIP provides the moisture transport into the VIP along with the associated drop in thermal conductivity. This section will cover the development of the model, including the wall construction and material properties, the exterior and interior conditions, and key assumptions that were made in the model.

This model was limited to a 1-dimenisonal simulation since the key mechanisms of interest are the conditions on either side of the center of the VIP. A 1-dimensional simulation provides the condition profile through the wall without the unnecessary complications due to the detail and variables introduced in a 2-D or 3-D simulation. However, the edge effects of the VIP are still accounted for in the following two ways:1) the thermal conductivity defined for the VIP is an assembly value (this means that the thermal conductivity value accounts for thermal bridging and 
edge effects), and 2) the water-vapour transmission properties of the panel include edge effects, such as moisture transport through the seam of a panel. The edge effects of a VIP that influence the lifespan of a VIP are accounted for while performing simpler 1-D simulations.

\subsection{Wall Definitions}

This section will discuss the materials, geometry, and dimensions of the walls chosen for this model. Two different wall constructions were built in this model both based on an NRC report on VIP-integrated walls in Canada (Maref, et al., 2013). The VIPs in both walls are installed as part of the exterior insulation layer, where the VIP is encased in an expanded polystyrene (EPS) foam panel.

The first wall construction (Wall A - Retrofit Case) represents an energy-retrofit case, where a home is upgraded to achieve a higher level of insulation while in accordance with building code requirements. This wall is shown in Figure 5-1. The wall consists of fibreboard siding in direct contact with a Tyvek Air Barrier, the VIP encased in one-inch layers of EPS, OSB sheathing, cavity insulation based on a 2 " by 4" wall construction, a polyethylene vapour barrier, and the final gypsum layer (including primer and latex paint). This construction does not include a capillary break, this provides a worst-case scenario as well as demonstrating the effect of the capillary break on VIP life. 


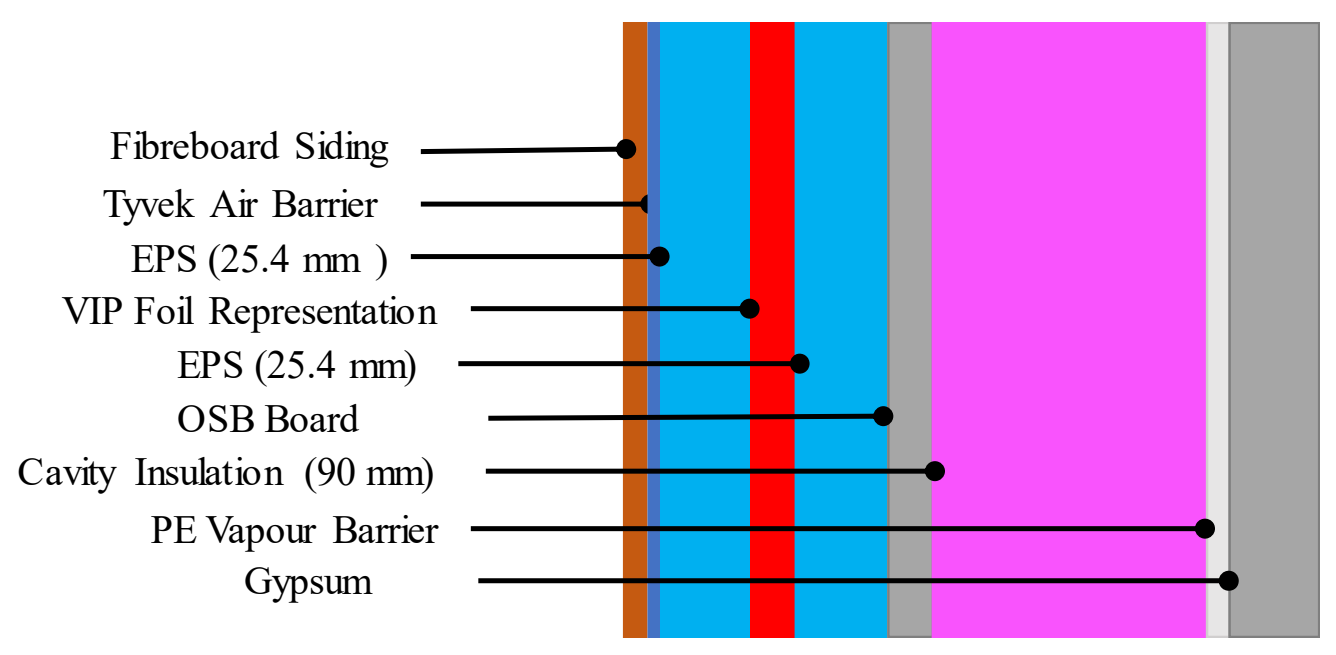

Figure 5-1: Wall A - Retrofit Wall Case

The second wall (Wall B - New Construction Case) represents a new construction case, where higher performance building techniques are used. However, this is still modelled to be a common wall construction. Figure 5-2 shows the building construction and material of this wall. This construction differs from Wall $\mathrm{A}$ in the following regards: there is a 1-inch capillary break (air gap) between the fibreboard siding and Tyvek air barrier, and the cavity insulation layer is based on a 2" by 6" wood stud construction. 


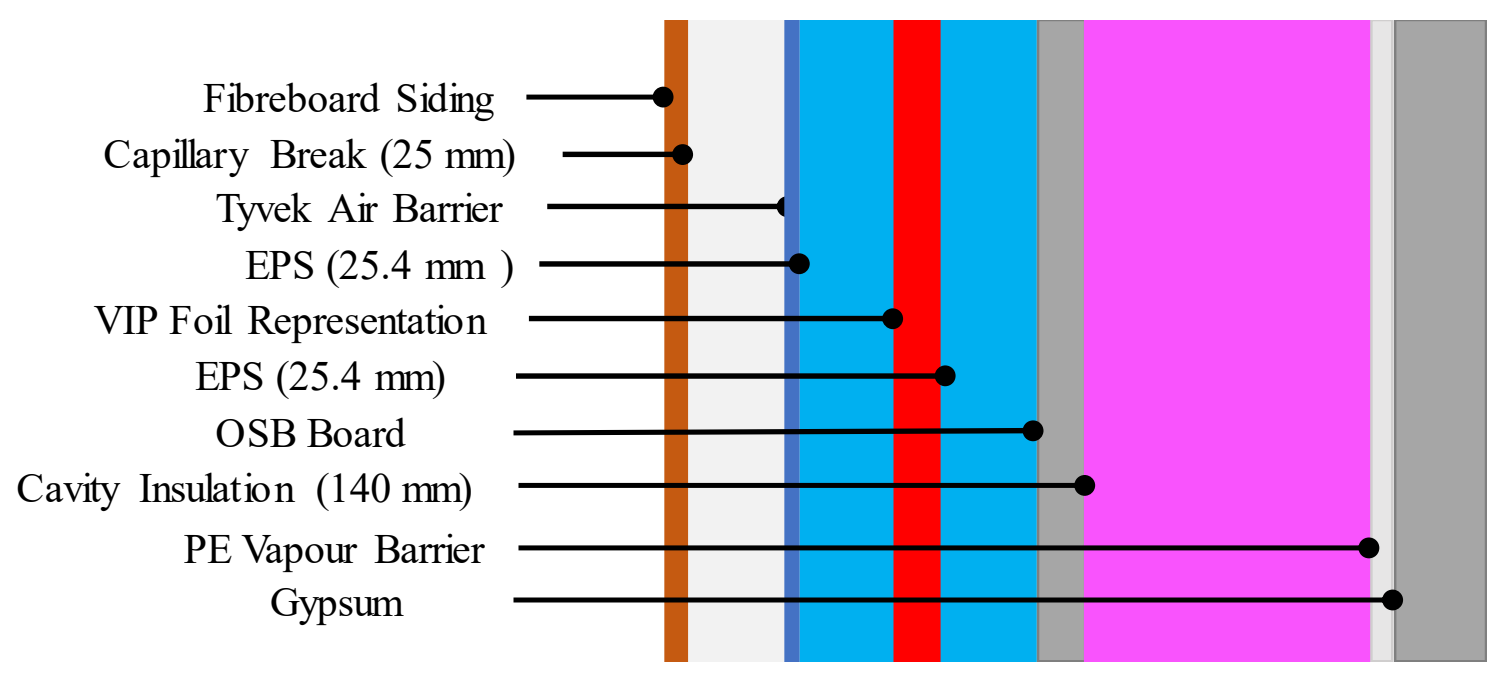

Figure 5-2: Wall B - New Construction Case

Numerous challenges existed in attempting to model the VIP in the modelling software. There proved to be no simple way to model the behavior of a VIP due to the low-pressure (vacuum) interior and moisture trapping properties. To overcome this challenge, a single material representation of a VIP core and foil was modelled. This consisted of a material definition that represents the permeability and thermal conductivity, this would provide the same heat and moisture behavior of the wall allowing for the water transport into the panel to be calculated in post-processing. The thickness of the representation was equal to the thickness of a VIP foil. The thermal conductivity was then adjusted to contribute the same thermal performance to the wall that the actual VIP would provide. The VIP foil generally behaves as a vapour impermeable material, but the permeability was defined based on Annex 39 material properties. The VIP properties were all statically defined, meaning that they do not vary as temperature, humidity, or water content change. This was deemed acceptable to simplify modelling as water dependent foil properties are 
unknown. Additionally, the impact of water content of the core is the variable of interest in the modelling, which was later found to have an inconsiderable impact on the conditions at the VIP.

The material properties were defined based on the NRC Construction Division Materials Database for Hygrothermal Simulations (National Research Council of Canada, 2013). This database provides experimentally validated material properties for most common construction materials. Each material property is provided as a trend varying with the water content by volume $\left(\mathrm{m}^{3} / \mathrm{m}^{3}\right)$, with the parent trend as the sorption isotherm, which provides the water content of a material from 0 to $100 \%$ relative humidity. This data set provided key properties for accurately modelling the moisture transport through the wall. The properties and units that were defined for each material in the model are as follows:

- Sorption Isotherm $\left(\mathrm{m}^{3} / \mathrm{m}^{3}\right.$ vs. relative humidity)

- Liquid Water Diffusivity $\left(\mathrm{m}^{2} / \mathrm{s}\right)$

- Air Permeability (Perms)

- Thermal Conductivity $(\mathrm{W} / \mathrm{m} \cdot \mathrm{K})$

- Water Vapour Permeability (s)

- Density $\left(\mathrm{Kg} / \mathrm{m}^{3}\right)$

- Heat Capacity $(\mathrm{J} / \mathrm{Kg} \cdot \mathrm{K})$

\subsection{Exterior and Interior Conditions}

The exterior conditions are defined with weather data. The data used in this model were also provided by the NRC Construction Division. The data was gathered for the purpose of hygrothermal simulations. For this model, weather data for two cities from 2013, 2014, 2015, and 2016 was provided. The climate locations for this testing were Ottawa and Niagara, Niagara was chosen to provide insight into the VIP lifespan in a higher humidity Canadian climate while Ottawa 
was chosen to provide insight into VIP lifespans in a colder climate. Integrated to the climate files is the orientation of the wall being simulated, this was determined during the preparation of the climate files as the angle that subjects the wall to the highest wind driven rain loads. This was determined to be $205^{\circ}$ and $225^{\circ}$ from north for Ottawa and Niagara, respectively.

The weather conditions considered in this model are as follows:

- Temperature $\left({ }^{\circ} \mathrm{C}\right)$

- Relative Humidity (\%)

- Direct Radiation (Shortwave and Longwave Components) $\left(\mathrm{W} / \mathrm{m}^{2}\right)$

- Diffuse Radiation (Shortwave and Longwave Components) $\left(\mathrm{W} / \mathrm{m}^{2}\right)$

- Atmospheric Counter Radiation $\left(\mathrm{W} / \mathrm{m}^{2}\right)$

- Sky Temperature $\left({ }^{\circ} \mathrm{C}\right)$

- Wind Velocity and Direction $(\mathrm{km} / \mathrm{h}$ and Degrees from North)

- Wind-Driven Rain $\left(\mathrm{L} / \mathrm{m}^{2} \mathrm{~s}\right)$

- Water Entry $\left(\mathrm{Kg} / \mathrm{m}^{3} \mathrm{~s}\right)$

One of the most important considerations in this model is the inclusion of wind-driven rain (WDR) and water entry. WDR and water entry have not currently been considered in VIP lifespan assessment. WDR represents the portion of rain with a horizontal velocity vector caused by wind. WDR is the most significant source of moisture entry into building walls (Kumaraperumal et al., 2018), and hence is key to determining the conditions at the VIP. ASHRAE 160 classifies the water entry amount as $1 \%$ of the wind-drive rain load (ANSI/ASHRAE 160, 2016). The water 
source was assumed to enter the wall at the back (interior face) of the siding for both the retrofit and new construction cases.

Specific to the new construction was the presence of a one-inch $(25.4 \mathrm{~mm})$ capillary break (air gap). This works to reduce the moisture transport through the wall and provide a mechanism for drying wall materials. The air change rate of this air gap was assumed to be $100 \mathrm{ACH}$ (Air Changes per Hour), which is the lower limit estimate for the ventilation rates of new vertically ventilated constructions (Langmans et al., 2015).

The interior conditions accounted for in this model are the temperature and relative humidity. The interior temperature and relative humidity were based on guidelines provided by ASHRAE 160, which provides criteria for analyzing moisture control and resiliency in buildings. Based on this standard, the interior temperature was set at a constant $22^{\circ} \mathrm{C}$ throughout the year. The relative humidity was based on a relationship with the exterior temperature. This trend is shown in Figure 5-3. The figure demonstrates that when the temperature is below $0^{\circ} \mathrm{C}$, the interior relative humidity is $40 \%$ and when the exterior temperature is above $20^{\circ} \mathrm{C}$, the interior relative humidity is $70 \%$. Between $0^{\circ} \mathrm{C}$ and $20^{\circ} \mathrm{C}$ the relative humidity following a linear trend from $40 \%$ to $70 \%$. 


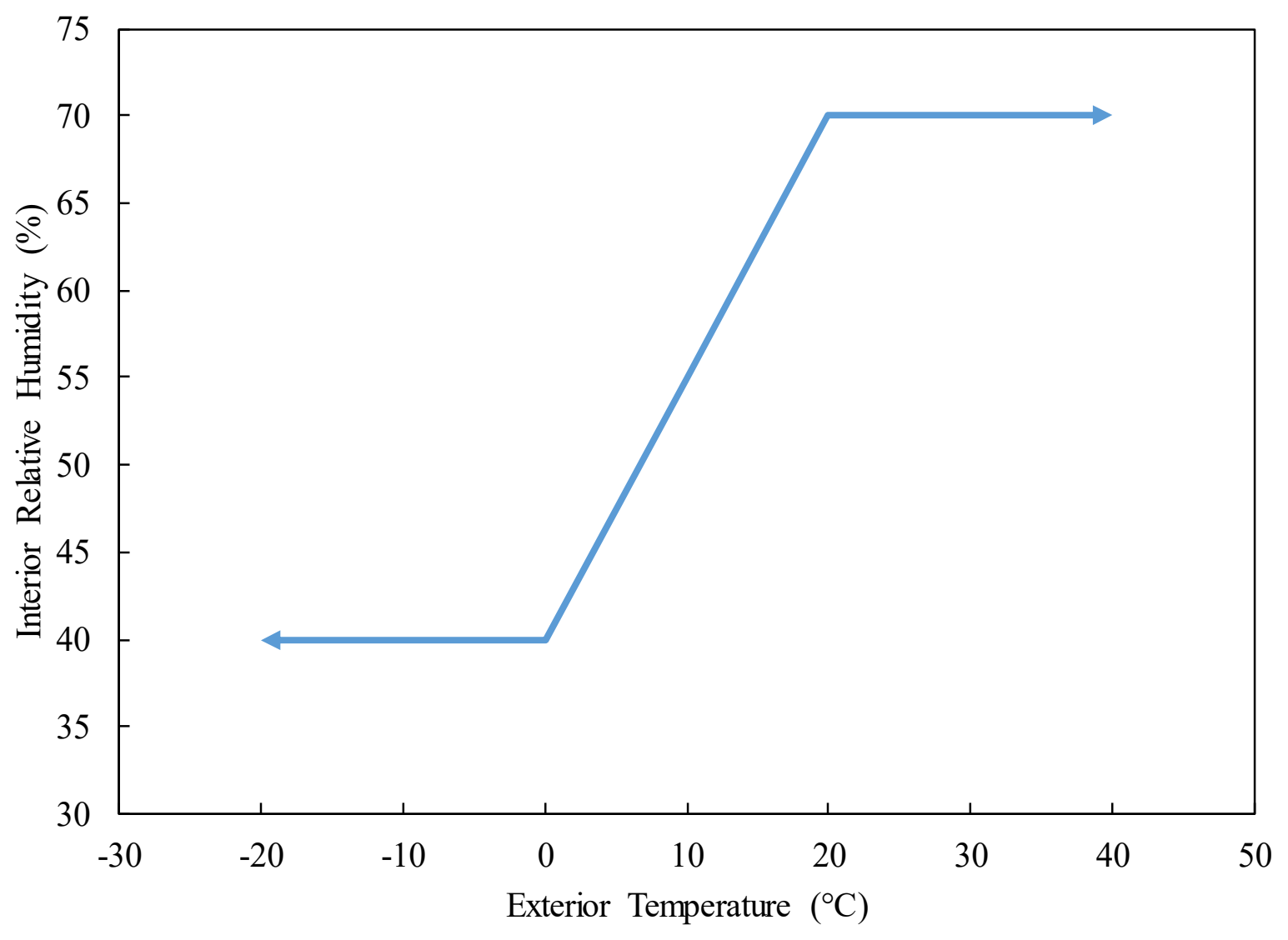

Figure 5-3: Interior Relative Humidity Trend

\subsection{Heat and Moisture Transfer Coefficients}

Delphin Hygrothermal provides the ability to adjust the definitions of heat and moisture transfer coefficients for the internal and exterior faces of a building wall. The exterior heat transfer convection coefficient was calculated as a function of wind speed at the wall using Equation (11), recommended by ASHRAE (Jayamaha et al., 1996).

$$
h_{c}=5.7+3.8(v)
$$

where $v$ is the wind velocity on the exterior wall, in $\mathrm{m} / \mathrm{s}$, and $h_{c}$ is the heat transfer convection coefficient in $\mathrm{W} / \mathrm{m}^{2} \mathrm{~K}$. The interior convection coefficient was set at a constant value of $8 \mathrm{~W} / \mathrm{m}^{2} \mathrm{~K}$, recommended by the program (Nicolai \& Grunewald, 2006). 
The moisture transfer convection coefficients were both assumed to be constant values. The exterior coefficient was taken as a constant $2 \cdot 10^{-7} \mathrm{~s} / \mathrm{m}$ and the interior value a constant $3 \cdot 10^{-8} \mathrm{~S} / \mathrm{m}$ (Nicolai \& Grunewald, 2006).

\subsection{Timestep, Simulation Run Time and Initial Conditions}

The weather data provided by the NRC provides hourly average values for each condition. To capitalize on this level of resolution, an hourly timestep was chosen for the model. The initial conditions of the materials in the simulation were $20^{\circ} \mathrm{C}$ and $80 \%$ relative humidity in accordance with the ASHRAE Standard on moisture in buildings (ANSI/ASHRAE 160, 2016). The high initial humidity stems from the tendency for moisture to enter the wall during construction. The simulations were run for 25 consecutive years for the weather years 2013 and 2016. These years were chosen as 2013 was the wettest and 2016 was the driest of the provided weather years for each city. This is based on both the vapour pressure throughout the year and the amount of wind driven rain impacting the wall. Using the driest and wettest representative year provides the ability to determine a high and low range of lifespan predictions. Since the actual weather a VIP will see are likely a combination of the wet and dry representative years, the actual lifespan will fall within the predicted range.

\subsection{Model Discretization}

The discretization of a Delphin Hygrothermal model is done by dividing each material into an equal number of discrete volumes, with the volume size dependent on the total thickness of each material. The convergence of results at increasing mesh refinements was investigated to determine the required discretization scale. 
Mesh refinements of $4,6,8,10,12$, and 15 volumes per material were compared. Figure 5-4 shows the simulation results for relative humidity at the external VIP face for each refinement across a year.

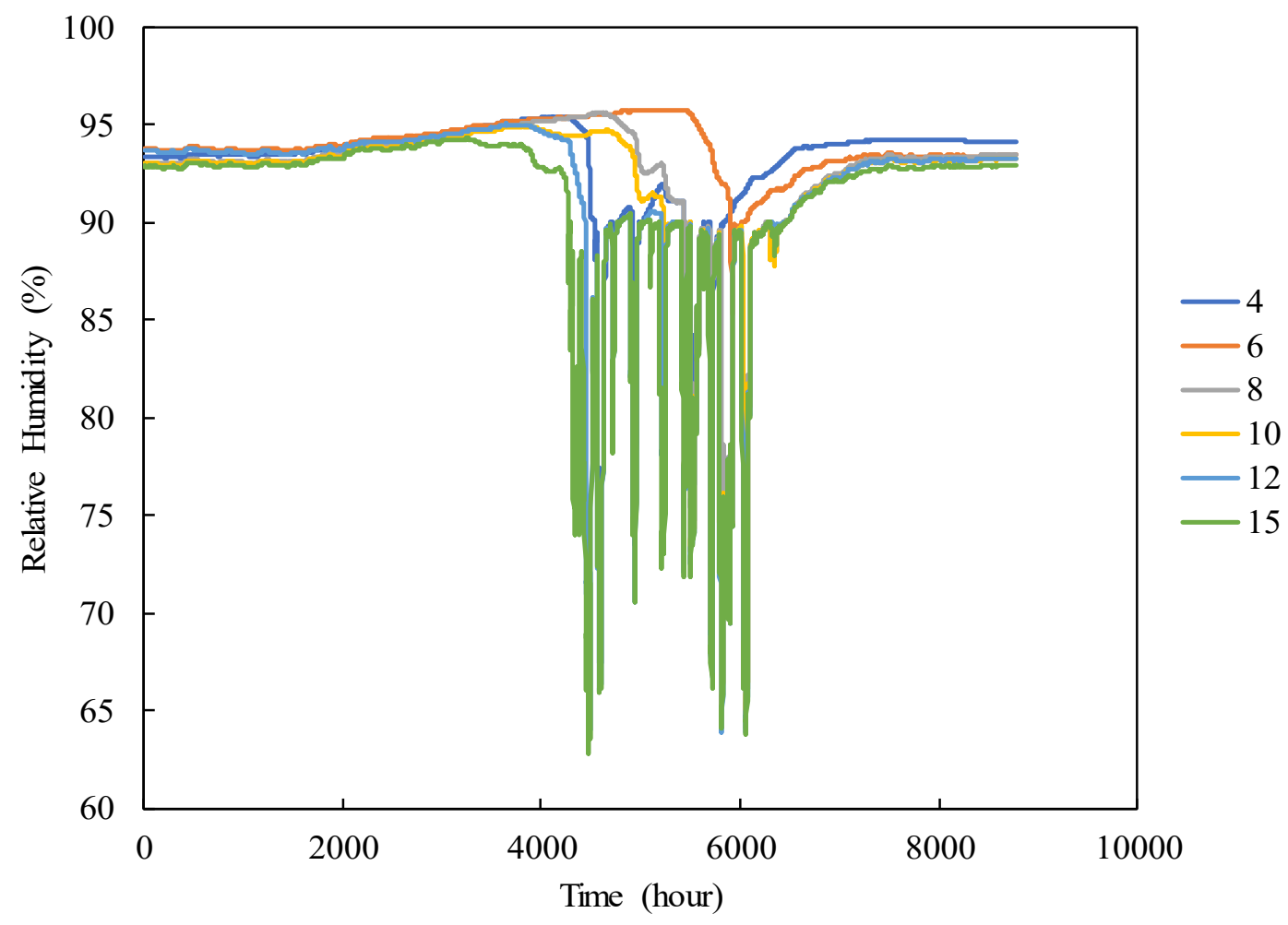

Figure 5-4: Model Discretization Results

The two finest refinements studied were 12 units per material and 15 units per material. The humidity at the VIP tracked very closely between these two levels of refinements, with an average difference of $0.8 \%$. There was a significant difference in computing time between a refinement of 12 units and 15 units. A 15 unit refinement took nearly ten times the computing time. Because of this large difference in computing time and small difference in results, a mesh refinement of 12 units was used. 


\subsection{Model Outputs}

The outputs of interest from this model are the temperature and relative humidity at the inner and exterior face of the VIP. In Delphin, outputs must be linked to a volume of the mesh. For this model, the final section of the EPS on either side of the VIP material was selected. This assumes that the VIP is in perfectly direct contact with the EPS on either side and the temperature and relative humidity the VIP is subject to is the temperature and relative humidity of the EPS in contact with the panel. The relative humidity and temperature at each face of the VIP will be used to calculate the WVTR into the VIP, which will then provide the moisture accumulation over the course of the VIP life. The moisture accumulation can then be used to determine the thermal performance of the VIP over time. 


\section{Chapter: Modelling Results and Lifespan Assessment}

This section will detail the simulation results and the analysis of these results to form a VIP lifespan prediction model. This consists of using the simulation results to determine the rate of moisture entry into the panel and the resultant increase in thermal conductivity, as well as extrapolating these values until a VIP failure criterion is met. This section will also discuss the key assumptions that were required for the lifespan model to be constructed.

\subsection{Hygrothermal Simulation Results}

The Delphin Hygrothermal model, discussed in Chapter 5, provided a method of determining the temperature and humidity at the VIP in a wall, depending on exterior climate conditions. Overall, 8 simulation cases were completed, consisting of the new and retrofit wall constructions and weather conditions for Niagara and Ottawa for years 2013 and 2016. The full graph shows the vapour pressure throughout the 25 -year simulation on both sides of the VIP. Vapour pressure is shown so that the data is reduced to one factor for comparisons as opposed to comparing across temperature and relative humidity.

The simulation results follow the same trend for each wall condition, city, and weather year. The temperature and relative humidity for the exterior of the VIP as well as the temperature at the interior face cycle with the weather each year. This yearly cycle repeats each year with nearly identical trend being repeated each year, as steady state is reached almost immediately. The relative humidity at the interior face of the VIP did not reach steady state until nearly 10 years into the simulation. This relative humidity at the interior face is initially high, due to the ASHRAE recommended value of $80 \%$. Along with this high initial value, the moisture has difficulty escaping from this center portion of the wall as it is contained by the low permeance VIP barrier and the PE 
vapour barrier. For each simulated case the humidity on the interior of the face gradually declines until approximately year 10 , when steady state is reached.

\subsection{Lifespan Model Development and Theory}

A mathematical model was developed to predict a lifespan of the VIP using the results from the hygrothermal simulation. Figure 6-1 shows the logic that was followed in the lifespan prediction model. The variable required to connect the external conditions to the thermal performance of the VIP is the water content of the panel. In order to determine this and calculate the theoretical drop in thermal performance, the logic flow shown in Figure 6-1 was developed into a mathematical model.

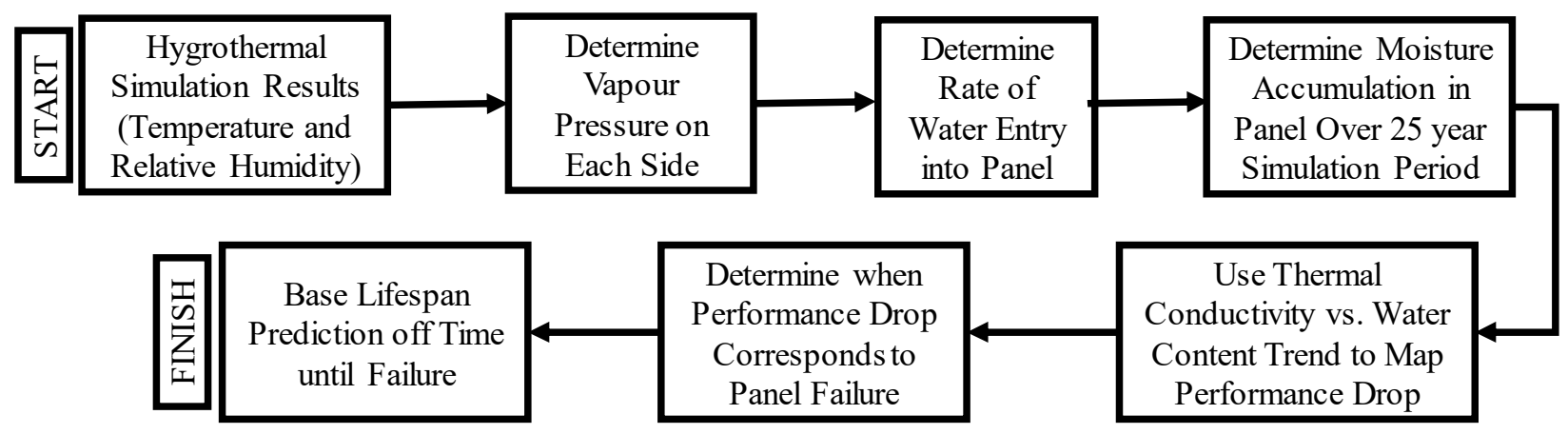

Figure 6-1: Lifespan Predication Steps

The inputs to the mathematical model were the temperature and relative humidity at the interior and exterior face of the VIP. Using this data, the vapour pressure at each face was determined. Next, the rate of water transfer into the panels was determined and integrated, providing the accumulation of moisture in the panels over time. The last step was correlating the moisture content to the thermal conductivity of the panel, using the results of this to estimate the lifespan of a VIP.

The approach to determining the amount of water entering the panels was based of the relationships provided by ASTM E96 for calculating the WVTR into dry cups. For this model, the 
VIP itself acts as the dry-cup prescribed by ASTM E96, this is possible because of the core material currently used in VIPs, fumed silica. Fumed silica itself is a desiccant and absorbs any moisture in the surrounding air, functioning as a drying agent (Baetens, et al., 2010). This property of the core material provides the assumption that the inside of the VIP remains at $0 \%$ throughout the length of the test (zero vapour pressure), the same assumption used for the interior cup conditions in ASTM E96. The vapour pressures were approximated using the hourly temperature and relative humidity provided by the simulation results and Equation (10). The trend shown in Figure 4-3 was utilized to determine the WVTR at each hour throughout the entire 25-year dataset. This trend relationship is shown by Equation (12).

$$
\text { WVTR }=\left(3.5 \cdot 10^{-6}\right) \cdot\left(P_{\text {Exterior }}-P_{\text {Core }}\right)
$$

Since the interior of the VIP remains at $0 \%$ throughout its life, Equation (12) reduces to Equation (13).

$$
\operatorname{WVTR}=\left(3.5 \cdot 10^{-6}\right) \cdot\left(P_{\text {Exterior }}\right)
$$

where $W V T R$ is the water vapour transmission rate of moisture into the panel, in $\mathrm{g} / \mathrm{m}^{2}$ hour and $P_{\text {Exterior }}$ is the vapour pressure on the outside of the VIP, in Pascals. The latter is calculated using Equation (10) from Chapter 4. This was calculated for both the interior and exterior face of the VIP. Using the hourly WVTR, the amount of moisture entering the panels every hour throughout the year was calculated using Equation (14).

$$
X_{W}=W V T R \cdot t \cdot A
$$

where $X_{\mathrm{W}}$ represents the total moisture increase of the VIP core in one hour, in grams. WVTR is the water vapour transmission rate across the hour in $\mathrm{g} / \mathrm{m}^{2}$ hour, $t$ is the timestep, equal to one hour for this case, and $A$ is the area of the VIP that is exposed to the conditions. The VIP used for this analysis was assumed to be $1 \mathrm{~m} \times 1 \mathrm{~m} \times 0.0254 \mathrm{~m}$, where one face and exactly half of the total 
surface area of the panel is subject to the exterior and the other half to the interior conditions. The accumulation of water in the panel in grams was converted to percentage of total panel mass, this was done by utilizing the core density of fumed silica, provided by Kevothermal Insulation as $180 \mathrm{~kg} / \mathrm{m}^{3}$ (Kevothermal, 2010).

The next step to predict the lifespan of the VIP was to relate the water content to the thermal conductivity of the VIP. This was done by using the relationship shown in Equation (6) in Chapter 2, the equation as it was used in this model is provided by Equation 15.

$$
\lambda\left(X_{\mathrm{w}}\right)=\left(0.0038+\left(0.5 \cdot 10^{-3} * X_{\mathrm{W}}\right)\right) \frac{\mathrm{W}}{\mathrm{m} \cdot \mathrm{K}}
$$

where $X_{\mathrm{W}}$ is the percent mass of moisture in the panel and $\lambda$ is the thermal conductivity of the panel at the given moisture content. The initial thermal conductivity at the center-of-panel was taken as $0.0038 \mathrm{~W} / \mathrm{m} \cdot \mathrm{K}$, the rated conductivity of Kevothermal VIPs (Kevothermal, 2010). This provided a prediction trend of the thermal conductivity of the panel over a period of time in use in a known climate. This prediction was based on the failure criteria discussed in Chapter 2, that when the VIPs thermal conductivity has doubled from its initial value the panel is deemed to have failed. For this study, an aged thermal conductivity of $0.0076 \mathrm{~W} / \mathrm{m} \cdot \mathrm{K}$ represents a failed VIP. Equation 16 shows the relationship that was used to search for the failed lifetime.

$$
\lambda\left(t_{\text {Failed }}\right) \geq 0.0076 \frac{\mathrm{W}}{\mathrm{m} \cdot \mathrm{K}}
$$

where $t_{\text {Failed }}$ represented the time, in hours, when the thermal conductivity doubles from the initial value of $0.0038 \mathrm{~W} / \mathrm{m} \cdot \mathrm{K}$ to $0.0076 \mathrm{~W} / \mathrm{m} \cdot \mathrm{K}$. The lifespan prediction provides a lifespan range with an associated uncertainty. As previously stated, the range is based on simulations using a representative dry year (2016), which provides a longer VIP lifespan and a representative wet/humid year (2013), which shows a shorter VIP lifespan. The uncertainty was based on the 
random and experimental error present in the measurement of WVTR. This error is represented in Figure 4-3 by the error bars present on the experimental data points.

\subsection{Lifespan Model Results}

This section will provide the results of the VIP lifespan assessment determined using the process detailed in Section 6.2. The thermal conductivity of a VIP over the length of the 25 year simulation is provided for Ottawa weather in Figure 6-2 and Figure 6-3 and for the Niagara climate in Figure 6-4 and Figure 6-5. Each figure shows the predicted thermal conductivity of the VIP installed in the new construction wall and the retrofit wall for a given representative year and climate location. The trend begins at the dry center-of-panel thermal conductivity of 0.0038 $\mathrm{W} / \mathrm{m} \cdot \mathrm{K}$. Additionally, the uncertainty on the thermal conductivity is shown by the dotted lines in each graph, based on the error from measuring the WVTR of VIP foils.

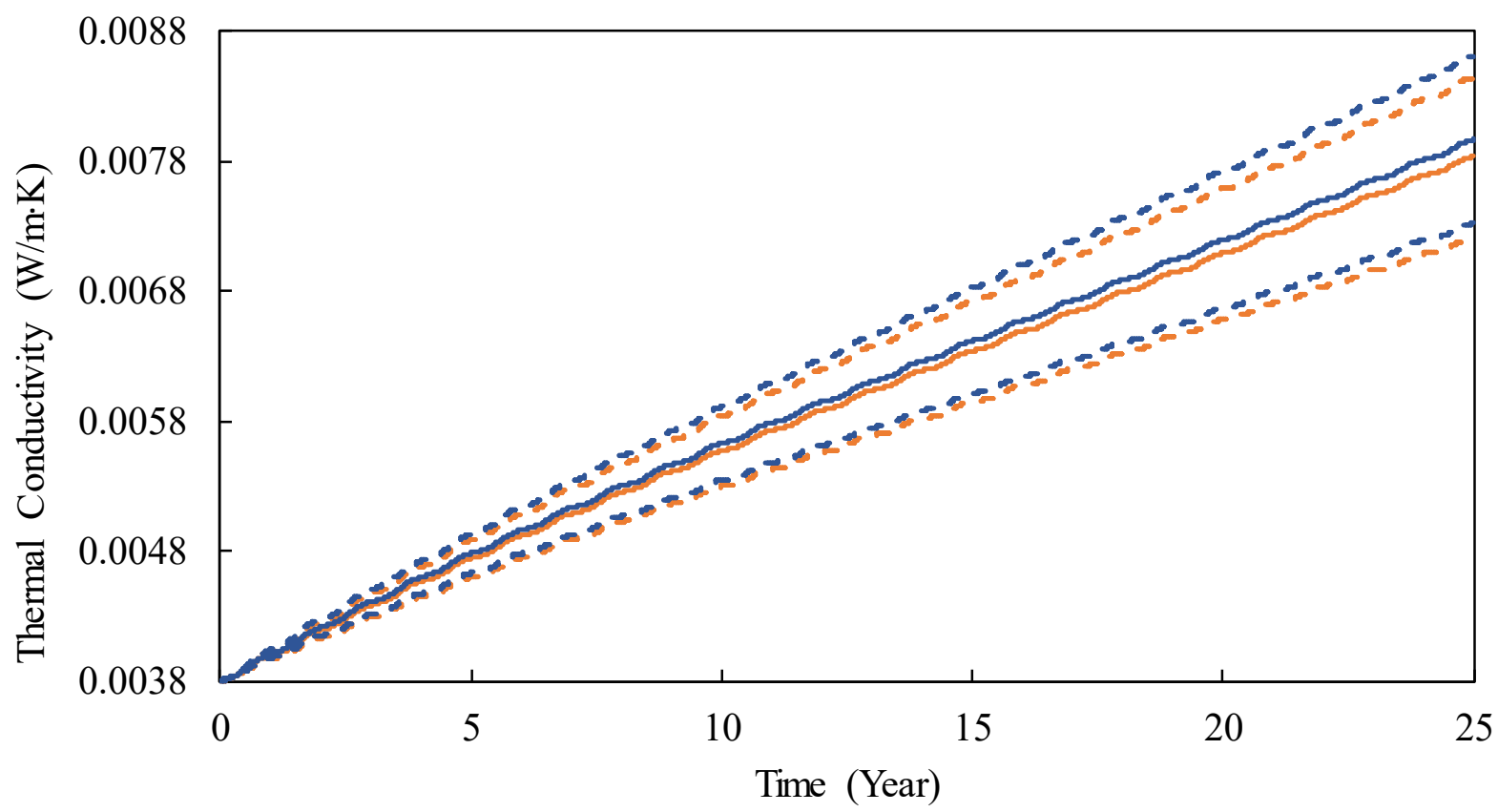

- New Construction - Retrofit Construction

Figure 6-2: Ottawa 2016 Lifespan Performance 


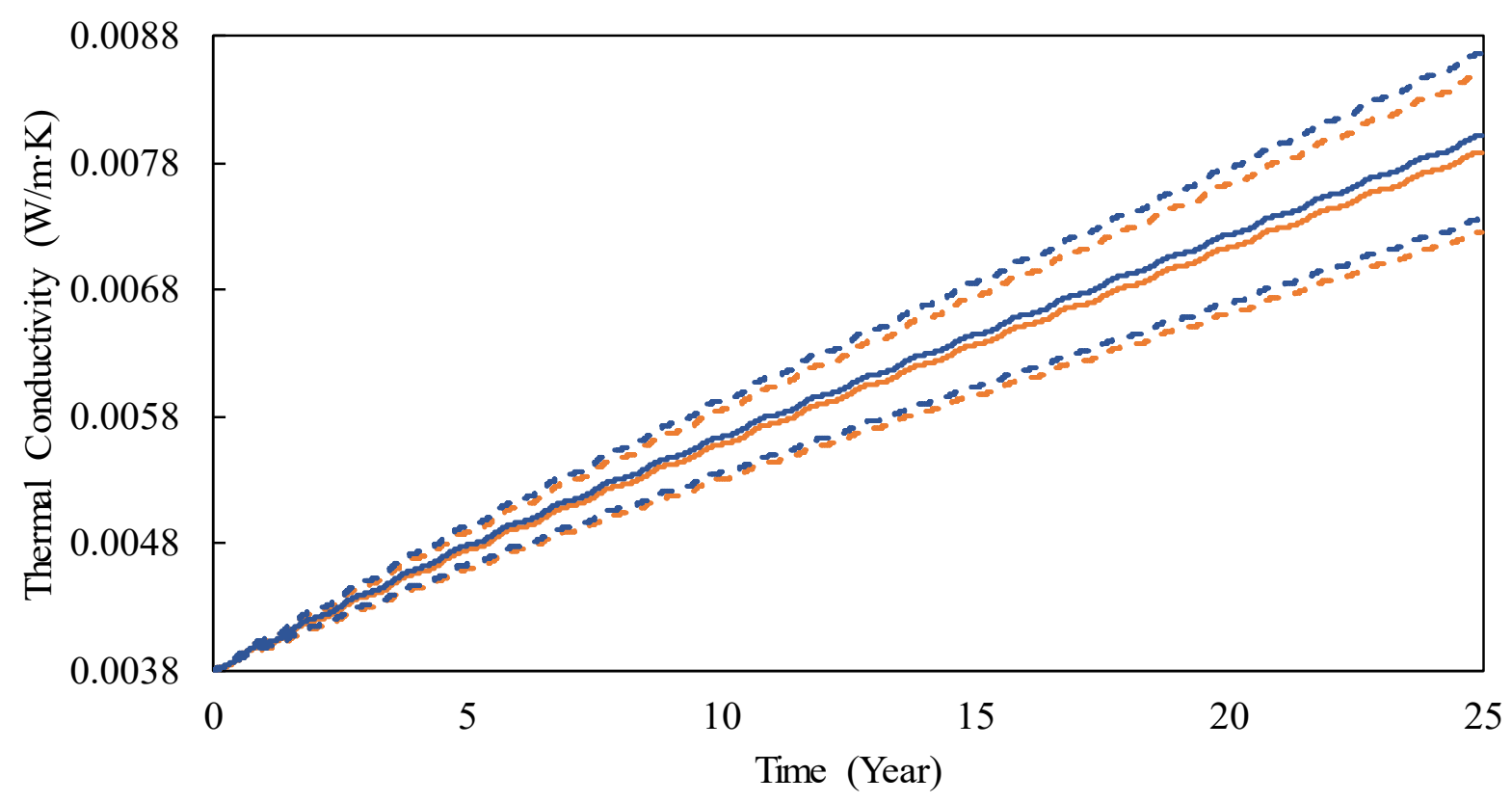

- New Construction - Retrofit Construction

Figure 6-3: Ottawa 2013 Lifespan Performance

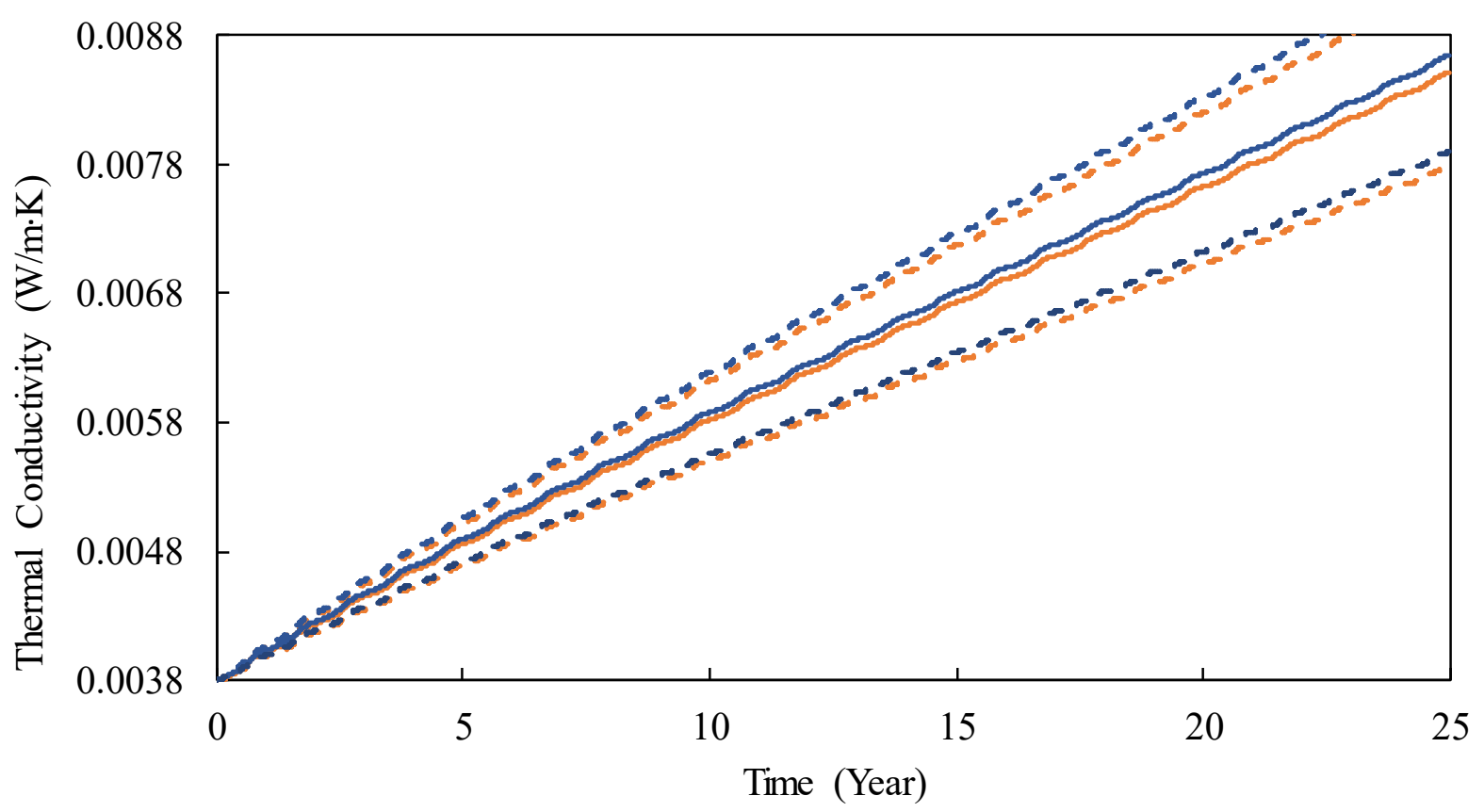

— New Construction — Retrofit Construction

Figure 6-4: Niagara 2016 Lifespan Performance 


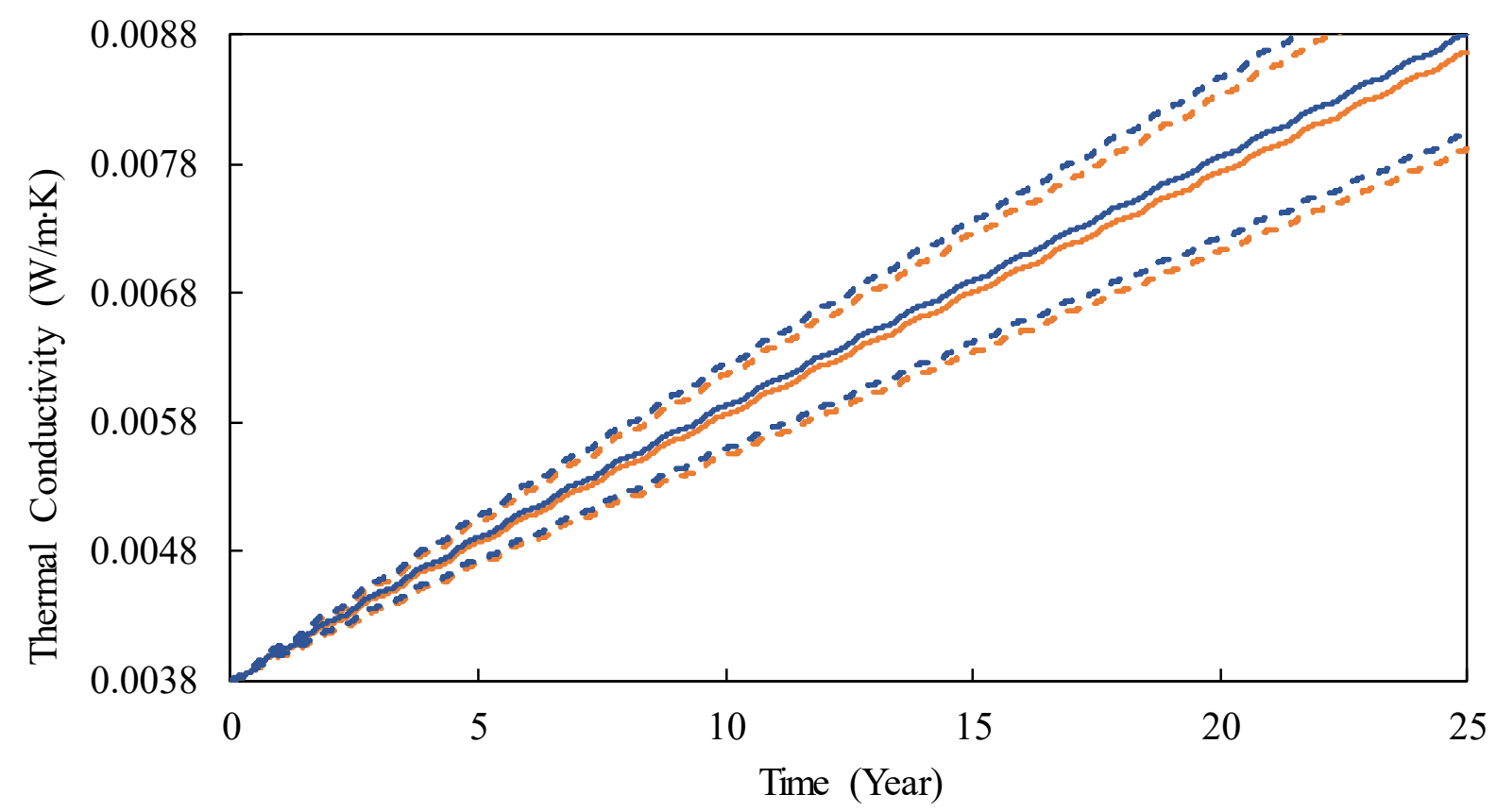

- New Construction — Retrofit Construction

Figure 6-5: Niagara 2013 Lifespan Performance

The trend of thermal conductivity over the 25 -year simulation provides the ability to search the line to determine the time at which the failure criteria from Equation (16) is satisfied. This was used to state the lifespan for each case, with a low-end lifespan based on the wet weather year (2013) and the high end based on the dry weather year (2016). For the Ottawa climate, in a retrofit construction the VIP predicted lifespan is 22.4 to 22.7 years, while for the new construction case the predicted lifespan is 23.2 to 23.5 years. For the more humid climate in Niagara, the VIP lifespan is predicted to be 18.6 to 19.4 and 19.4 to 19.8 years for the retrofit and new constructions, respectively. Figure 6-6 shows the results for each simulated case. These results are shown in Table 11. 


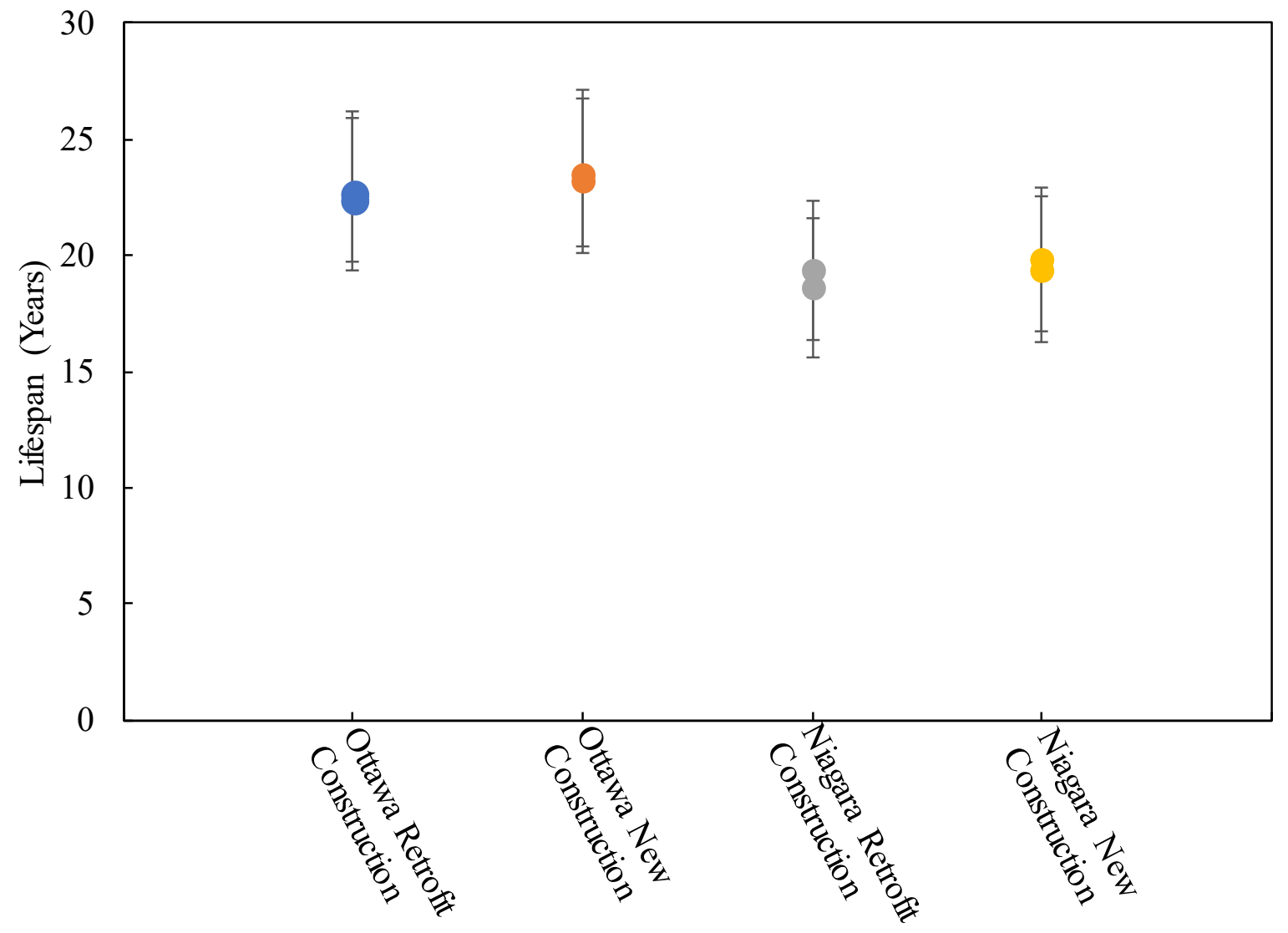

Figure 6-6: Predicted VIP Lifespans

Table 11: Predicted VIP Lifespans

\begin{tabular}{|l|l|l|l|l|}
\hline \multirow{2}{*}{} & \multicolumn{3}{|l|}{ Predicted Lifespan (Years) } \\
\cline { 2 - 5 } & \multicolumn{2}{|l|}{ Retrofit Construction } & \multicolumn{2}{l|}{ New Construction } \\
\cline { 2 - 5 } & $\begin{array}{l}\text { Wet Year } \\
(2013)\end{array}$ & $\begin{array}{l}\text { Dry Year } \\
(2016)\end{array}$ & $\begin{array}{l}\text { Wet Year } \\
(2013)\end{array}$ & $\begin{array}{l}\text { Dry Year } \\
(2016)\end{array}$ \\
\hline Ottawa Climate & $22.4 \pm 3.5$ & $22.7 \pm 3.5$ & $23.2 \pm 3.6$ & $23.5 \pm 3.6$ \\
\hline Niagara Climate & $18.6 \pm 2.9$ & $19.4 \pm 3.0$ & $19.4 \pm 3.0$ & $19.8 \pm 3.1$ \\
\hline
\end{tabular}

These results show that the model performed as expected, with higher humidity weather proving to reduce the lifespan of VIP panels. 


\subsection{Validation of Assumptions}

The mathematical model created for the purpose of predicting VIP lifespan, detailed in Section 6.2, was based on two significant assumptions. Firstly, that the internal core of the VIP remained at $0 \% \mathrm{RH}$ throughout the length of its simulated life. Secondly, the VIP thermal conductivity in the simulated model remained constant for the entire 25 -year test, it was assumed that the changing thermal conductivity had negligible effects on the conditions at the VIP.

The origin of the first assumption, as stated in Section 6.2, comes from ASTM E96. In this standard, it states that the interior of the dry cup is assumed to be $0 \% \mathrm{RH}$ for the duration of the tests. The standard states that the test and its underlying theory are no longer valid once the mass of the system has increased $10 \%$ from its initial value. Because of this, the assumption of $0 \% \mathrm{RH}$ inside the panel is valid based on ASTM E96 until the panel mass increase is greater than 10\% of the initial mass. Using Equation (15) and Equation (16), the relationship for thermal conductivity and water content, respectively, the water content is known when the failure criteria is satisfied. For this case, the water content of the panel was $7.6 \%$ (by mass) at the time of failure. For the entire simulated time, 25 years, the water content only reached $8.5 \%$ (by mass). This validates the assumption that the VIP interior remains at $0 \%$ relative humidity is correct for the lifespan of the panel, based of ASTM E96.

In the 25-year simulation, a constant value for the VIP thermal conductivity was used, even though the thermal conductivity is gradually increasing due to moisture ingress into the panels. This was done to simplify the simulations by not requiring an iterative step to readjust the thermal conductivity constantly. This was based on the assumption that the relative humidity in the wall is insensitive to the changes in thermal conductivity seen by the VIP over its life. To justify this assumption, a sensitivity analysis check was completed. This was completed by running the 25 
year simulation with the thermal conductivity doubled to the failure criteria value, $0.0076 \mathrm{~W} / \mathrm{m} \cdot \mathrm{K}$ and estimating the lifespan based on these results. For the Ottawa 2016 retrofit case, the predicted lifespan using a doubled thermal conductivity value was $23.1 \pm 3.6$ years. This is only a $1.7 \%$ difference from the original lifespan prediction of $23.5 \pm 3.6$ years. This validated the assumption that the lifespan is insensitive to changes in thermal conductivity. The dominating uncertainty in the lifespan prediction stems from the WVTR measured for the foils, and not the thermal conductivity of the VIP in the wall.

In summary, the moisture accumulation in the VIP in each case was calculated for the 25 year simulation based on the temperature and relative humidity at each VIP face with the WVTR trend of MF2 foils dictating the rate of moisture entry into the panel. The thermal conductivity of the VIP over the life was determined based on the moisture accumulation in the panel. The lifespan of the VIP was determined based on the thermal performance trend, when the thermal conductivity doubled from $0.0036 \mathrm{~W} / \mathrm{m} \cdot \mathrm{K}$ to $0.0078 \mathrm{~W} / \mathrm{m} \cdot \mathrm{K}$ the panel was deemed failed. The lifespan predictions are provided in Table 11. 


\section{Chapter: Discussion}

The purpose of this section is to discuss the results and key findings related to the results. This includes results and findings from the experimental work, simulation results, and results from the lifespan prediction model. The discussion section will cover two main topics. Firstly, discussion of the lifespan prediction results. This includes the difference between lifespans of different cases as well as the acceptability of these results and a comparison of these results to previously published lifespan predictions. The second portion of the discussion will focus on potential methods to improving the lifespan of VIPs.

\subsection{Results}

This section will discuss and provide insight on the results retrieved from the lifespan prediction model. From Table 11, the results are provided for each wall construction, for wet and dry representative years. It can be assumed that over the life of the VIP the weather would be a combined average of dry and wet weather years. The dry and wet representative years only have a minor impact on the result for the predicted lifespan. For Ottawa, there was only a 0.3 -year difference between the dry and wet years. For Niagara there was a 0.8- and 0.4-year difference between the dry and wet years, respectively. This again reinforces that the uncertainty on the lifespan is more related to the measured WVTR of the foil and not the exact weather. Averaging the two representative weather years provides a single lifespan value for VIPs. This single lifespan value is provided in Table 12. 
Table 12: Predicted VIP Lifespan

\begin{tabular}{|l|l|l|}
\hline \multirow{2}{*}{ Ottawa Climate } & \multicolumn{2}{|l|}{ Predicted Lifespan (Years) } \\
\cline { 2 - 3 } & Retrofit Construction & New Construction \\
\hline Niagara Climate & $22.6 \pm 3.5$ & $23.4 \pm 3.6$ \\
\hline
\end{tabular}

The first factor to compare on is the difference between the retrofit type construction and the new construction. The two differences between these constructions is the presence of a capillary break (air gap) in the new construction and a cavity insulation layer based on a $2 \times 6$ construction rather than $2 \times 4$ in the retrofit construction. The difference in the lifespan prediction between the two wall constructions was 0.8 years ( $3.4 \%$ difference) and 0.6 year ( $3.1 \%$ difference) for Ottawa and Niagara, respectively. This difference is well within the uncertainty range caused by the WVTR measurements of the foils. This small difference shows that the capillary gap has a relatively minor effect on the vapour pressure at the face of the VIP. This could be attributed to the water entry consideration in the model, and that the presences of liquid water ( $1 \%$ of WDR) is the main contributor to moisture on the exterior face of the VIP, and that the capillary break does not adequately ventilate this moisture.

The literature review of this document provided a summary of predicted VIP lifespans. These predictions range from 30 to 50 years, generally falling in the low 30 -year range. This is more than $25 \%$ longer than the predicted lifespans in this model. The aging mechanisms used in this simulation was similar in approach to the mechanisms used by previous publishers. These generally consisted of obtaining the moisture transmissions rates, and gas transmission rates in certain scenarios. The previously published predictions took these measured rates and extrapolated them into a predicted lifespan, however, most predictions were not clear in how this extrapolation 
was completed. The difference in predicted lifespan between this work and previously published simulations is due to the use of detailed weather data and hygrothermal modelling. The use of actual weather data along with hygrothermal modelling provided a mechanism to determine the actual conditions the VIP is subjected to when installed in the wall, something the published predictions have seemingly failed to do. This includes initial conditions, wind-driven rain, and liquid water entry in the wall. The use of these moisture sources with hygrothermal modelling provided this prediction with confidence in the conditions the VIP is subject to over the course of its life. This results in the shorter predicted lifespan as the high levels of moisture and vapour pressure at the VIP were considered in the prediction. Proving that previous VIP lifespan predictions underestimated the severity of the vapour pressure gradients across the VIP foil.

In addition to this, over half of the moisture ingress into panels comes from the interior face of the panel. The moisture gain through each face is shown in Figure 7-1 for the Ottawa wet year (2013) new and retrofit construction cases for the duration of the 25 year simulation. 


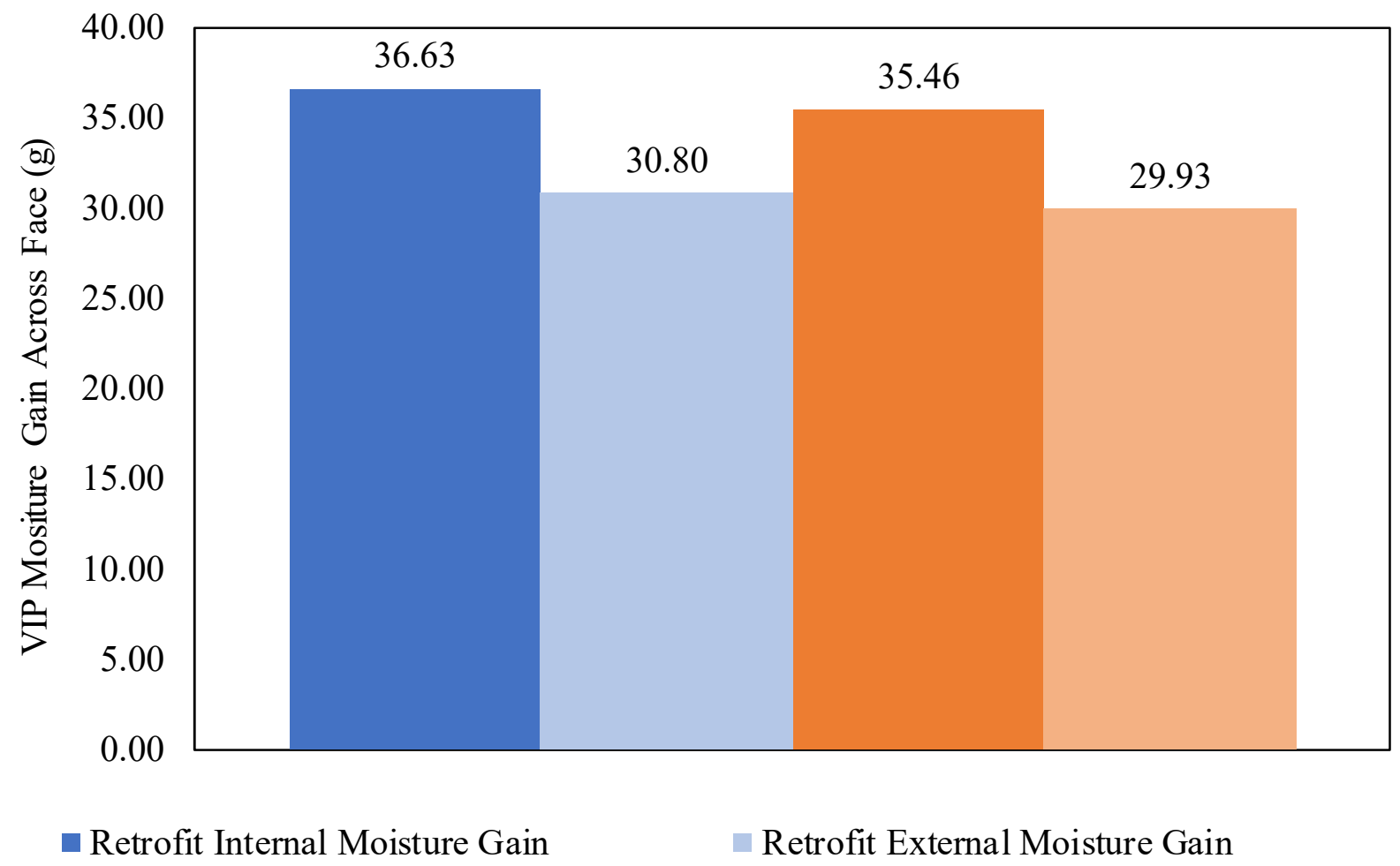

- New Construction Internal Mositure Gain $\quad$ New Construction External Mositure Gain

Figure 7-1: Ottawa Wet Year (2013) Panel Face Moisture Ingress Amounts

The higher amount of moisture entering the panel through the interior face is due to the warmer temperatures present on the inside of the wall, resulting in higher vapour pressure gradients driving higher amounts of moisture into the panel. This shows the sensitivity of the panel life to the internal wall conditions, which limits the effect of the capillary gap on the predicted lifespan. The conditions on the interior side of the face are predominately influenced by the initial condition, which was set to $80 \%$ relative humidity as per ASHRAE guidelines.

The building construction used in this research is based on current guidelines for building constructions in Canada with VIPs added to the exterior insulation layer. This was chosen to represent a standard building construction. VIPs are high barrier materials, acting as vapour barriers themselves. Installing VIPs on the exterior while a vapour barrier is installed on the interior 
creates a two-barrier effect where moisture has the potential to become captured between the two barrier layers. This is a concern as moisture caught in the wall without a method of escape or ventilation has the potential to produce mould within the wall. However, designers can avoid this problem. Double vapour barrier walls do exist in numerous instances outside of VIP constructions. Closed cell rigid insulation with internal vapour barriers also act as a two-barrier construction. In order to mitigate mould growth the construction must be nearly completely air-tight. This prevents bulk vapour transmission through air and should greatly reduce the likelihood of mould growth (Lstiburek, 2016). However, investigation should be made into whether a VIP assembly truly acts as a vapour barrier. Gaps between individual VIPs may provide the necessary pathways for vapour transport such that the VIP layer cannot be defined as a vapour barrier.

This modelling considered the wind drive rain loads as well as moisture entry caused by the wind driven rain loads. These were important to include, as previously stated, because they are the biggest source of bulk moisture in building walls. The moisture entry source was assumed to be $1 \%$ of wind driven rain and to enter the wall through the exterior of the fibreboard siding. As the wind driven rain impacts the fibreboard siding, the moisture entry due to rain is initially must pass through defects in the siding. Because of this, the moisture source was stated to enter through the rear of the siding. The impact on VIP lifespans that varying quantities and varying locations of the moisture source was not investigated. However, the minor differences in VIP lifespan between the retrofit and new construction walls show that the location of water entry likely do not have a large impact on VIP life. It is not likely that water would enter on the interior of the VIP layer, the 
materials on the exterior side of the VIP are water permeable. This likely results in the exact location of water entry not significantly affecting conditions at the VIP.

The predicted lifespan of VIPs must be considered in terms of minimum acceptable lifespan for building materials. The Canadian Mortgage and Housing Corporation (CMHC) states that building owners should assume between a 40 to 100-year service life for buildings (Canada Mortgage and Housing Corporation, 2007). This would result in 2 to 5 new sets of VIPs required throughout the life of a building. CMHC also provides minimum acceptable component life for different building components. Although, VIP panels are a new material type and do not clearly fall under a specific category. There are two categories presented by CMHC where VIPs could fall under. For the construction studied in this work the VIPs where integrated into an exterior insulation layer of a wood-framed construction. For this construction type, the VIPs are categorized as "Wall Sheathing and Exterior Finishes". This category explicitly includes continuous exterior insulation layers. CMHC states that for this category a minimum service life of 30 years is anticipated and has been measured by field studies (Canada Mortgage and Housing Corporation, 2013). The predicted VIP lifespans are only approximately $2 / 3$ of the recommended minimum service life for materials in this category. It is important to note that there is no consensus on the service life of building materials. The Government of British Columbia provides a Residential Tenancy Policy Guideline which includes guidelines for the Useful Life of Building Elements. Under these guidelines, the useful life of building insulation is listed as 20 years (Government of British Columbia, 2012). This may be lower than the life required by CMHC as considerations were taken into British Columbia's higher humidity climate aging the materials faster. The minimum life provided by $\mathrm{CMHC}$ is a single value developed across Canada has been formulated and tested while considering lower humidity climates in Canada. Under this definition 
the predicted VIP lifespan for the Ottawa climate are suitable, as they last longer that the 20-year service life requirements. For Niagara, the VIP lifespans are slightly below the 20 -year service life, but close enough that the predicted lifespan could be considered suitable while considering the range of WVTR measurements and the associated range of lifespans.

FannieMae ${ }^{\circledR}$ provides a third definition for useful life of building insulation. This pertains to insulation that is integral in the wall construction. The estimated useful life is greater than or equal to 50 years for this construction type, or equal to the useful life of the building itself (FannieMae, 2014). The VIPs are predicted to fail in less than half of this useful life requirement. For this study the VIPs are not installed as an integral part of the wall structure allowing the possibility of replacement, so not meeting the FannieMae ${ }^{\circledR}$ useful life of 50 years is not a concern. However, it shows that VIPs should be incorporated into wall constructions in a way that allows replacement at time intervals appropriate for the VIP life. This would consist of installing the VIPs such that they are defined as part of the exterior insulation layer. This installation method would reduce the level of invasiveness required to replace the VIPs, reducing the cost and encouraging the replacement of VIPs.

An important consideration when discussing the installation and replacement of VIPs is the cost. VIPs have substantially higher upfront costs, including material and installation costs than conventional insulation. Based on the lifespan of VIPs, numerous replacements would have to be done throughout the life of a building. This requires building owners to be responsible for the high costs of VIP installation numerous times throughout the life of the building. For VIPs to be feasible the benefits from increasing the thermal performance of the building must outweigh the costs associated with the installation and replacement of the panels. The installation costs of VIPs greatly depend on geographical location as well the construction type and the method of integrating the 
VIPs into the wall. Installation costs per square meter of wall are shown in Table 13. These costs are for $30 \mathrm{~mm}$ and $20 \mathrm{~mm}$ thick VIPs as well as conventional insulation installed as the exterior insulation layer in a concrete construction house.

Table 13: Insulation Installation Costs (Cho, Hong, \& Seo, 2014)

\begin{tabular}{|l|l|}
\hline & Installation Cost \\
\hline Standard Polystyrene Insulation & $8 \mathrm{US} \$ / \mathrm{m}^{2}$ \\
\hline $20 \mathrm{~mm}$ VIP & $56 \mathrm{US} \$ / \mathrm{m}^{2}$ \\
\hline $30 \mathrm{~mm}$ VIP & $84.5 \mathrm{US} \$ / \mathrm{m}^{2}$ \\
\hline
\end{tabular}

Based on these installation costs, VIPs are 7 to 11 times more costly to install in the external insulation layer than conventional insulation. This means that each installation of VIPs in a house must reduce heating loads of the building to a point where these high installation costs are recuperated. Additionally, these costs must be recuperated while considering the declining thermal performance of VIPs as they age, something not seen to such extremes in conventional insulation. This is because conventional insulation does not experience significant declines in thermal conductivity over time. The payback period for VIPs must be within their lifespans, which are relatively short in comparison to minimum useful life values.

It is likely that in climates similar to those tested in this research, Ottawa and Niagara, the VIPs would not reach the payback period within their lifespan, however this is greatly dependent on energy cost and future weather conditions. VIPS provide benefits additional to increasing the thermal performance of a building, considering these additional benefits can help increase economic feasibility. An example of an additional benefit being provided by VIPs would be in areas where land is scarce and very costly. VIPs would provide value in such a scenario by 
reducing the footprint of the building wall required to achieve the desired thermal performance. Reducing the building footprint would increase the amount of useful floor space within the building itself without requiring additional property space. Incorporating this additional usable square footage into the economic benefit of VIPs has the potential to help the costs be recuperated faster than the panels fail.

Another important note when discussing the predicted lifespan of panels is that it is assumed that each panel in the wall reaches its predicted life, i.e. that every panel reaches failure based on long-term moisture accumulation and the resultant drop in thermal performance. What this does not consider is premature panel failure. Premature panel failure can be caused by many factors including manufacturing defects, improper installation, or puncturing of the foil. From Chapter 2, it has been recorded that VIPs installed in buildings experience observable premature failure of several panels. It is unlikely that panels that fail prematurely will be replaced before the end of life for the entire batch of installed panels. It would be difficult to discover and locate a failed panel without the use of a thermal camera to investigate the temperature profiles across the wall. Additionally, the cost to enter a building envelope to remove a single panel is likely not economical feasible. The result of this is that the economic benefit of VIPs must also be adjusted to account for the inevitable premature failure of a certain amount of the installed panels. Thus, reducing the overall thermal performance of the wall and increasing heating loads required.

The VIP lifespans predicted in this work were approximately 20 years (depending on climate) provide owners with the foresight of replacement timelines and requirements. This knowledge provides owners with the ability to mitigate the future cost and challenges of replacing VIPs. The focus of mitigating cost should be in the method of VIP integration and location in the envelope. The VIPs must be installed as part of the exterior insulation layer. As previously stated, 
this is because the minimum required useful life of exterior insulation layers is in line with the predicted lifespan of VIPs. Knowing that the VIPs must be replaced provides the ability to tailor the construction of the wall, specifically the layers exterior to the VIP and the materials to make replacement easier and less costly. This mostly pertains to the material choice for the exterior façade. The façade should be constructed of a more modular material that would be easier and relatively non-destructive to remove and replace. Façade materials that would make the VIP replacement procedure more difficult and costlier would be materials such as brick masonry and stucco. Both brick masonry and stucco would require destructive removal to gain access the exterior insulation layer. As well, brick masonry and siding are both costlier and labour intensive to install. These additional costs would be seen at each reinstallation of panels. An ideal façade system for VIPs may be a modular panel that integrates the exterior envelope components together, a conceptual example of such a façade is shown in Figure 7-2. This conceptual modular panel consists of a wood sheathing to which EPS with a single large VIP is encased. Next, there is a layer of sheathing with an exterior facing air barrier. Finally, there are 0.75 inch vertical strapping to form a capillary break before the vinyl siding.

This modular panel would simplify the construction of envelopes with VIPs as the entire panel assembly would be installed and removed as required, as the entire panel simply attaches to the building structure. A modular panel such as this would also mitigate against loses due to prematurely failed panels as the composite panel could be removed and replaced, where conventional building techniques would require more destructive and invasive work to access the panels. This modular VIP wall panel would also provide value to energy retrofit projects, where building envelopes are retrofitted with new additional layers of insulation. This panel would allow 
less invasive work to be done on existing building by removing the existing façade and insulation layer (if present) and installing this modular panel.

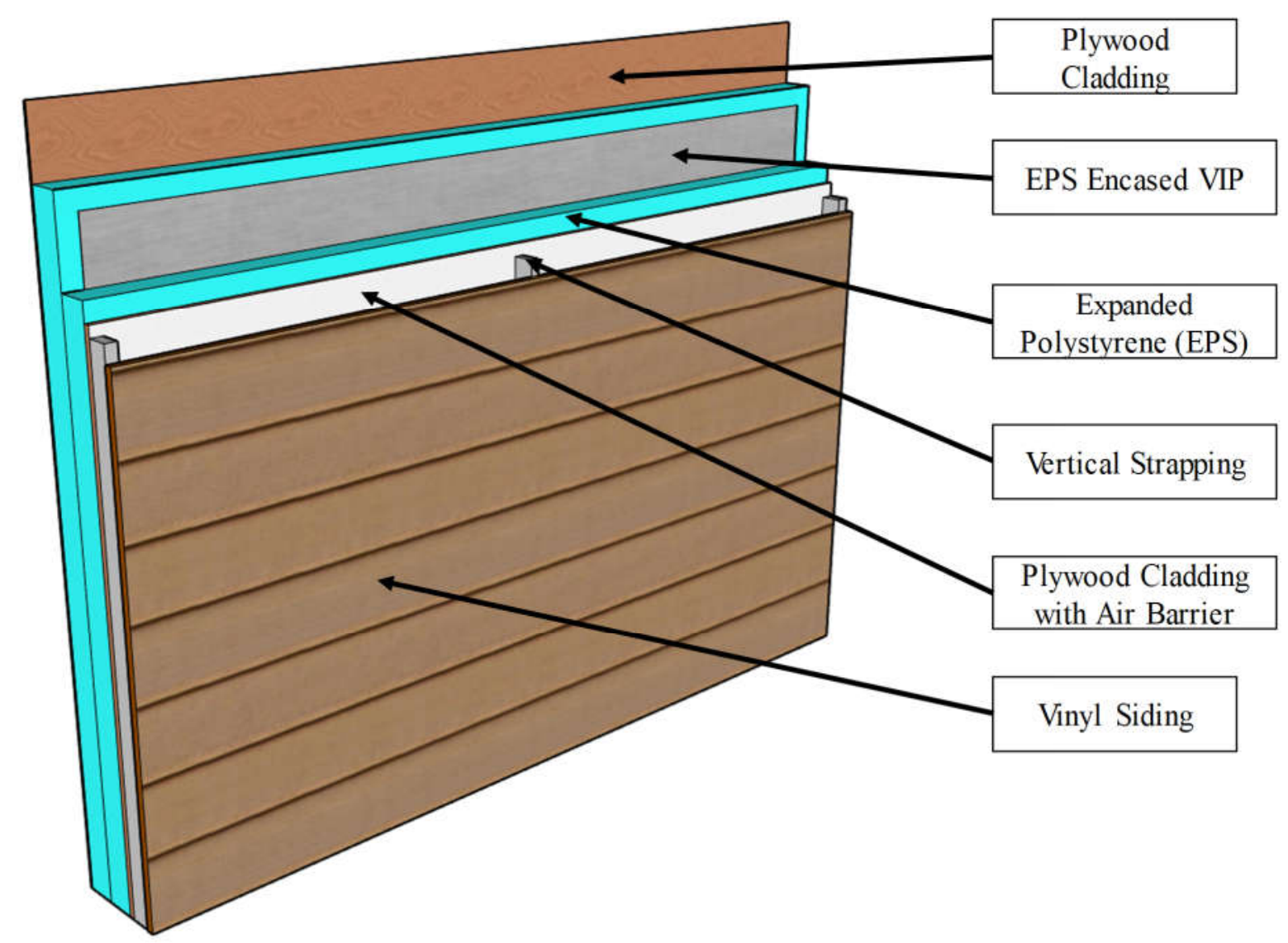

Figure 7-2: Conceptual Modular VIP Layer

The criteria for defining a VIP as failed is based on the doubling of the initial thermal conductivity, measured at the center of panel. The effective thermal conductivity of a VIP is much greater than this value. This is because the center of panel value does not account for panel-scale or building-scale thermal bridging effects. The effective thermal conductivity $\left(k_{\text {eff }}\right)$ represents the practical and achievable thermal conductivity of a body. For VIPs, the effective thermal conductivity accounts for the low conductivity center of panel along with the higher conductivity edges and foil of the panel, both of which are subject to thermal bridging effects. 
The effective thermal conductivity of the large $1 \mathrm{~m} \times 1 \mathrm{~m}$ VIP used in this analysis is, on average, 1.4 times greater than the center-of-panel conductivity (Ghazi et al., 2004). The composite R-value for a wall with an exterior insulation layer based on

Figure 7-2 and a standard $2 \times 6,24$ " OC wood studs cavity wall was calculated based on static thermal conductivity values for each material (National Research Council of Canada, 2013). Table 14 provides the effective R-value of a wall with for new VIPs, failed VIPs, and EPS.

Table 14: Comparison of VIP Effect on Wall Thermal Conductivity

\begin{tabular}{|l|l|l|l|}
\hline & VIP Wall - Initial & $\begin{array}{l}\text { VIP Wall -Failed } \\
\text { (Aged) }\end{array}$ & EPS \\
\hline $\begin{array}{l}\text { Wall Assembly R-Value } \\
\left(\mathrm{m}^{2} \mathrm{~K} / \mathrm{W}\right)\end{array}$ & 27.9 & 24.9 & 22.7 \\
\hline
\end{tabular}

This shows that for a wall containing VIPs the $\mathrm{R}$ value is $27.9 \mathrm{~m}^{2} \mathrm{~K} / \mathrm{W}$ initially and $24.9 \mathrm{~m}^{2} \mathrm{~K} / \mathrm{W}$ once the panel failure criteria has been satisfied. For an identical wall with conventional insulation in place of the VIPs the assembly thermal conductivity is $22.7 \mathrm{~m}^{2} \mathrm{~K} / \mathrm{W}$. This means that the wall with failed VIPs still has a 9.2\% greater R-value than conventional insulation. This demonstrates that while the VIPs are considered failed (based on moisture accumulation), the actual wall is still achieving high levels of insulations. The effective thermal conductivity of a failed (based on moisture accumulation) VIP is $0.0106 \mathrm{~W} / \mathrm{m} \cdot \mathrm{K}$, nearly three times greater than the standard thermal conductivity of EPS insulation. This shows that timelines for the replacement of VIPs may be more appropriately based on the minimum useful lifespan for external insulation layers. However, this holds less true as VIP size decreases. Smaller panels are more greatly affected by thermal bridging effects and will have a smaller positive impact on the effective R-value of a wall.

One of the most important considerations that this work demonstrates is the need for designers to acknowledge the decline in thermal performance that will occur to a wall containing 93 
VIPs. Table 14 shows that just between the beginning and end of life of a VIP the entire wall structure experiences over a $12 \%$ drop in R-value. This is a significant decline in the thermal performance of a building envelope and would increase the heating loads of the buildings. This shows that building designers must incorporate VIP lifespan assessments into HVAC sizing calculations. The designer must size the HVAC system to be capable of handling the heating load based not on the initial thermal performance of the wall but based on the future load. This means that the replacement schedule of VIPs must be in agreement with the HVAC sizing. As HVAC systems generally last 15-25 years, the HVAC system will last long enough to experience the increase in thermal loads due to the aging of VIPs. This increase in heating load could be addressed by resizing the HVAC system during periodic replacements to account for the new thermal performance of the envelop. Alternatively, it could be addressed by sizing the HVAC system to the future building thermal performance level, allowing the thermal performance "catch up" to the HVAC capabilities. The failed VIPs must be replaced prior to a point where the HVAC system is encroaching on not being able to handle the increasing load.

\subsection{Considerations to Increase VIP Lifespan}

This section will discuss methods that can be used to potentially increase the predicted life of VIPs. These methods are based on the aging mechanisms seen in the laboratory testing and modelling work. Two mechanisms of aging will be analyzed, the limiting of these mechanisms will work to increase VIP life: 1) Vapour pressure at the VIP faces and 2) Transfer of moisture through the foil into the panel. This work has shown that moisture transports into panels is 
connected to both the vapour pressure and the VIP foil materials, reducing the vapour pressure or the rate of transport across foils will work to increase VIP life.

The rate of moisture transport into the panels is directly connected to the vapour pressure at either face of the VIP. As vapour pressure is a combination of temperature and relative humidity, limiting either of which will reduce the vapour pressure. There are two methods that will be focused on to limit the vapour pressure experienced by the panel. Firstly, the location of the VIP in the wall can be moved manipulates so that the vapour pressures the VIP are subjected to are lower. Secondly, VIP use can be tailored to climates that have lower temperature and humidity, which will result in lower vapour pressure at the VIP.

Since vapour pressure increases with both temperature and relative humidity, lowering either will work to lower the vapour pressure. On a given cold day the temperature profile of the wall shows the temperature gradually increasing through the wall from the exterior to interior surfaces with significant increases in temperature occurring over each layer of insulation. Installing the VIP closer to the exterior face of the wall will help maintain lower temperatures at each face of the VIP. A small insulation layer on the exterior face of the VIP may be required to help protect the VIP. Locating the VIP in this position would make it essentially the first layer of insulation, providing the first increase in temperature across the wall. This means that the VIP would be subject to the lowest temperatures during heating days. Thus, lowering the vapour pressure seen by the panel, compared to placing the panel further into the wall, where prior insulation layers have increased the temperature and, in turn, increased the vapour pressure. However, placing VIPs as exterior as possible locates the VIPs closer to the wetting plane. Which is the area of the wall most affected by WDR and water entry. The reduction in moisture transport due to temperature 
decreases must outweigh the possibility of the wetting plane reaching the VIP for this placement to be beneficial.

Climatic conditions also have a significant impact on the lifespan of VIPs, for the Ottawa and Niagara climates investigated during this work there was over a $17 \%$ difference in the predicted VIP lifespans when subject to each city's climate. This is a combination of Niagara having higher temperatures, higher humidity, and more precipitation than Ottawa. Figure 7-3 shows the yearly average vapour pressure for several Canadian cities, based on 2016 Canadian Weather Year for Energy Calculation (CWEC) data. This shows the difference between average vapour pressures of cities. This metric can be used to determine the suitability of the city's climate to VIPs. A city with a higher average vapour pressure will results in shorter VIP lifespans. Figure 7-3 demonstrates that cities such as Vancouver, Toronto, Windsor, Niagara and Halifax have higher yearly vapour pressures which may result in short enough VIP lifespans to limit the economic feasibility of VIPs installed in these locations. Alternatively, Cities such as Edmonton, Winnipeg, Ottawa, and Montreal have much lower vapour pressures. The lower vapour pressure in these cities makes them more suitable for VIPs, increasing their lifespan and potential economic feasibility. 


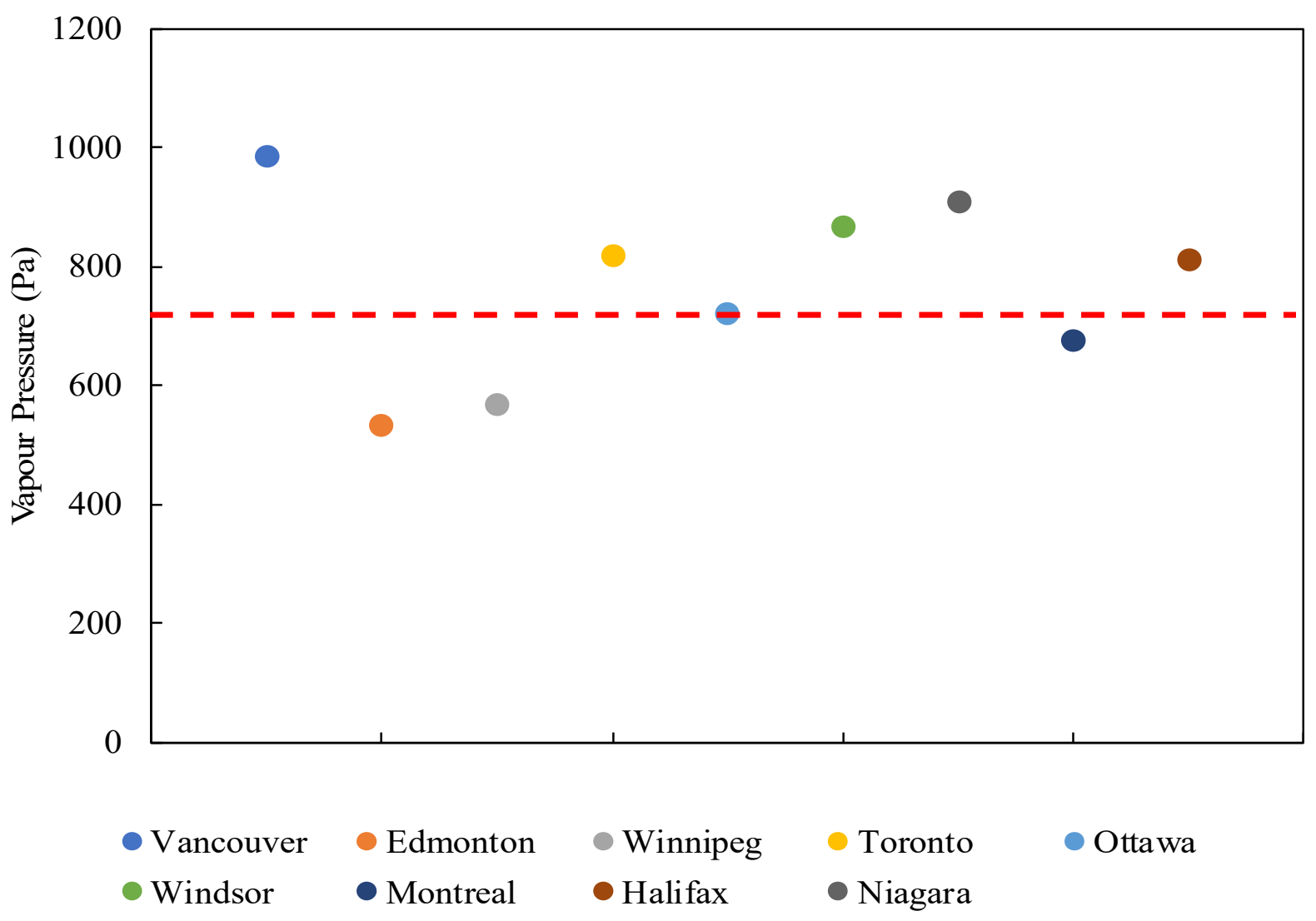

Figure 7-3: Yearly Average Vapour Pressure for Canadian Cities (CWEC, 2016)

This research focused on a single type of VIP foil, MF2. This is a multilayer foil consisting of two layers of metallized aluminum and several layers of polyethylene plastic. This type of foil has been in common use in VIPs because of the benefits for moisture transfer resistance and thermal bridging that MF2 foils provide. As previously stated in the literature review, foils with more metalized aluminum layers provide greater resistance to the transport of moisture. The greater number of aluminum layers mitigate the microdefects in the layers that provide pathways for moisture to travel through. However, greater numbers of aluminum layers increase thermal bridging through the VIP foil resulting in poorer thermal performance. This research has shown that a potential weakness of VIPs are the relatively low lifespans. Using a foil type with more aluminum layers, such as MF3 (three aluminum layers) or MF4 (four aluminum layers), may 
increase the lifespan to a more economical length. The additional layers of metallized aluminum provided by MF3 and MF4 reduce the pathways through pores and microdefects available for water molecules to travel through. MF3 and MF4 increasingly reduce the rate that moisture would be able to accumulate in VIPS which would increase the lifespan of the panels. As increasing the number of metallized aluminum layers reduces moisture transport it also increases thermal conductivity. However, since these VIPs would have longer lifespans and would require less frequent replacements, it may be economically feasible to install more VIPs in a higher density configuration, such as a staggered two layer configuration, shown in Figure 7-4. This is similar to Figure 7-2 and would work as a modular panel that attaches to the outside of a more conventional building construction. This configuration would mitigate the loss of thermal performance from using foils with more metallized layers, while the greater number of layers increases lifespans enough to make the higher number of VIPs economical. 


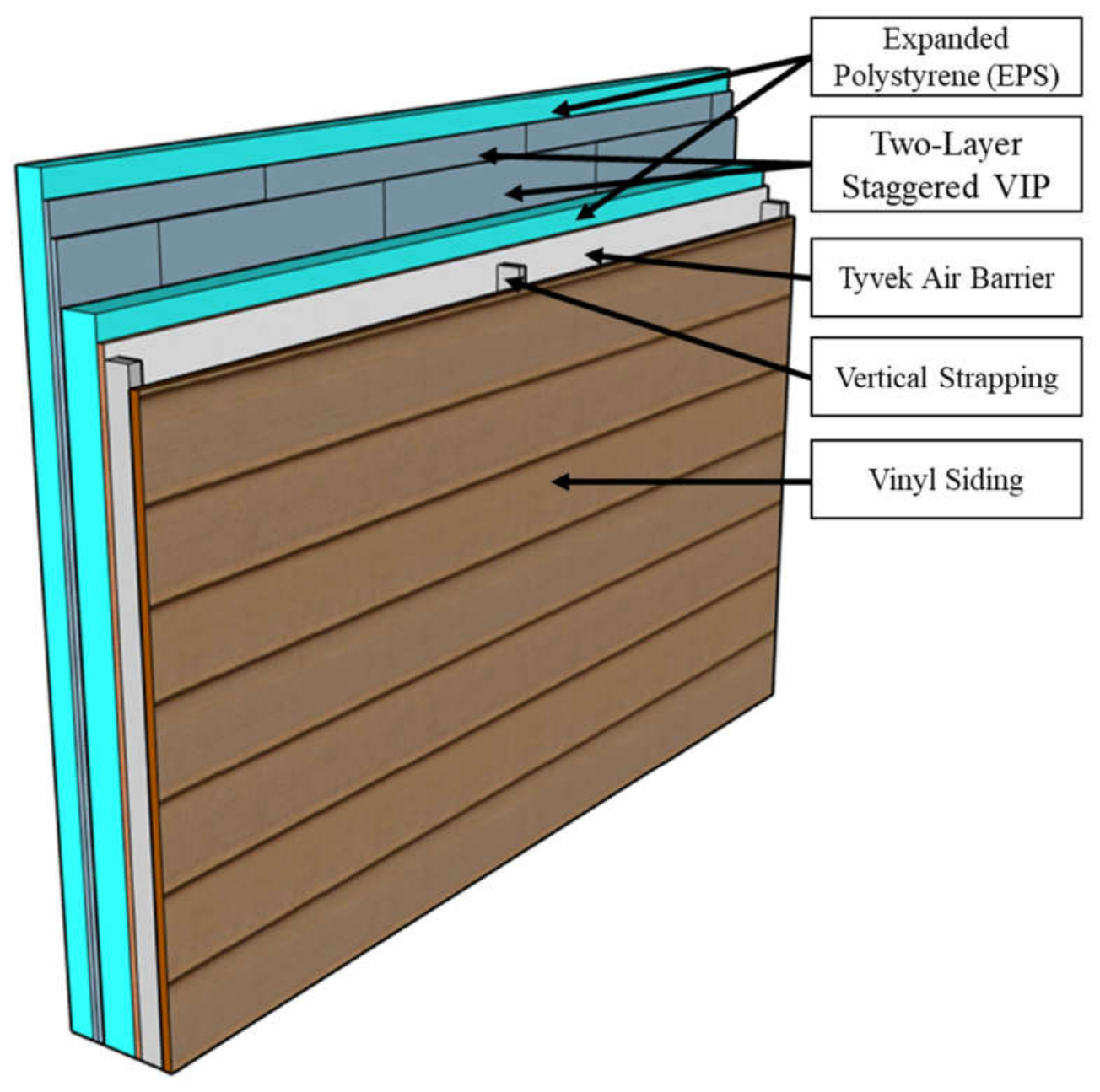

Figure 7-4: Staggered VIP Wall Construction 


\section{Chapter: Conclusions and Future Work}

\subsection{Conclusions}

As Canada and the world transition to a more sustainable future a major stepping stone has been the reduction in energy usage, this includes energy consumption used for the heating and cooling of commercial and residential buildings. Building owners, operators, regulators and designers now have a vested interest in reducing the energy consumption and carbon footprint of buildings. An effective way to reduce the energy consumption of a building is through reducing the necessary heating load of the building. This can be done by increasing the level building insulation, the R-value. The R-value of a building can be increased by either increasing the physical amount of insulation present or by switching to materials that are better performing insulators. Increasing the amount of conventional insulation materials can create an array of challenges. These challenges include the necessary construction methods arising from abnormally thick building walls and the increase in the physical footprint of the building walls, which reduces usable floor space or reduces available property area. A promising new insulation material for buildings are VIPs. VIPs consist of an evacuated open-cell core material, generally fumed silica. The core is held under vacuum with a multilayer foil consisting of various layers of polyethylene and aluminum. VIPs provide significantly lower thermal conductivity values than conventional insulation but their integration into buildings is challenged by complexity of integrating without conventional fasteners and uncertainty on the useful life on building envelopes.

The purpose of this work was to investigate the aging mechanisms and lifespan of VIPs installed in buildings in Canada. A detailed review of the literature showed that the main aging factor in VIPs is moisture transport through the foil and into the VIP. As this moisture accumulates in the panel the thermal conductivity increases. In this work, the rate of moisture transport into 
panels was measured using two different experimental methods, both based on ASTM E96, which provides a process for measuring the water vapour transmission rates of materials. Additionally, the relationship between water content and thermal conductivity was measured experimentally using panels aged in a controlled climate chamber and a guarded hot plate apparatus. Using both the experimentally measured aging values and published aging values, a detailed model was constructed in Delphin Hygrothermal. This model was used to simulate a VIP installed in a typical wall construction subjected to 25 years of weather, based on actual weather data. This allowed for the tracking of moisture content in the VIP over the simulation and the prediction of the VIP life.

A detailed literature review was conducted. This provided insight into mechanisms of panel aging, and current literature on the lifespan of VIPS in buildings. The literature showed that although both air and moisture accumulate in panels overtime, the amount of moisture entering panels is significantly higher and has a much greater impact on the thermal conductivity of the panel. Diffusion is the driving force of moisture transport through panels as the VIP foils have small nanopores and microdefects creating pathways for molecules. There were numerous predictions of VIP life available, generally based on measurements of ATR and WVTR. There was a significant gap in the literature between how measured transmission rates related to the actual conditions a VIP in a wall would be subjected to. There were three key takeaways from the literature review. Firstly, the literature provided a definition for what constitutes a failed panel. This failure criteria is defined as when the center-of-panel thermal conductivity has doubled from its initial value. The second takeaway was the aging mechanisms of VIPs, which consists of moisture transport through the foil. The final main takeaway were experimentally measured 
relationships between the relative humidity and temperature a VIP foil is subject to and the related WVTR into the foil.

In order to both measure the WVTR and drive moisture into VIPs, a controlled humidity and temperature environment was required. This was achieved through the construction of climate chambers. Two climate chambers were constructed, each allowing a controllable setpoint for temperature and relative humidity to be achieved. This was used in accordance with ASTM E96 to measure the WVTR of VIP foils using the dry cup method, in which a significant known vapour pressure gradient is introduced across the foil. Providing the ability to monitor moisture accumulation over time. This was also completed for complete panels, where the core material worked to absorb moisture and the panel weight was monitored in order to determine moisture accumulation.

Upon completion of the experimental testing the measured data was combined with available published data. The experimental data measured in this work was found to be in agreement with published data, following the same trend and building on the available range of measured data. This provided the ability to construct a wall model using Delphin Hygrothermal. Two different wall constructions were modelled, both containing VIPs as part of the exterior insulation layer, both based on typical Canadian building constructions. One wall represented a new construction while the other had minor changes oriented towards more of a retrofit construction case. The model provided the ability to subject the wall to detailed climatic conditions, these include temperature, relative humidity, radiation, wind-driven rain, and moisture entry into the wall. Climates from two different Canadian cities, Niagara and Ottawa were used. A dry representative and wet representative year were used for each city and each wall construction. The simulation was run for 25 consecutive year, with hourly results being provided 
for the temperature and relative humidity at both the interior and exterior face of the VIP. A mathematical post-processing model was constructed using the results from the Hygrothermal simulation. The moisture accumulation in the panel was determined by using the hourly simulation results and the trend of WVTR at different vapour pressure gradients. Once the moisture content over the 25 years is known, the hourly thermal conductivity was calculated using trends between thermal conductivity and water content. This provided the ability to determine the time until the failure thermal conductivity is reached, providing an estimated lifespan for the VIP and fulfilling the primary goal of this work. For the Ottawa climate, the predicted lifespans were $22.6 \pm 3.5$ and $23.4 \pm 3.6$ years for the retrofit and new construction, respectively. For the Niagara climate, the predicted lifespans were $19.0 \pm 3.0$ and $19.6 \pm 3.0$ years, for the retrofit and new construction, respectively.

The conclusions drawn in this thesis show that there is value in the use of Hygrothermal modelling along with detailed weather data to more accurately determine the conditions that a VIP in a wall is subject to over its life. The experimental work proved the ability to measure moisture accumulation properties and thermal performance of VIPs using laboratory equipment. This work has provided a procedure for the development of models to monitor VIP lifespan and moisture content. The low-cost testing method, the modelling procedure and future work can combine a standard procedure for the prediction of life for VIPs in any climate or wall construction.

\subsection{Future Work}

The work performed in this thesis contributes to the development of VIP lifespan prediction models and techniques, including the measurement of VIP aging in laboratory setting and the computer simulation of moisture transport into VIPs. This work provides a basic approach to 
complete a lifespan prediction model, however, several areas of the work can be developed and analyzed deeper to build on the basic approach provided.

The first area of predicting the lifespan of VIPs includes the measurement of the WVTR of VIP foils. Currently, these measurements were based on ASTM E96, but were only found to work reliably when using entire panels. However, being able to measure the WVTR of specific specimens would be beneficial as fill VIP tests bring uncertainty and complexity due to the inclusion of the heat-sealed flange and any other aspects of the VIP (such as preinstalled adhesives). A testing method that can be investigated for use on VIPs is ASTM F1249-13 Standard Test Method for Water Vapour Transmission Rate Through Plastic Film and Sheeting Using a Modulated Infrared Sensor. This standard uses large differences in pressure and vapour pressure across material samples to create more measurable rates of transfer for very low permeance materials. The standard explicitly includes multilayer films as suitable testing samples, proving suitability for VIP foil testing.

Another important goal of future work would be the experimental validation and coupling with the Hygrothermal model. The Hygrothermal model is very much an idealized case, with perfect construction and contact between materials. The use of a split-condition climate chamber, where a wall sample can split two different climate conditions, one representing indoor and one representing outdoor climate conditions. This is shown by Figure 8-1. This would provide the ability to perform experiments that the model is able to recreate. This would provide the ability to validate portions of the model, as well as the ability to create various correction factors. The 
correction factors could include how construction quality effects moisture content through the layers of the wall, how seams, joints, and damage effect the moisture content in the wall.

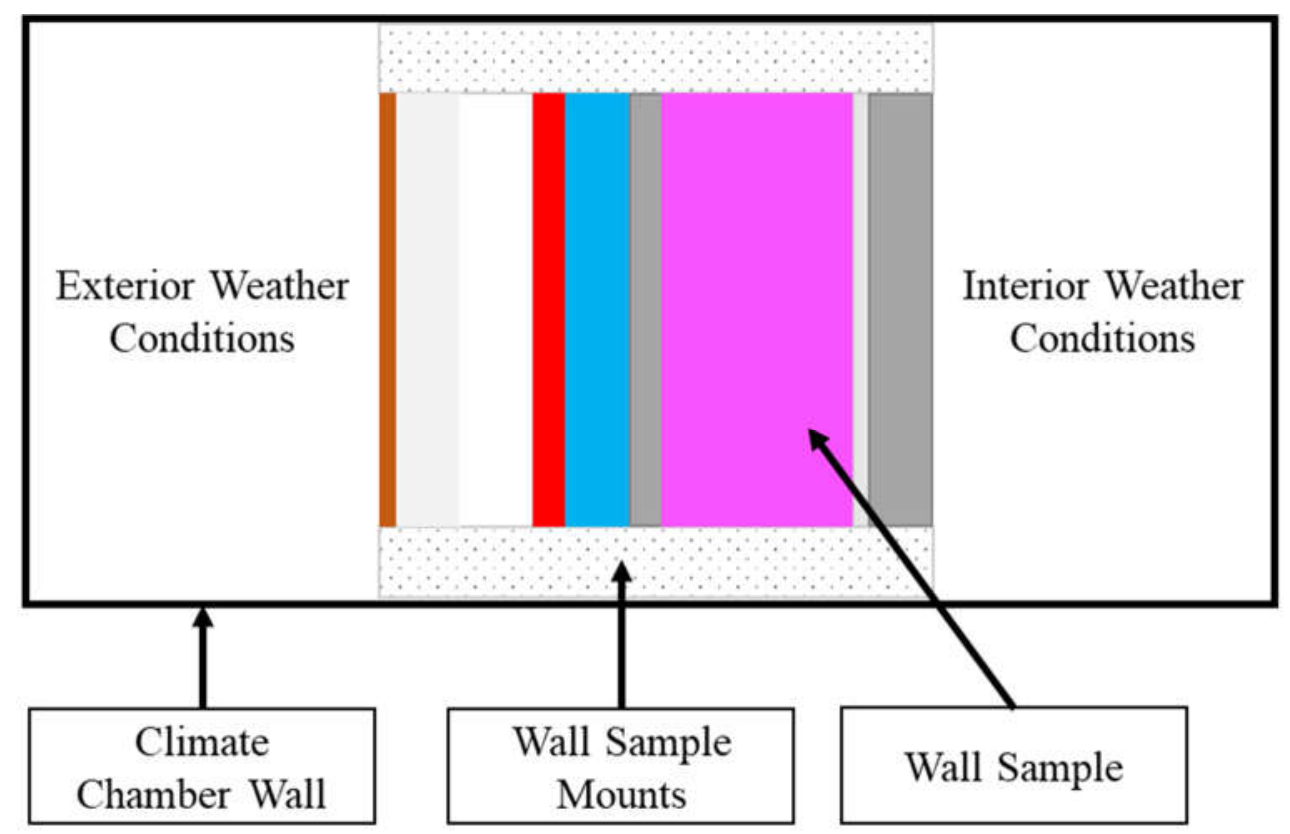

Figure 8-1: Split Climate Chamber Concept

Further work can be done on increasing the detail and coverage of the Hygrothermal model. In this thesis, the model was limited to 1-Dimenisonal. Investigation should be done on the effects and suitability of increasing the model to 2 or 3 dimensions. This would have a significant increase on the complexity of the simulation but may provide a better representation of the moisture transport through the wall and conditions at the VIP. This includes considering edge effects in walls, as well as defects and moisture transport pathways in walls. Considering these factors may provide more realistic simulated moisture profiles. In addition to this, the development of the detailed weather files for more cities should be completed, providing the ability to perform lifespan predictions in a greater variety of climates.

The final consideration for future work would be the consideration of more aging factors. This work focused on the most significant factor; moisture due to vapour pressure differences. It 
may be important to consider how stack pressure in the wall impacts the moisture transport into the core. Additionally, several other factors may exist. This includes the transfer of air into panels, as well as two less clear aging factors. Firstly, the corrosion of aluminum in the VIP foil, investigation should be done on how this effects the WVTR of the foil. Secondly, the aging of the fumed silica core, this has been proven as an aging factor, but the effect on total lifespan prediction has not been considered at great depth. Considering this in the simulation would be a step to determining its influence on the predicted lifespan. 


\section{References}

ANSI/ASHRAE 160. (2016). Criteria for Moisture-Control Design Analysis in Buildings. ANSI/ASHRAE.

ASTM International. (2013). Standard Test Method for Water Vapor Transmission Rate Through Plastic Film and Sheeting Using a Modulated Infared Sensor. West Conshohocken: ASTM International.

ASTM International. (2013). Standard Test Method for Water Vapour Transmission of Materials. West Conshohocken: ASTM International.

ASTM International. (2015). Standard Test Method for Determining Gas Permeability Characteristics of Plastic Film and Sheeting. West Conshohocken: ASTM International.

Baetens, R., Jelle, B. P., Thue, J. V., Tenpierik, M. J., Grynning, S., \& Uvslokk, S. (2010). Vacuum Insulation Panels for Building Applications: A Review and Beyond. Energy and Buildings, 42, 147-172.

Barrett, P. (2016, February 3). Dorken Insights Understanding the Difference Between Vapor Barriers and Vapor Retarders. (Dorken) Retrieved January 03, 2019, from Dorken Insights: https://dorken.com/insights/

Blocken, B., \& Carmeliet, J. (2004). A Review of Wind-Driven Rain Research in Building Science. Journal of Wind Engineering and Industrial Aerodynamics, 92(13), 1079-1130.

Bouquerel, M., Duforestel, T., Baillis, D., \& Rusaouen, G. (2012). Mass Transfer Modelling in Gas Barrier Envelopes for Vacuum Insulation Panels: A Review. Energy and Buildings, 55, 903-920.

Bradford West Gwillimbury Building Division. (2012). 2012 Ontario Building Code Requirments for New Construction. 
Bristow, D. N., \& Bristow, M. (2017). Retrofitting for Resiliency and Sustainability of Households. NRC Research Press, 44, 530-538.

Brunner, S., \& Simmler, H. (2008). In Situ Performance Assessment of Vacuum Insulation Panels in a Flat Roof Construction. Surface Engineering, Surface Instrumentation \& Vacuum Technology, 82, 700-707.

Brunner, S., Stahl, T., \& Ghazi Wakili, K. (2012). An Example of Deteriorated Vacuum Insulation Panels in a Building Facade. Energy and Buildings, 54, 278-282.

Canada Mortgage and Housing Corporation . (2013). Canadian Wood-Framed House Construction. Canada Mortgage and Housing Corporation.

Canada Mortgage and Housing Corporation. (2007). Service Life of Multi-Unit Residential Building Elements. CMHC.

Canada Mortgage and Housing Corporation. (2013). Canadian Wood-Frame House Construction. Canada Mortgage and Housing Corporation.

Canadian Wood Council. (2017). Addressing Climate Change in the Building Sector - Carbon Emission Reductions. Canadian Wood Council .

Canadian Wood Council. (2018). Wall Thermal Design Calculator. Ottawa: Canadian Wood Council.

Cho, K., Hong, Y., \& Seo, J. (2014). Assessment of the Economic Performance of Vacuum Insulation Panels for Housing Projects. Energy and Buildings, 70, 45-51.

Conley, B., Cruickshank, C. A., \& Carver, M. (2018). Hygrothermal Analysis of a Vapour-Open Assembly with Vacuum Insulation. Ottawa: Carleton University.

CWEC. (2016). Canadian Weather Year for Energy Calculation (CWEC). Government of Canada. 
Delphin. (n.d.). Bauklimatik Dresden - Software for Building Science. Retrieved from 2019: http://bauklimatik-dresden.de/index.php

DuPont. (2007). DuPont Tyvek Homewrap - Building Science Bulletin. www.dupont.com/products-and-services/construction-materials.

Falk, J., Molnar, M., \& Larsson, O. (2014). Investigation of a Simple Approach to Predict Rainscreen Wall ventialtion Rates for Hygrothermal Simulation Purposes. Building and Environment, 88-96.

FannieMae. (2014). Instructions for Perfoming a Multifamily Property Condition Assessment. FannieMae.

Ferland, J.-L. (2017). Government of Canada sets ambitious GHG reduction targets for federal operations. (Treasury Board of Canada Secretariat) Retrieved June 22, 2018, from https://www.canada.ca/en/treasury-boardsecretariat/news/2017/12/government_of_canadasetsambitiousghgreductiontargetsforfede ralop.html

Ghazi Wakili, K., Bundi, R., \& Binder, B. (2004). Effective Thermal Conductivity of Vacuum Insulation Panels. Building Research and Information, 293-299.

Government of British Columbia. (2012). Residential Tenancy Policy Guideline. Government of British Columbia.

Government of Canada. (2017). Adapting to the Effects of Climate Change. (Government of Canada) Retrieved 06 22, 2018, from 
https://www.canada.ca/en/services/environment/weather/climatechange/climateaction/adapting-to-effects.html

Hayes, A. (2018). Design and Construction of a Guarded Hot Plate Apparatus to Evaluate the Thermal Resistance of Vacuum Insulated Panels using a New Accelerated Aging Process. Ottawa: M.A.Sc. Thesis, Carleton University.

Hens, H. (2012). Building Physics: Heat, Air and Moisture. Fundamentals and Engineering Methods with Examples and Exercises. Ernst \& Sohn GmbH \& Co.

Intelligent Weighing Technology. (2015). Intell-Lab Toploading Balance PBX Series. Intelligent Weighing Technology.

Jayamaha, S., Wijeysundera, N., \& Chou, S. (1996). Measurment of the Heat Transfer Coefficient for Walls. Building and Environment, 399-407.

Jelley, N. (2017). A Dictionary of Energy Science. Oxford University Press.

Jelley, N. (2017). A Dictionary of Energy Science - Building Envelope. Oxford University Press. Kevothermal. (2010). Kevothermal Vacuum Insualtion Panel (VIP) Technical Data Sheet. Kevothermal.

Koci, V., Vejmelkova, E., Cachova, M., Konakova, D., Madera, J., Keppert, M., \& Cerny, R. (2016). Effect of Moisture Content on Thermal Properties of Porous Building Materials. International Journal of Thermophysics, 1-12.

Kumaraperumal, A., Sanders, C., Baker, P., Galbraith, G., \& Essah, E. (2018). Wind-Driven Rain Distribution and its Hygrothermal Effect on Two Different Types of Building Geometry. Glasgow: Glasgow Caledonian University. 
Kwon, J.-S., Jang, C. H., Jung, H., \& Song, T.-H. (2010). Vacuum Maintenance in Vacuum Insulation Panels exemplified with a Staggered Beam VIP. Energy and Buildings, 42(5), $590-597$.

Langmans, J., Desta, T. Z., Alderweireldt, L., \& Roels, S. (2015). Experimental Analysis of Cavity Ventilation Behind Residential Rainscreen Cladding Systems. 6th International Building Physics Conference (pp. 1750-1755). Elsevier.

Maref, W., Saber, H., Armstrong, M., Glazer, R., Ganapathy, G., Nicholls, M., .. . Mukhopadyaya, P. (2013). Intergration of Vacuum Insulation Panels into Canadian Buildings. Ottawa: National Research Council of Canada.

Meares, P. (1966). Sorption and Diffusion in Polymers. European Polymer Journal, 2(2), 95106.

Molleti, S., Lefebvre, D., \& Reenan, D. (2018). Long-Term In-Situ Assessment of Vacuum Insualtion Panels for Integration into Roofing Systems: Five Years of Field Performance. Energy and Buildings, 168, 97-105.

Morgan Advanced Materials. (2017). VACUPOR Vacuum Insulation Panel Technical Information.

Morlidge, M. (2014). A Critical Review of Long-Term Thermal Performance of Vacuum Insulation Panel in Building Envelope Construction. 14th Canadian Conference on Building Science and Technology. Toronto.

National Research Council of Canada. (2013). Hygrothermal Materials Database. Ottawa: National Research Council. 
Natural Resources Canada. (2009). Overview - Residential Energy Use and GHG Emissions. (Natural Resources Canada) Retrieved June 22, 2018, from http://oee.rncan.gc.ca/publications/statistics/trends11/chapter3.cfm?attr=0

Nicolai, A., \& Grunewald, J. (2006). Delphin Hygrothermal: User Manual and Program Reference. : Delphin Hygrothermal.

Park, C., \& Allaby, M. (2013). A Dictionary of Environment and Conservation. Oxford University Press.

Saber, H. H., Maref, W., Gnanamurugan, G., \& Nicholls, M. (2015). Energy Retrofit using Vacuum Insulation Panels: An Alternative Solution for Enhancing the Thermal Performance of Wood-Frame Walls. Journal of Building Physics, 39(1), 35-68.

Schwab, H., Heinemann, U., Beck, A., Ebert, H.-P., \& Fricke, J. (2005). Dependence of Thermal Conductivity on Water Content in Vacuum Insulation Panels with Fumed Silica Kernels. Journal of Thermal Environment and Building Science, 28(4), 319-326.

Schwab, H., Heinemann, U., Beck, A., Ebert, H.-P., \& Fricke, J. (2005). Permeation of Different Gases Through Foils used as Envelopes for Vacuum Insulation Panels. Journal of Thermal Environmental and Building Science, 28(4), 293-317.

Schwab, H., Heinemann, U., Beck, A., Ebert, H.-P., \& Fricke, J. (2005). Prediction of Service Life for Vacuum Insualtion Panels with Fumed Silica Kernel and Foil Cover., 28, pp. 357-373.

Simmler, H., \& Brunner, S. (2005). Vacuum insulation panels for building application- Basic properties, aging mechanisms and service life. Energy and Buildings, 37, 1122-1131. 
Simmler, H., Brunner, S., Heinemann, U., Schwab, H., Kumaran, K., Mukhopadhyaya, P., . . . Erb, M. (2005). Vacuum Insulation Panels: Study on VIP-Components and Panels for Service Life Predictionof VIP in Building Applications (Subtask A). IEA/EBC Annex 39.

Song, K., \& Mukhopadhyaya, P. (2016). Vacuum Insulation Panels (VIPs) in Building and International Review of Applied Sciences and Engineering, 7(2), 113-119.

Swinton, M. (2013). Integration of Vacuum Insulation Panels into Canadian Buildings. Ottawa: National Research Council.

Thorsell, T. (2010). A Hybrid Model for Diffusion through Barrier Films with Multiple Coatings. Journal of Building Physics, 35(4), 351-381.

U.S. Department of Energy. (2014, August 1). Building Science Introduction - Moisture Flow. Retrieved July 10, 2018, from https://basc.pnnl.gov/information/building-scienceintroduction-moisture-flow

Wegger, E., Jelle, B., Sveipe, E., Grynning, S., Gustavsen, A., Baetens, R., \& Thue, J. (2010). Aging Effects on Thermal Properties and Service Life of Vacuum Insulation Panels. Journal of Building Physics, 128-167.

Yeo, I., Jung, H., \& Song, T.-H. (2014). Gas Permeation Characteristics through heat-Sealed Flanges of Vacuum Insulation Panels. Vacuum, 104, 70-76.

Yrieix, B., Morel, B., \& Pons, E. (2014). VIP Service Life Assessment: interactions between barrier laminates and core material, and significance of silica core aging. Energy and Buildings, 85, 617-630. 
Appendix A Simulation Results 
The following figures provide the results from the computer simulations used in this work. These simulations consist of 25 consecutive weather years. The outputs from the simulations are temperature and relative humidity at the interior and exterior face of the VIP. Shown in these graphs is the vapour pressure at each face, calculated based on the temperature and relative humidity provided by the simulation. These figures are important as they show the wall conditions predicted by the simulation. Showing the conditions over lifespan could provide insight into how drying, ventilation, and initial conditions affect the conditions as part of future work. Results are shown for each case investigated in this work, new and retrofit construction cases for 2013 and 2016 weather years. Figure A- 1 shows the internal and external vapour pressures over the length of the simulation for the Niagara 2013 case. Similarly, Figures A- 2 through A- 8 provide the simulated conditions for each case as specified.

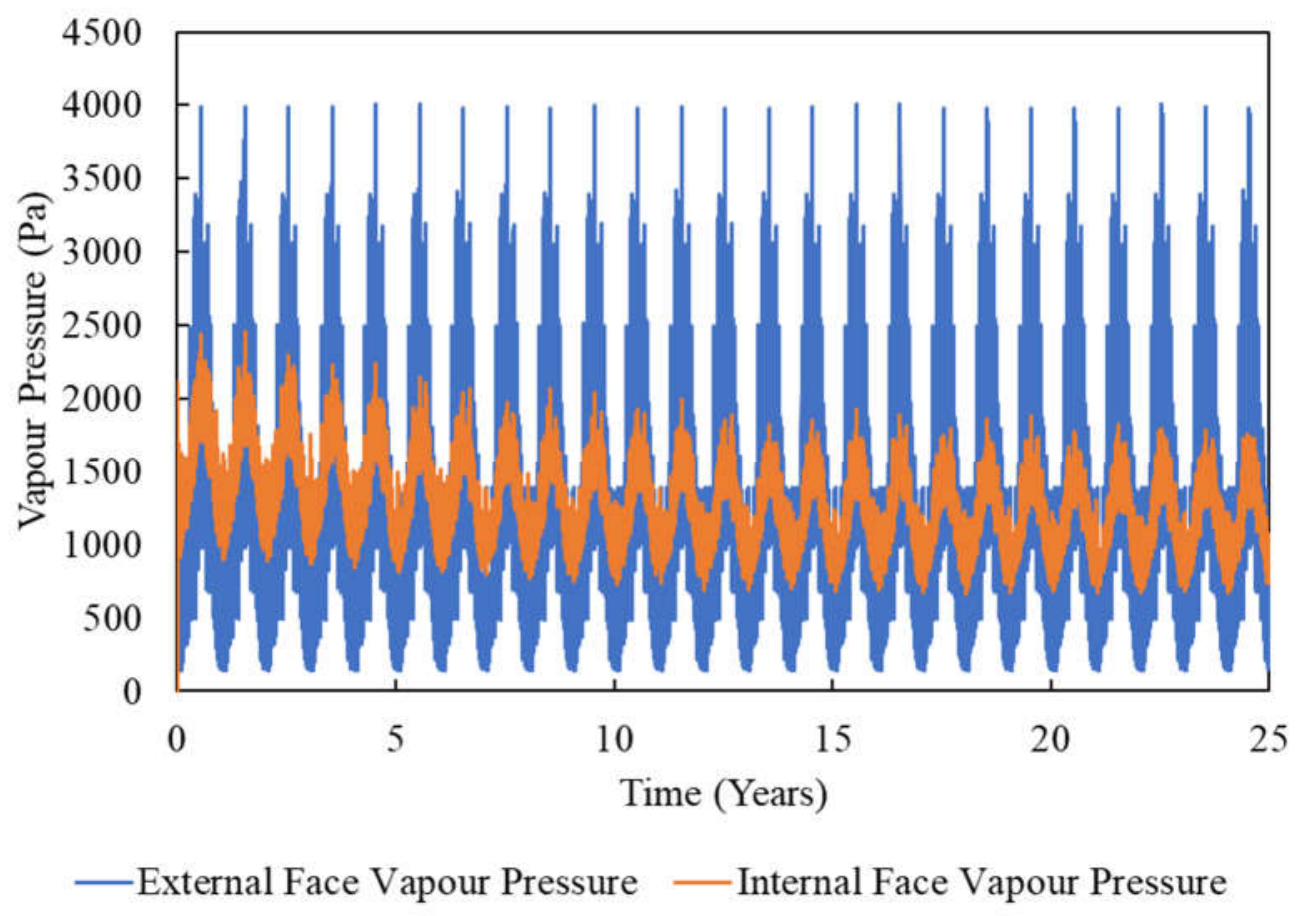

\section{A- 1: 2013 Niagara New Construction Results}




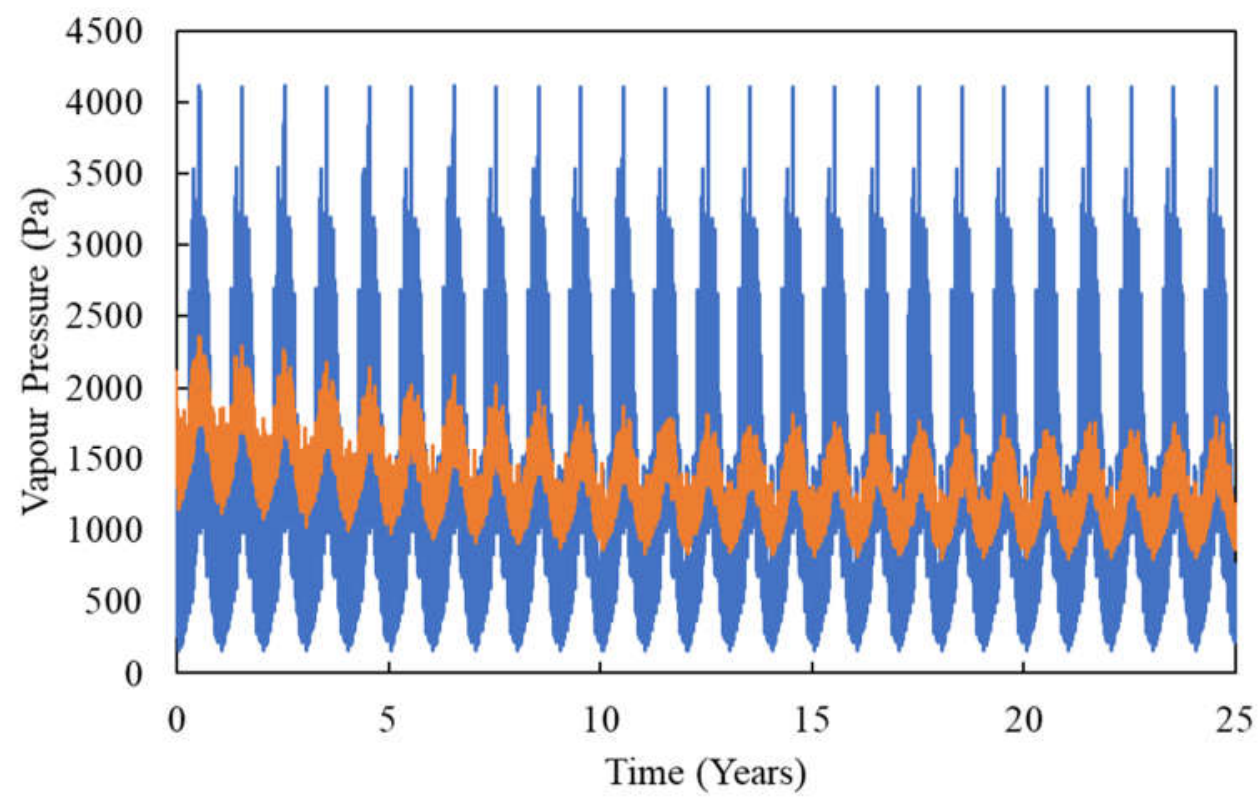

—External Face Vapour Pressure — Internal Face Vapour Pressure

A- 2: 2013 Niagara Retrofit Construction Results

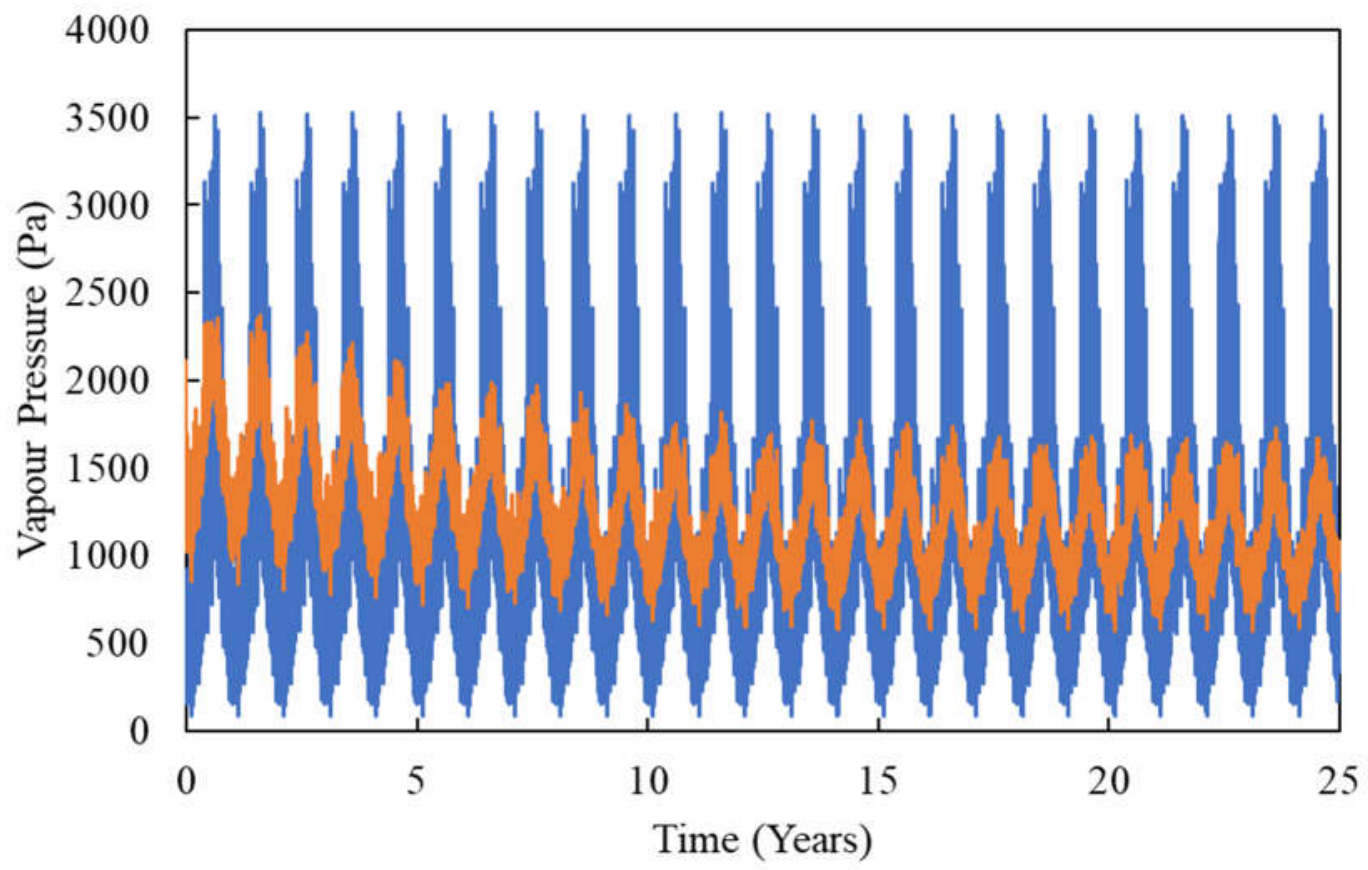

—External Face Vapour Pressure — Internal Face Vapour Pressure

\section{A- 3: 2016 Niagara New Construction Results}




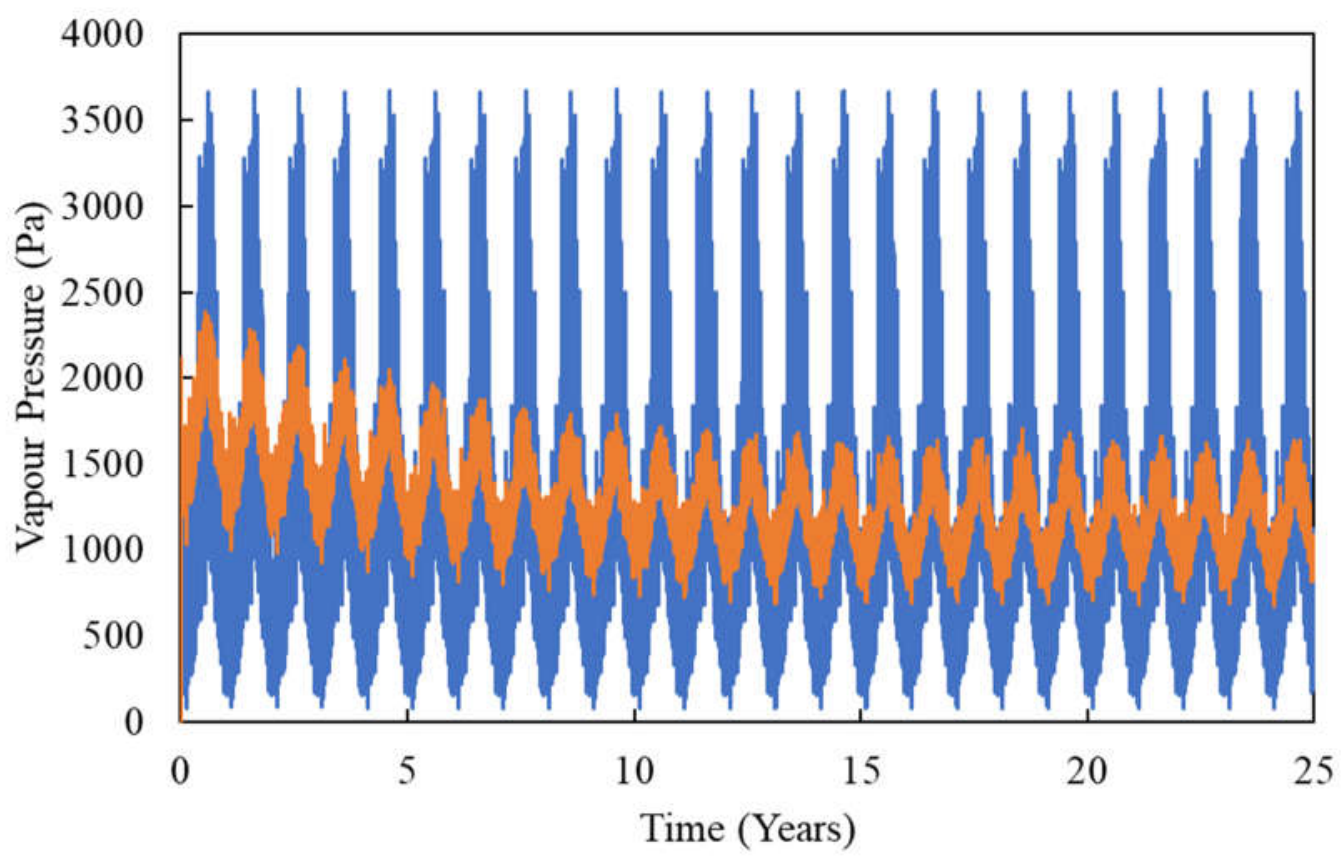

—External Face Vapour Pressure - Internal Face Vapour Pressure

A- 4: 2016 Niagara Retrofit Construction Results

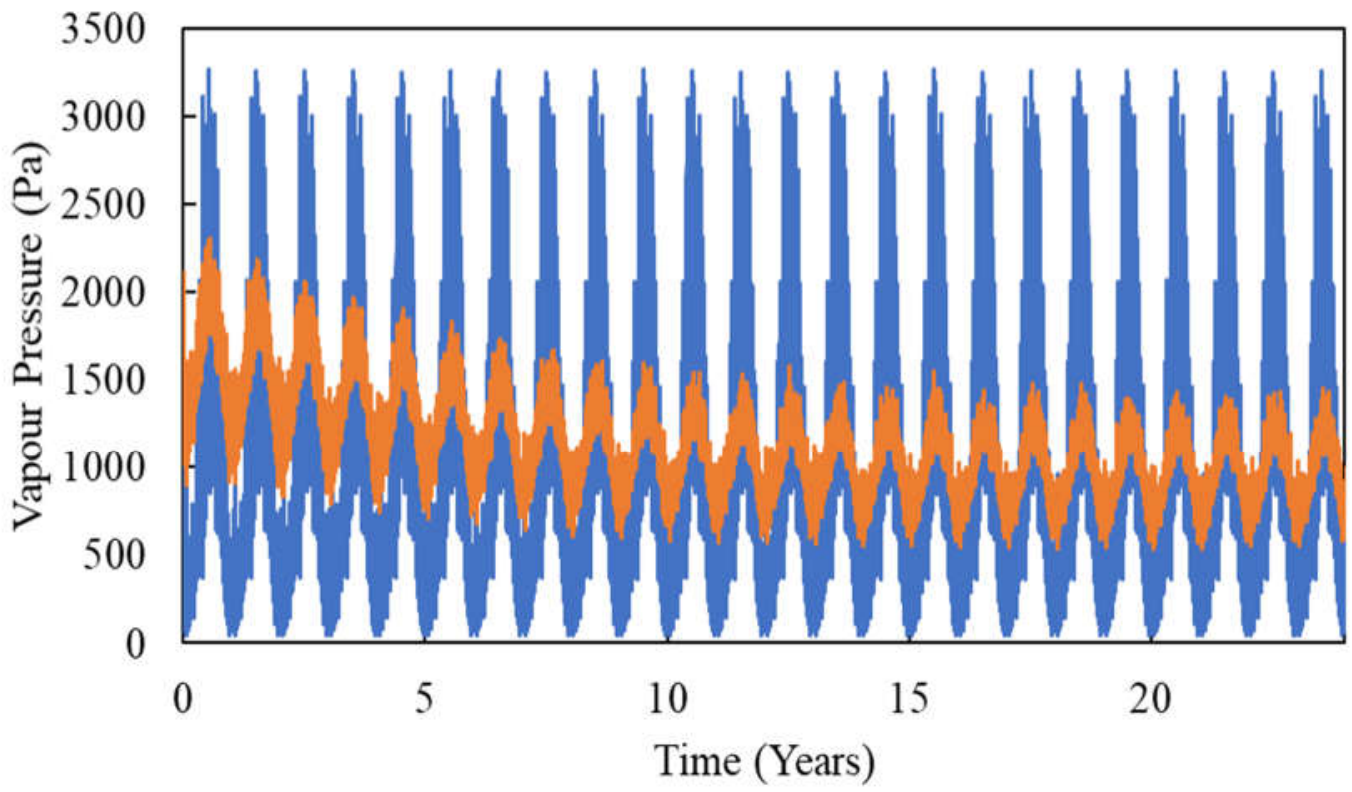

—External Face Vapour Pressure —-Internal Face Vapour Pressure

\section{A- 5: 2013 Ottawa New Construction Results}




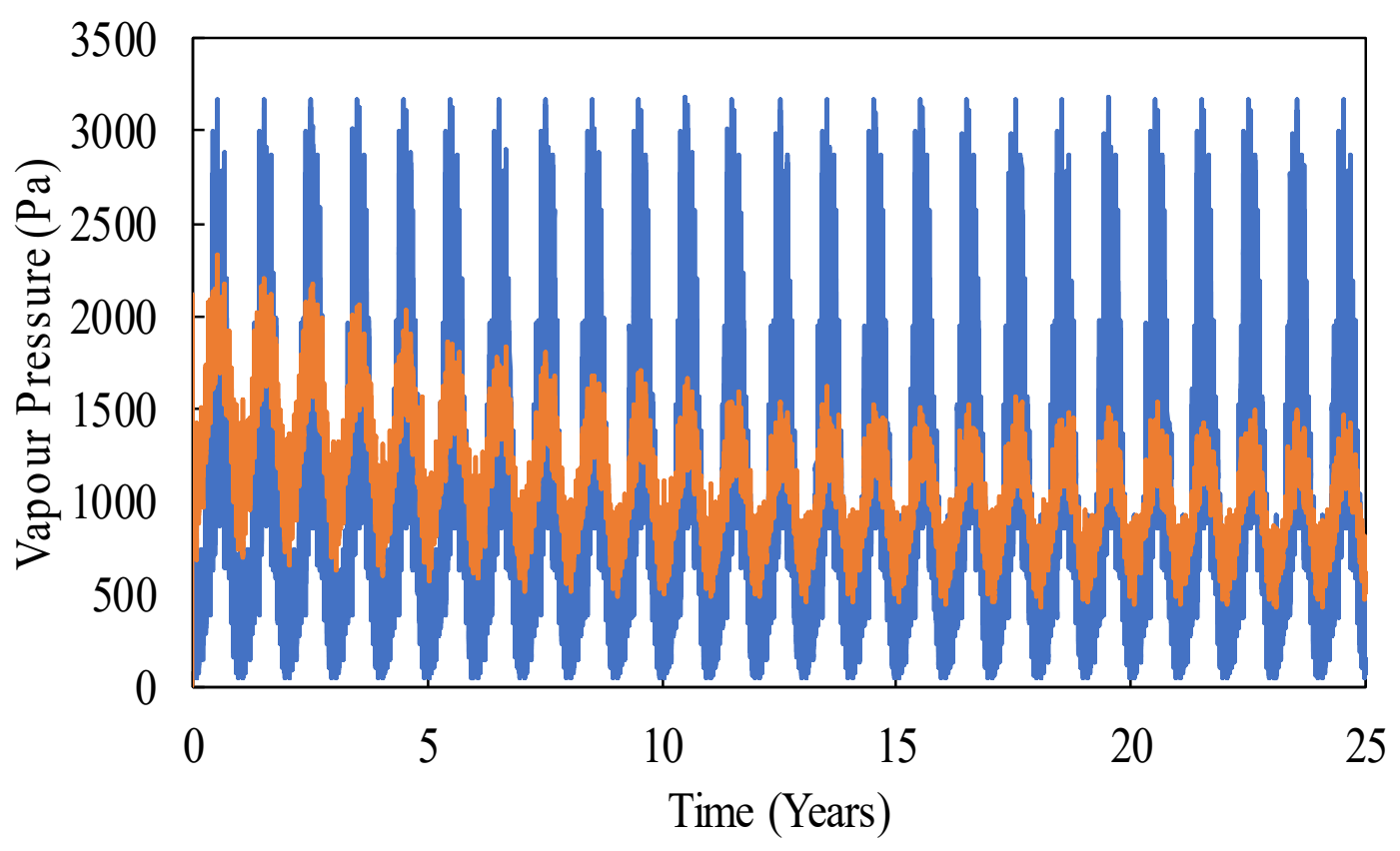

—External Face Vapour Pressure — Internal Face Vapour Pressure

\section{A- 6: 2013 Ottawa Retrofit Construction Results}

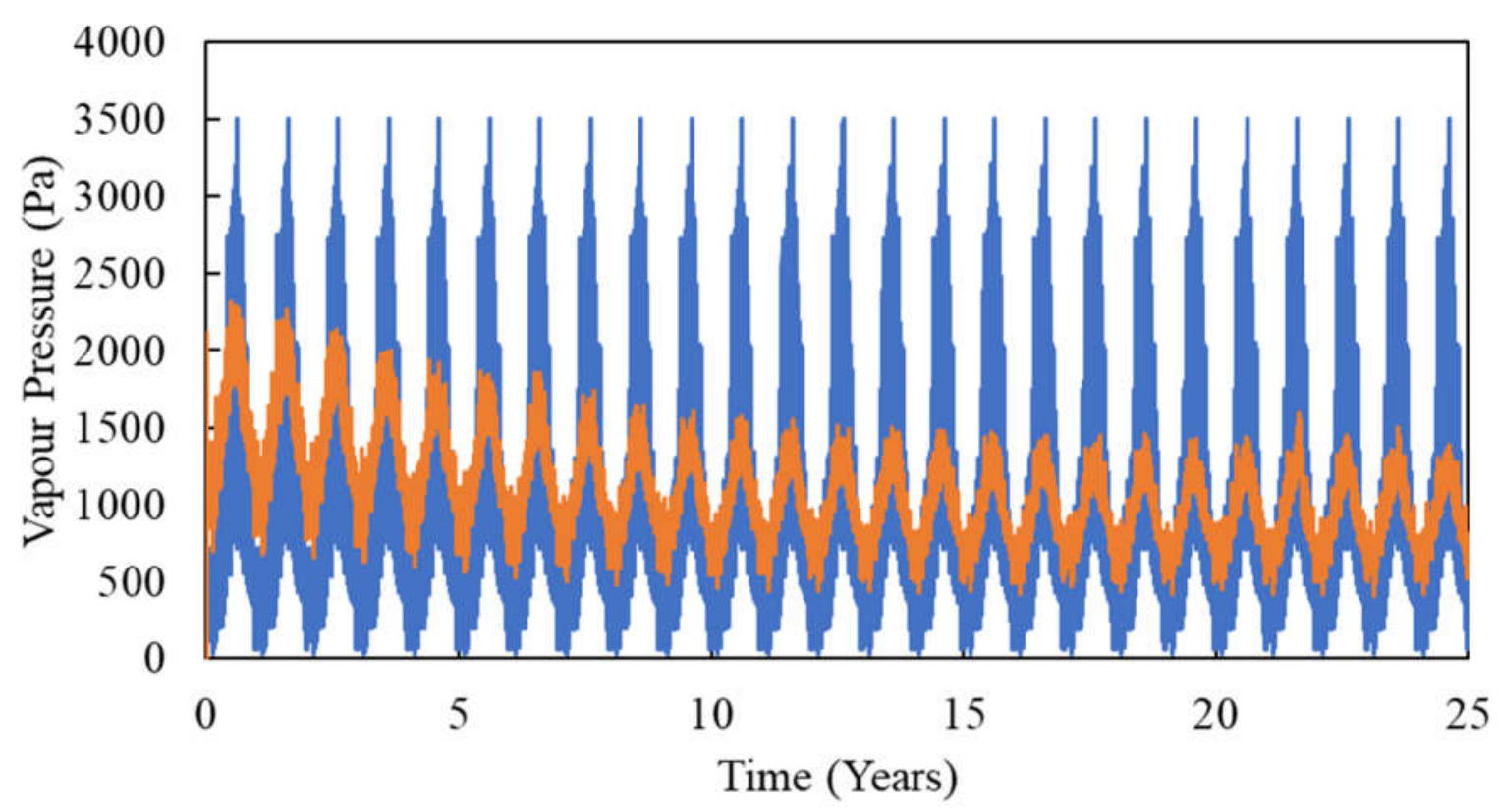

—External Face Vapour Pressure - Internal Face Vapour Pressure 


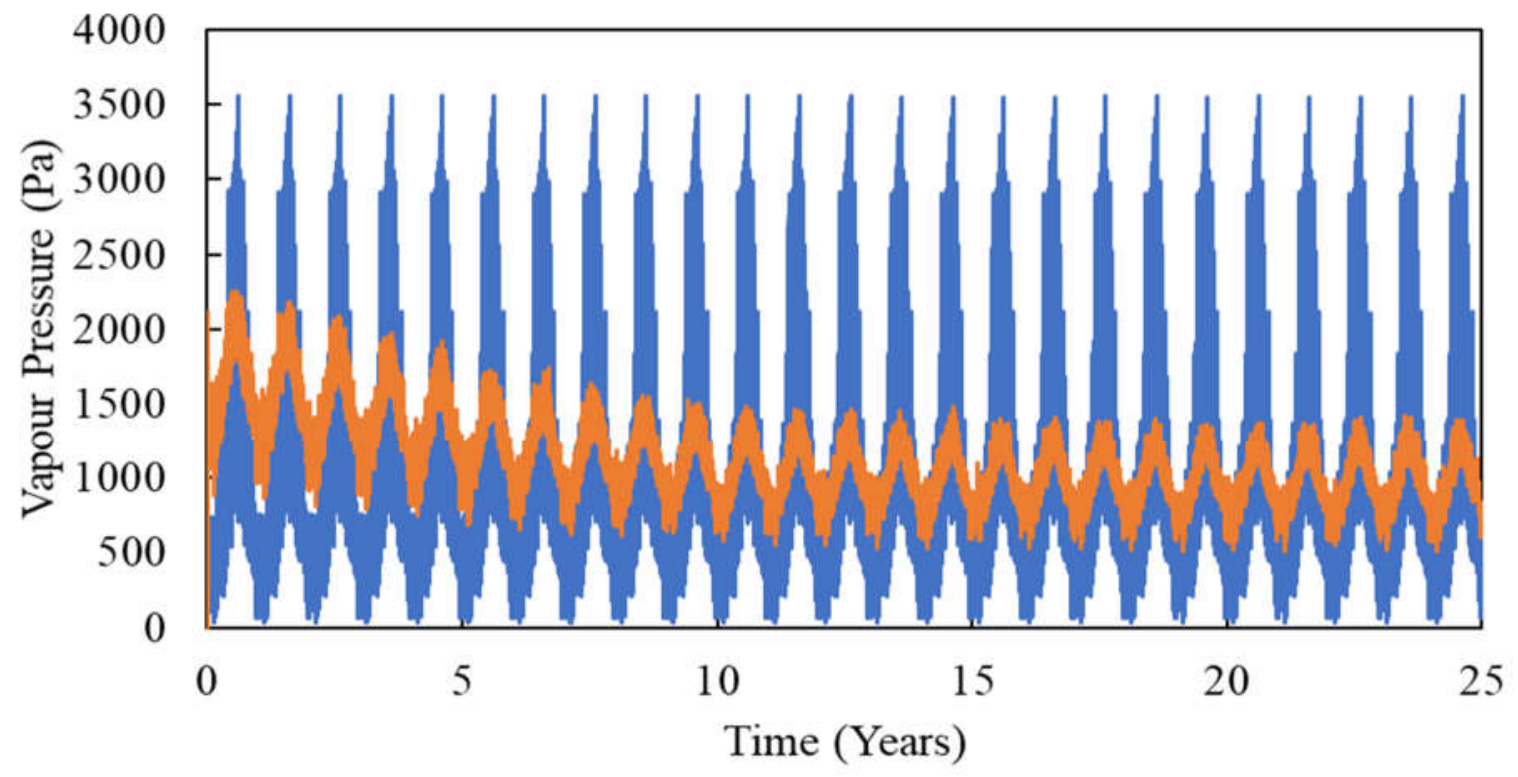

-External Face Vapour Pressure - Internal Face Vapour Pressure

A- 8: 2016 Ottawa Retrofit Results 